OAK RIDGE

NATIONAL LABORATORY

MANAGED BY UT-BATTELLE

FOR THE DEPARTMENT OF ENERGY

\title{
ELEVATED-TEMPERATURE FERRITIC AND MARTENSITIC STEELS AND THEIR APPLICATION TO FUTURE NUCLEAR REACTORS
}

November 2004

R. L. Klueh

UT-BATTELLE 
This report was prepared as an account of work sponsored by an agency of the United States government. Neither the United States government nor any agency thereof, nor any of their employees, makes any warranty, express or implied, or assumes any legal liability or responsibility for the accuracy, completeness, or usefulness of any information, apparatus, product, or process disclosed, or represents that its use would not infringe privately owned rights. Reference herein to any specific commercial product, process, or service by trade name, trademark, manufacturer, or otherwise, does not necessarily constitute or imply its endorsement, recommendation, or favoring by the United States government or any agency thereof. The views and opinions of authors expressed herein do not necessarily state or reflect those of the United States government or any agency thereof. 
ORNL/TM-2004/176

Metals and Ceramics Division

\section{ELEVATED-TEMPERATURE FERRITIC AND MARTENSITIC STEELS AND THEIR APPLICATION TO FUTURE NUCLEAR REACTORS}

Date Published: November 2004

Prepared by

OAK RIDGE NATIONAL LABORATORY

Oak Ridge, Tennessee 37831-6285

managed by

UT-BATTELLE, LLC

for the

U.S. DEPARTMENT OF ENERGY

under contract DE-AC05-00OR22725 



\section{CONTENTS}

Page

ABSTRACT vii

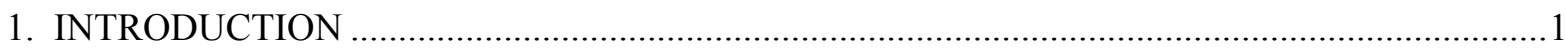

2. FERRITIC/MARTENSITIC STEELS IN NUCLEAR APPLICATIONS .....................................

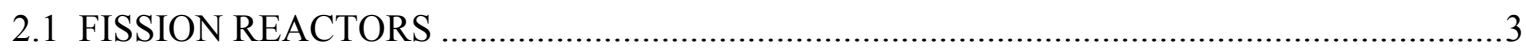

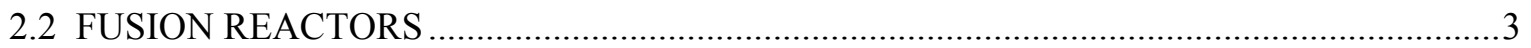

3. IRRADIATION EFFECTS ON FERRITIC/MARTENSITIC STEELS ….....................................

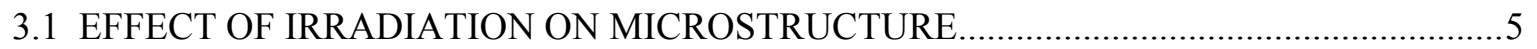

3.2 EFFECT OF IRRADIATION ON MECHANICAL PROPERTIES ......................................

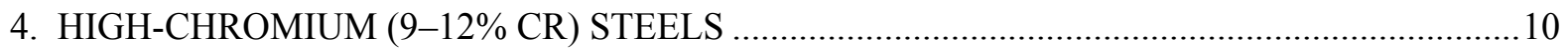

4.1 EVOLUTION OF STEELS FOR POWER-GENERATION INDUSTRY …...................... 10

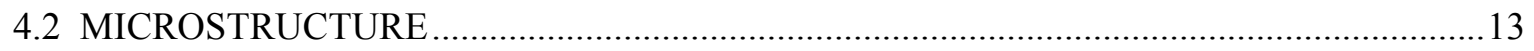

4.2.1 Normalized-and-Tempered and Quenched-and-Tempered Microstructure ....................13

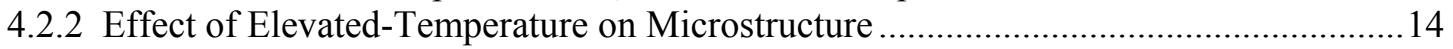

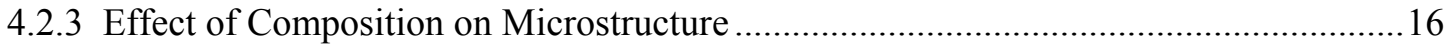

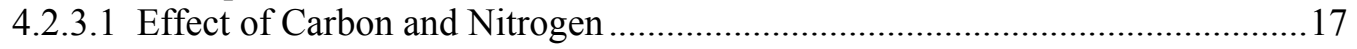

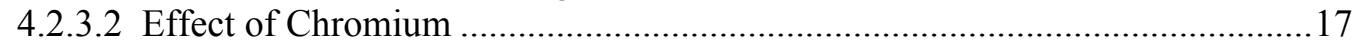

4.2.3.3 Effect of Tungsten and Molybdenum........................................................ 17

4.2.3.4 Effect of Vanadium, Niobium, and Tantalum ................................................. 18

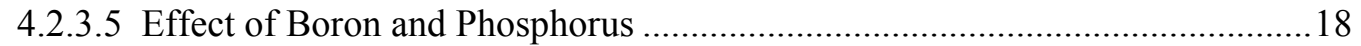

4.2.3.6 Effect of Nickel, Manganese, and Cobalt........................................................ 18

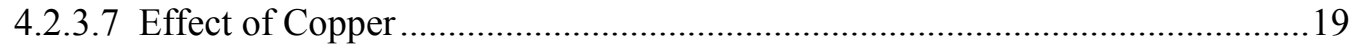



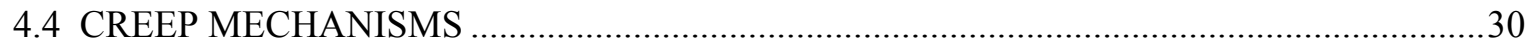

4.5 HIGH-CHROMIUM STEELS FOR NUCLEAR APPLICATIONS …..................................32

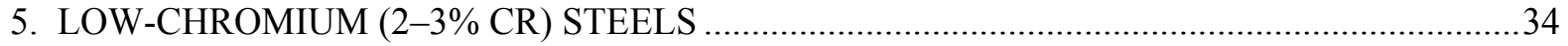

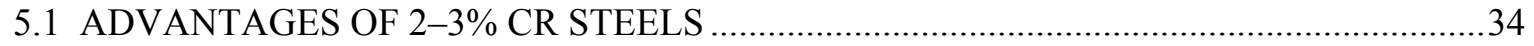

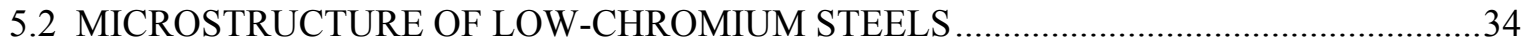

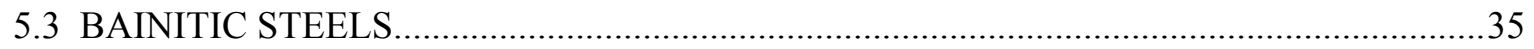

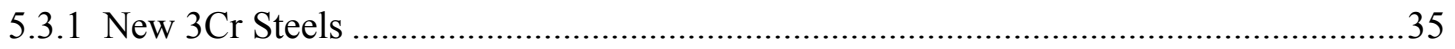

5.4 LOW-CHROMIUM STEELS FOR OUT-OF-CORE NUCLEAR

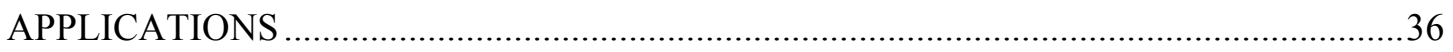

6. FERRITIC AND MARTENSITIC STEELS FOR THE FUTURE ….......................................42

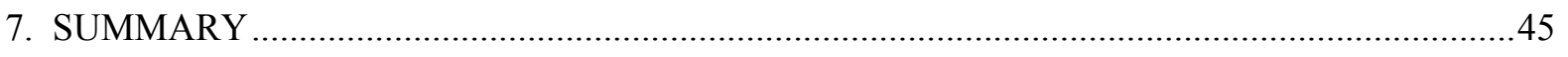

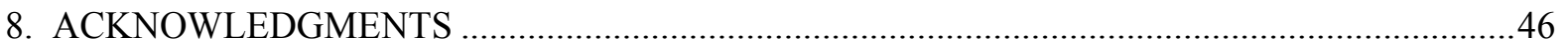

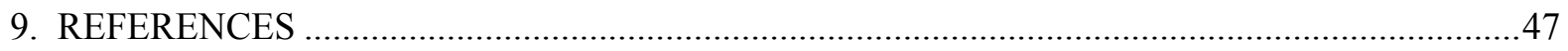





\section{LIST OF FIGURES}

Figure

1 Swelling behavior of six commercial heats of ferritic/martensitic steels compared to type 316 stainless steel after irradiation in EBR-II at $420^{\circ} \mathrm{C}$ to $\approx 80 \mathrm{dpa}$ 6

2 Yield stress and ultimate tensile strength of normalized-and-tempered, thermally aged, and irradiated modified $9 \mathrm{Cr}-1 \mathrm{Mo}(9 \mathrm{Cr}-1 \mathrm{MoVNb})$ steel...............7

3 Uniform and total elongation of normalized-and-tempered, thermally aged, and irradiated modified $9 \mathrm{Cr}-1 \mathrm{Mo}(9 \mathrm{Cr}-1 \mathrm{MoVNb})$ steel

4 Charpy curves for half-size specimens of Sandvik HT9 (12Cr-1MoVW) steel before and after irradiation to 10 and $17 \mathrm{dpa}$ at $365^{\circ} \mathrm{C}$ in $\mathrm{FFTF}^{45}$

5 Comparison of the unirradiated and irradiated Charpy curves for one-thirdsize specimens of HT9 and ORNL 9Cr-2WVTa steels irradiated in FFTF at $365^{\circ} \mathrm{C}^{6}$

6 Optical photomicrograph of normalized-and-tempered modified $9 \mathrm{Cr}-1 \mathrm{Mo}$ steel showing tempered martensite microstructure.

7 Transmission electron micrographs of 12Cr-1MoVW (HT9) steel in (a) normalized and (b) normalized-and-tempered conditions

8 Creep-rupture curves for heats of 0.5 Mo steels showing the sigmoidal shape of the curves for tests at 450,500 , and $550^{\circ} \mathrm{C}^{90}$

9 Schematic illustration taken from Kimura et al. for an explanation of the mechanism for sigmoidal creep-rupture curves ${ }^{90}$

10 Larson-Miller plots for creep-rupture stress of low-alloy Cr-Mo steels that show a large variation for the different steels at low Larson-Miller parameters (short-time tests, low temperatures), but differences narrow at high LarsonMiller parameters (long-time tests, high temperatures) ${ }^{90}$

11 Larson-Miller plots for Vickers hardness of creep specimens of $12 \mathrm{Cr}-1 \mathrm{Mo}-$ $1 \mathrm{~W}-0.3 \mathrm{~V}$ and $9 \mathrm{Cr}-1 \mathrm{Mo}-\mathrm{V}-\mathrm{Nb}$ steels that show how the steels have a large difference in hardness for low Larson-Miller parameters but similar values for high parameters ${ }^{90}$.

12 Creep-rupture curves for E911 steel showing the downward curvature for low-stress tests at high temperatures ${ }^{92}$

13 Creep-rupture curves for P9, P91, P92, and 12Cr1MoV steels tested at $600^{\circ} \mathrm{C}^{56}$

14 Transmission electron micrographs of (a) P91, (b) P92, and (c) $12 \mathrm{Cr} 1 \mathrm{MoV}$ steels ${ }^{56}$

15 Dislocation density for P91 and P92 as a function of exposure time in a creep test at $600^{\circ} \mathrm{C}^{56}$

16 Dependence of steady-state creep on stress for NF616 (P92) steel tested at 600 and $650^{\circ} \mathrm{C}$

17 Dependence of steady-state creep on stress for modified 9Cr-1Mo steel at 600-62 $5^{\circ} \mathrm{C}$ 


\section{LIST OF FIGURES (continued)}

Figure

18 Comparison of new 3Cr-3WV and 3Cr-3WVTa steels in the normalized (N) and normalized-and-tempered conditions with normalized-and-tempered T23 $(2.25 \mathrm{Cr}-1.6 \mathrm{WVNb})$ and T24 (2.25Cr-1MoVTi) steels ${ }^{116}$ .36

19 Creep-rupture curves for $3 \mathrm{Cr}-3 \mathrm{WV}$ and $3 \mathrm{Cr}-3 \mathrm{WVTa}$ steels in the normalized and normalized-and-tempered conditions (a) at $600^{\circ} \mathrm{C}$ compared to T23 (2.25Cr-1.6WVNb), T24 (2.25Cr-1MoVTi), and T91 (9Cr-1MoVNb) steels and (b) at $650^{\circ} \mathrm{C}$ compared to $\mathrm{T} 91$ steel $^{116}$

20 Larson-Miller Parameter for 3Cr-3WVTa steel in the normalized and normalized-and-tempered condition compared to T23 (2.25Cr-1.6WVNb) and T22 (21/4Cr-1Mo) steels ${ }^{116}$

21 Optical microstructure of (a) 3Cr-3WV and (b) 3Cr-3WVTa steels showing the bainite microstructure and grain refinement provided by tantalum ${ }^{116}$

22 Photomicrographs of (a) 3Cr-3WV and (b) 3Cr-3WVTa steels showing the fine needle precipitates that provide the creep strength of the steels ${ }^{117}$

23 Photomicrographs of (a) 3Cr-3WV and (b) 3Cr-3WVTa steels after creeprupture test at $650^{\circ} \mathrm{C}, 83 \mathrm{MPa} ; 3 \mathrm{Cr}-3 \mathrm{WV}$ ruptured in $1141 \mathrm{~h}$ and $3 \mathrm{Cr}-3 \mathrm{WVTa}$ in $3086 \mathrm{~h}$ 


\begin{abstract}
In the 1970s, high-chromium (9-12\% Cr) ferritic/martensitic steels became candidates for elevated-temperature applications in the core of fast reactors. Steels developed for conventional power plants, such as Sandvik HT9, a nominally Fe-12Cr$1 \mathrm{Mo}-0.5 \mathrm{~W}-0.5 \mathrm{Ni}-0.25 \mathrm{~V}-0.2 \mathrm{C}$ steel (composition in wt \%), were considered in the United States, Europe, and Japan. Now, a new generation of fission reactors is in the planning stage, and ferritic, bainitic, and martensitic steels are again candidates for in-core and outof-core applications. Since the 1970s, advances have been made in developing steels with $2-12 \% \mathrm{Cr}$ for conventional power plants that are significant improvements over steels originally considered. This paper will review the development of the new steels to illustrate the advantages they offer for the new reactor concepts. Elevated-temperature mechanical properties will be emphasized. Effects of alloying additions on long-time thermal exposure with and without stress (creep) will be examined. Information on neutron radiation effects will be discussed as it applies to ferritic and martensitic steels.
\end{abstract}





\section{INTRODUCTION}

The expected increasing world-wide demand for energy in the twenty-first century has spurred international cooperation to consider ways to meet energy needs while maintaining and improving the environment. This has led naturally to nuclear energy, since it can be produced without the environmental effects that accompany the use of coal or petroleum products. Although renewable energy sources offer the possibility of clean energy, there are concerns about economic efficiency and reliability, whereas the economic reliability of nuclear energy has been demonstrated by the reactors operating today. Rather than relying on the present generation of reactors, an international collaboration is directed toward developing a new generation (Generation IV) of reactors that will produce abundant, reliable, inexpensive energy in safe and proliferation-resistant reactors. ${ }^{1}$

Generation IV reactor concepts include thermal and fast water-cooled (Super Critical Water Reactor-SCWR-Th and SCWR-F), gas-cooled (Very High-Temperature Reactor-VHTR, Gas Fast Reactor-GFR), and liquid-metal-cooled (Sodium and Lead Fast Reactors - Na-LMR and Pb-LMR) designs. Reactor conditions, such as the elevated temperatures of the VHTR and the liquid sodium and lead/bismuth coolants of $\mathrm{Na}-\mathrm{LMR}$ and $\mathrm{Pb}$-LMR, offer a challenge for engineers and designers on structural and cladding materials selection. ${ }^{1}$

For several proposed reactor concepts (VHTR, GFR, SCWR-Th, SCWR-F, Na-LMR, and $\mathrm{Pb}-\mathrm{LMR}$ ), ferritic and martensitic steels are contemplated as possible structural and/or cladding materials. This paper will examine some of the "new" ferritic and martensitic steels that should be considered for this challenge, based primarily on the major advances in steel technology made in recent years for non-nuclear power generation systems. ${ }^{2-4}$ These advances were driven by the need for improved efficiencies that come through higher operating temperatures of new ultrasupercritical coal-fired power plants that are envisioned for the future. In Japan and Europe, these plants are being put into operation already, and they are eventually expected to push power-plant efficiencies above $40 \%$, thus reducing the environmental impact (reduced $\mathrm{SO}_{\mathrm{x}}, \mathrm{NO}_{\mathrm{x}}$, and $\mathrm{CO}_{2}$ emissions) produced by burning coal. To meet this challenge, steels are being developed for operation to $650^{\circ} \mathrm{C}$ and at higher steam pressures than used in the past. ${ }^{2-4}$

In this paper, the discussion will be directed primarily at high-temperature mechanical properties (i.e., creep) of the new 9-12\% Cr steels. It will have two objectives: (1) to demonstrate the improvement achieved for these types of ferritic/martensitic steels since they were last seriously considered for advanced reactor applications, and (2) to demonstrate why these steels should be considered for Generation IV reactors. Lower-chromium bainitic steels will also be discussed briefly to demonstrate advantages of new steels that are available for use at lower temperatures (e.g., for pressure-vessel applications). Before discussing the steels, a brief introduction to the effects of irradiation on ferritic and martensitic steels will be presented. 
It is recognized that because of the high temperatures and various, possibly harsh, operating environments envisioned for some of the Generation IV reactors, corrosion and compatibility could present problems for the steels. However, this paper will concentrate on mechanical properties, and corrosion and compatibility will not be addressed.

Throughout the paper, various commercial and experimental steels will be referred to, and in Table 1, the compositions of the steels to be discussed are presented for reference.

Table 1. Nominal Composition of Commercial and Experimental Steels (wt \%)

\begin{tabular}{|c|c|c|c|c|c|c|c|c|c|c|c|}
\hline Steel & C & Si & Mn & $\mathbf{C r}$ & Mo & $\mathbf{W}$ & V & $\mathbf{N b}$ & B & $\mathbf{N}$ & Other \\
\hline A533 Grade B & $\begin{array}{l}0.25 \\
\max \end{array}$ & 0.20 & 1.30 & & 0.50 & & & & & & \\
\hline 21/4Cr-1Mo (T22) & $\begin{array}{l}0.15 \\
\max \end{array}$ & 0.3 & 0.45 & 2.25 & 1.0 & & & & & & \\
\hline $\begin{array}{c}2.25 \mathrm{Cr}-1.6 \mathrm{WVNb} \\
(\mathrm{T} 23)\end{array}$ & 0.06 & 0.2 & 0.45 & 2.25 & 0.1 & 1.6 & 0.25 & 0.05 & 0.003 & & \\
\hline 2.25Cr-1MoVTi (T24) & 0.08 & 0.3 & 0.50 & 2.25 & 1.0 & & 0.25 & & 0.004 & $\begin{array}{l}0.03 \\
\max \end{array}$ & $0.07 \mathrm{Ti}$ \\
\hline ORNL 3Cr-3WV & 0.10 & 0.14 & 0.50 & 3.0 & & 3.0 & 0.25 & & & & \\
\hline ORNL 3Cr-3WVTa & 0.10 & 0.14 & 0.50 & 3.0 & & 3.0 & 0.25 & & & & $0.10 \mathrm{Ta}$ \\
\hline 9Cr-1Mo (T9) & 0.12 & 0.6 & 0.45 & 9.0 & 1.0 & & & & & & \\
\hline Mod 9Cr-1Mo (T91) & 0.10 & 0.4 & 0.40 & 9.0 & 1.0 & & 0.2 & 0.08 & & 0.05 & \\
\hline E911 & 0.11 & 0.4 & 0.40 & 9.0 & 1.0 & 1.0 & 0.20 & 0.08 & & 0.07 & \\
\hline NF616 (T92) & 0.07 & 0.06 & 0.45 & 9.0 & 0.50 & 1.8 & 0.20 & 0.05 & 0.004 & 0.06 & \\
\hline W. Nr. 1.4914 & 0.15 & 0.45 & 0.35 & 11.0 & 0.50 & & 0.30 & 0.25 & 0.008 & 0.03 & $0.70 \mathrm{Ni}$ \\
\hline MANET I & 0.14 & 0.40 & 0.75 & 10.8 & 0.75 & & 0.20 & 0.15 & 0.009 & 0.02 & $0.90 \mathrm{Ni}$ \\
\hline $12 \mathrm{Cr} 1 \mathrm{MoV}$ & 0.20 & 0.30 & 0.50 & 12.0 & 1.0 & & 0.25 & & & & $0.70 \mathrm{Ni}$ \\
\hline $12 \mathrm{Cr}-1 \mathrm{MoV}$ (HT91) & 0.20 & 0.4 & 0.60 & 12.0 & 1.0 & & 0.25 & & & & $0.5 \mathrm{Ni}$ \\
\hline 12Cr-1MoWV (HT9) & 0.20 & 0.4 & 0.60 & 12.0 & 1.0 & 0.50 & 0.25 & & & & $0.5 \mathrm{Ni}$ \\
\hline HCM12 & 0.10 & 0.3 & 0.55 & 12.0 & 1.0 & 1.0 & 0.25 & 0.05 & & 0.03 & \\
\hline TB12 & 0.10 & 0.06 & 0.50 & 12.0 & 0.50 & 1.8 & 0.20 & 0.05 & 0.004 & 0.06 & $0.1 \mathrm{Ni}$ \\
\hline $\mathrm{TB} 12 \mathrm{M}$ & 0.13 & 0.25 & 0.50 & 11.0 & 0.50 & 1.8 & 0.20 & 0.06 & & 0.06 & $1.0 \mathrm{Ni}$ \\
\hline HCM12A (T122) & 0.11 & 0.1 & 0.60 & 12.0 & 0.40 & 2.0 & 0.25 & 0.05 & 0.003 & 0.06 & $\begin{array}{l}1.0 \mathrm{Cu} \\
0.3 \mathrm{Ni}\end{array}$ \\
\hline NF12 & 0.08 & 0.2 & 0.50 & 11.0 & 0.20 & 2.6 & 0.20 & 0.07 & 0.004 & 0.05 & $2.5 \mathrm{Co}$ \\
\hline SAVE12 & 0.10 & 0.3 & 0.20 & 11.0 & & 3.0 & 0.20 & 0.07 & & 0.04 & $\begin{array}{c}3.0 \mathrm{Co} \\
0.07 \mathrm{Ta} \\
0.04 \\
\mathrm{Nd}\end{array}$ \\
\hline
\end{tabular}




\section{FERRITIC/MARTENSITIC STEELS IN NUCLEAR APPLICATIONS}

\subsection{FISSION REACTORS}

High-chromium (9-12\% Cr) ferritic/martensitic steels were first considered for elevated-temperature in-core applications (cladding, wrappers, and ducts) for fast reactors in the 1970s, because of their excellent thermal properties and irradiation resistance (low swelling) relative to austenitic stainless steels. ${ }^{5}$ Sandvik HT9, nominally Fe-12Cr-1Mo$0.5 \mathrm{~W}-0.5 \mathrm{Ni}-0.25 \mathrm{~V}-0.2 \mathrm{C}$ (all compositions are in wt \%), which was developed in Europe in the 1960s for the power-generation industry, was chosen as the material for investigation in the U.S. fast reactor program. Similar types of steel were chosen in Europe and Japan (EM-12, FV448, DIN 1.4914, and JFMS in France, United Kingdom, Germany, and Japan, respectively). A large amount of information was generated in the respective nuclear programs on the properties of these steels before and after irradiation. ${ }^{6}$

Because of the high temperatures envisioned in the designs of Generation IV reactors (up to $650^{\circ} \mathrm{C}$ and higher) where ferritic and martensitic steels are considered for application, the primary emphasis here will be on the high-chromium $(9-12 \% \mathrm{Cr})$ steels. However, in some designs, the out-of-core components (e.g., pressure vessel, piping, etc.) will operate at lower temperatures, thus providing an opportunity to use a lower-alloy steel. In commercial light-water reactors, low-alloy ferritic and bainitic steels such as A533B (nominally Fe- $1.25 \mathrm{Mn}-0.5 \mathrm{Ni}-0.5 \mathrm{Mo}-0.2 \mathrm{C}$, see Table 1 ) are used for the pressureboundary components. Because of the higher operating temperatures of the Generation IV reactors, the pressure-boundary components will also operate at higher temperatures, thus probably negating the use of steels such as A533B. However, steels with lower chromium than $9-12 \%$ could possibly be used for this application, and such steels will be discussed.

\subsection{FUSION REACTORS}

When ferritic/martensitic steels were considered as structural materials for fusion reactors in the late 1970s, Sandvik HT9 was the first one considered in the U.S. Program. ${ }^{6,7}$ Similarly, the first such steels in the programs in Europe and Japan were the steels previously considered in their fast reactor programs mentioned above. ${ }^{6,8}$ In the mid-1980s, the idea of low-activation materials was introduced into the international fusion programs. ${ }^{9-17}$ The objective was to build reactors from materials that would either not activate when irradiated by neutrons or, if activated, develop low-level radiation or the radioactivity would decay quickly, allowing for improved safety of operation as well as hands-on maintenance. ${ }^{9,10}$ Truly "low-activation" steels defined in this way are not possible, because they are limited by the decay of the products from transmutation of iron atoms. "Reduced-activation" steels, where the activity decays in a relatively short time, thus allowing for shallow land burial, as opposed to deep geological storage, were considered possible, and their development was pursued.

Beginning in the mid-1980s, fusion reactor materials research programs in Japan, the European Union, and the United States began working toward developing "reduced- 
activation" ferritic/martensitic steels for use in a fusion energy demonstration reactor and subsequent power reactors. ${ }^{10-28}$ The development evolved from calculations to determine which elements must be replaced in conventional Cr-Mo steels to obtain a rapid decay of induced radioactivity after irradiation in a fusion reactor. ${ }^{9,10}$ Such calculations indicated that the typical steel-alloying elements $\mathrm{Mo}, \mathrm{Nb}, \mathrm{Ni}, \mathrm{Cu}$, and $\mathrm{N}$ must be eliminated or minimized to obtain "reduced activation." Proposals for reduced-activation ferritic steels involved the replacement of molybdenum in conventional Cr-Mo steels by tungsten ${ }^{12,14-19}$ and/or vanadium. ${ }^{14,18}$

Fusion materials programs in Japan, the European Union, and the United States have developed $\mathrm{Cr}-\mathrm{V}$ and $\mathrm{Cr}-\mathrm{W}-\mathrm{V}$ steels ${ }^{11-22}$ to which tantalum is sometimes added as a replacement for niobium. ${ }^{12,14-16,22}$ Steels with 7-9\% Cr were favored, because of the difficulty of eliminating $\delta$-ferrite in a $12 \% \mathrm{Cr}$ steel without increasing carbon or manganese for austenite stabilization. Delta-ferrite can lower toughness, and manganese promotes chi-phase precipitation during irradiation, which can cause embrittlement. ${ }^{18}$ Low-chromium $(2.25 \% \mathrm{Cr})$ steels were also considered, ${ }^{11,12,18,21,22}$ but in the end, $7-9 \%$ $\mathrm{Cr}$ steels were chosen for further study and development.

In Japan, an Fe-7.5Cr-2.0W-0.2V-0.04Ta-0.10C (F82H) ${ }^{15,23,24}$ and Fe-9Cr-2W-0.2V$0.07 \mathrm{Ta}-(\mathrm{JLF}-1)^{21,25,26}$ steel were chosen, and in Europe, an Fe-9.3Cr-1.0W-0.25V0.04Cu-0.10C (OPTIFER Ia) and Fe-9.4Cr-1.1Ge-0.30V-0.13C (OPTIFER II) were originally chosen and investigated. ${ }^{20,27}$ The steel with the best properties in the U.S. was ORNL 9Cr-2WVTa steel. ${ }^{12,17,22,28}$ Based on the earlier work on the reduced-activation steels, a new composition was more recently developed in Europe called EUROFER. ${ }^{29}$ Compositions of reduced activation steels presently of interest in international fusion programs are given in Table 2.

Table 2. Nominal Composition of Reduced-Activation Steels (wt \%)

\begin{tabular}{cccccccccccc}
\hline \multirow{2}{*}{ Program } & Steel & C & Si & Mn & Cr & W & $\mathbf{V}$ & Ta & N & B & Other \\
\hline \multirow{2}{*}{ Japan } & F82H & 0.10 & 0.2 & 0.50 & 8.0 & 2.0 & 0.2 & 0.04 & $<0.01$ & 0.003 & \\
& JLF-1 & 0.10 & 0.08 & 0.45 & 9.0 & 2.0 & 0.20 & 0.07 & 0.05 & & \\
\multirow{2}{*}{ Europe } & OPTIFER Ia & 0.10 & 0.06 & 0.50 & 9.30 & 1.0 & 0.25 & 0.07 & 0.015 & 0.006 & \\
& OPTIFER II & 0.125 & 0.04 & 0.50 & 9.40 & & 0.25 & & 0.015 & 0.006 & 1.1 \\
& EUROFER & 0.11 & 0.05 & 0.50 & 8.5 & 1.0 & 0.25 & 0.08 & 0.03 & 0.005 & \\
\multirow{2}{*}{ USA } & ORNL 9Cr- & & & & & & & & \\
& 2WVTa & 0.10 & 0.30 & 0.40 & 9.0 & 2.0 & 0.25 & 0.07 & & & \\
\hline
\end{tabular}




\section{IRRADIATION EFFECTS ON FERRITIC/MARTENSITIC STEELS}

The effect of neutron irradiation on microstructure and mechanical properties of ferritic/martensitic steels has been reviewed recently, ${ }^{6}$ and only a brief discussion of these subjects will be presented here, giving selected examples of irradiation effects on some of the steels discussed above.

\subsection{EFFECT OF IRRADIATION ON MICROSTRUCTURE}

High-energy neutron irradiation in a fast reactor or fusion reactor displaces atoms from their normal matrix positions to form vacancies and interstitials. It is the disposition of the "displacement damage," measured as displacements per atom (dpa), that affects the mechanical properties (discussed below). The general progressive change in microstructure with irradiation dose and temperature involves the agglomeration of vacancies and interstitials into voids and dislocation loops that cause swelling. Loops form below $400-450^{\circ} \mathrm{C}$. Loop size increases and loop number density decreases with increasing temperature, eventually becoming unstable. ${ }^{30-34}$ In ferritic/martensitic steels, agglomeration of vacancies can lead to void swelling up to about $500^{\circ} \mathrm{C}$.

Ferritic steels first became of interest for the fast reactor program because they are low swelling compared to conventional austenitic stainless steels (e.g., type 304 or 316 stainless steels) when irradiated in the Experimental Breeder Reactor (EBR-II) (Fig. 1). Swelling is defined as $\Delta \mathrm{V} / \mathrm{V}_{0}$, where $\Delta \mathrm{V}$ and $\mathrm{V}_{0}$ are volume change and original volume, respectively. At the maximum swelling temperature of around $400-420^{\circ} \mathrm{C}$, less than $2 \%$ swelling was observed for HT9 and modified 9Cr-1Mo (T91) irradiated to $200 \mathrm{dpa}$ in the Fast Flux Test Facility (FFTF). ${ }^{32}$

Irradiation-induced precipitate changes can also affect properties. ${ }^{30-32,34,35}$ Precipitates formed in the $9-12 \% \mathrm{Cr}$ steels during irradiation include $\alpha^{\prime},{ }^{30,35} \mathrm{G}$-phase, ${ }^{35}$ $\mathrm{M}_{6} \mathrm{C},{ }^{31,34}$ and chi-phase. ${ }^{32,35}$ For most of the $9-12 \% \mathrm{Cr}$ Cr-Mo steels investigated, Laves phase, which forms during thermal aging at $\approx 400$ to $600^{\circ} \mathrm{C},{ }^{30,32,34-36}$ can cause embrittlement; ${ }^{36}$ it does not form if irradiation is above $\approx 600^{\circ} \mathrm{C} .{ }^{30,32,35,36}$

Displacement damage produced by the neutron irradiation will lead to transmutation reactions of neutrons with metal atoms to produce a new atom (usually another metal atom with a smaller atomic number) and a gas atom - helium or hydrogen. The new nongaseous atom is generally thought not to affect the properties of the steel, although this atom is the source of the radioactivity that "activates" the structural material and provided the impetus for the search for a "low-activation" material in the fusion program. The effect of the hydrogen was generally thought to be minimal, because most of it was expected to migrate out of the lattice at reactor operating temperatures. However, ion ${ }^{37}$ and proton ${ }^{38,39}$ irradiations have produced evidence for retention of considerable amounts of the hydrogen, but it is not expected to be an issue in martensitic steels above about $250^{\circ} \mathrm{C} .^{39}$ For a fusion reactor, where the helium:dpa ratio is about 10 , indications are that helium can affect swelling, ${ }^{31}$ although the $9-12 \% \mathrm{Cr}$ steels still remain low swelling. The 


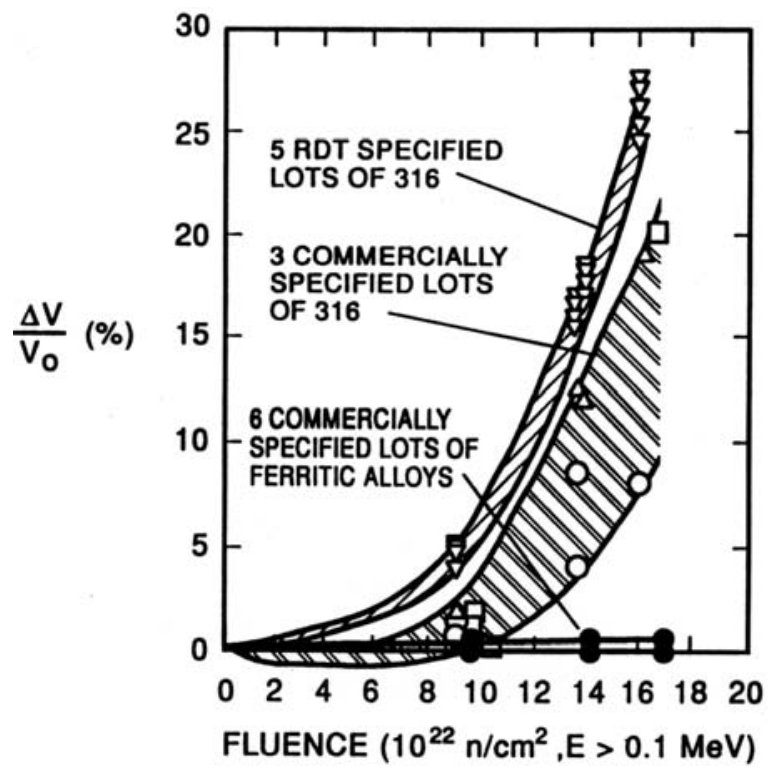

Fig. 1. Swelling behavior of six commercial heats of ferritic/martensitic steels compared to type 316 stainless steel after irradiation in EBR-II at $420^{\circ} \mathrm{C}$ to $\approx 80 \mathrm{dpa}$ (from D. S. Gelles, unpublished research).

helium:dpa ratio for ferritic/martensitic steels in most fission reactors is about two ordersof-magnitude lower and has a minimal effect on swelling.

\subsection{EFFECT OF IRRADIATION ON MECHANICAL PROPERTIES}

The effect of irradiation on the tensile behavior of the $7-12 \% \mathrm{Cr}$ ferritic/martensitic steels depends on temperature. ${ }^{40-43}$ Hardening, as measured by an increase in yield stress and ultimate tensile strength (Fig. 2), occurs at irradiation temperatures up to 425$450^{\circ} \mathrm{C}^{42}$ The hardening causes a decrease in ductility (Fig. 3). This irradiation hardening is caused by the high density of dislocation loops and tangles that form from

displacement damage, along with irradiation-induced precipitate changes. ${ }^{30,32,34,35,44}$ Hardening saturates with increasing fluence, and saturation occurs by $10 \mathrm{dpa}^{41}$ For irradiation above $425-450^{\circ} \mathrm{C}$, properties are generally unchanged (Figs. 2 and 3), but there may be enhanced softening, depending on fluence. ${ }^{40,41}$ At these temperatures, microstructures change slowly through dislocation recovery processes and precipitates coarsening. Irradiation enhances diffusion and/or precipitate redistribution, which can enhance recovery and coarsening, and thus, increase the rate of softening.

Irradiation hardening affects other properties, such as fatigue and toughness. The latter is of considerable concern and will be discussed briefly. Irradiation effects on toughness are the greatest concern for fusion applications of ferritic/martensitic steels and for pressure-vessel steels for light-water reactors. The effect is observed in a Charpy impact test as an increase in ductile-brittle transition temperature (DBTT) and a decrease in upper-shelf energy (USE), ${ }^{45-50}$ as shown in Fig. 4 for HT9 irradiated in FFTF. As seen 


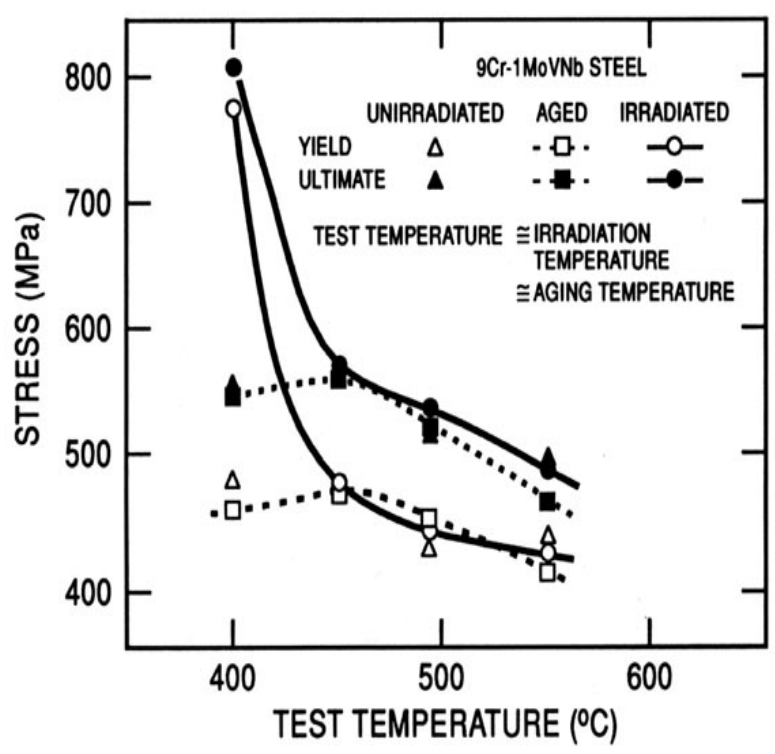

Fig. 2. Yield stress and ultimate tensile strength of normalized-and-tempered, thermally aged, and irradiated modified $9 \mathrm{Cr}-1 \mathrm{Mo}(9 \mathrm{Cr}-1 \mathrm{MoVNb})$ steel. Irradiation was in EBR-II to 9 dpa. ${ }^{42}$
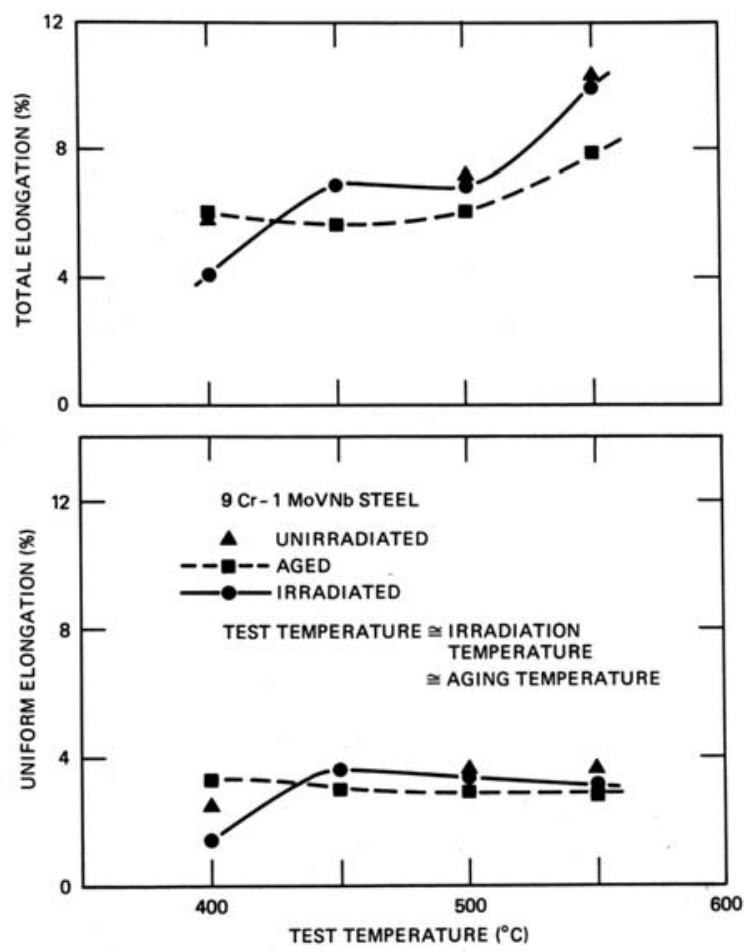

Fig. 3. Uniform and total elongation of normalized-and-tempered, thermally aged, and irradiated modified 9Cr-1Mo (9Cr-1MoVNb) steel. Irradiation was in EBR-II to 9 dpa. $^{42}$ 


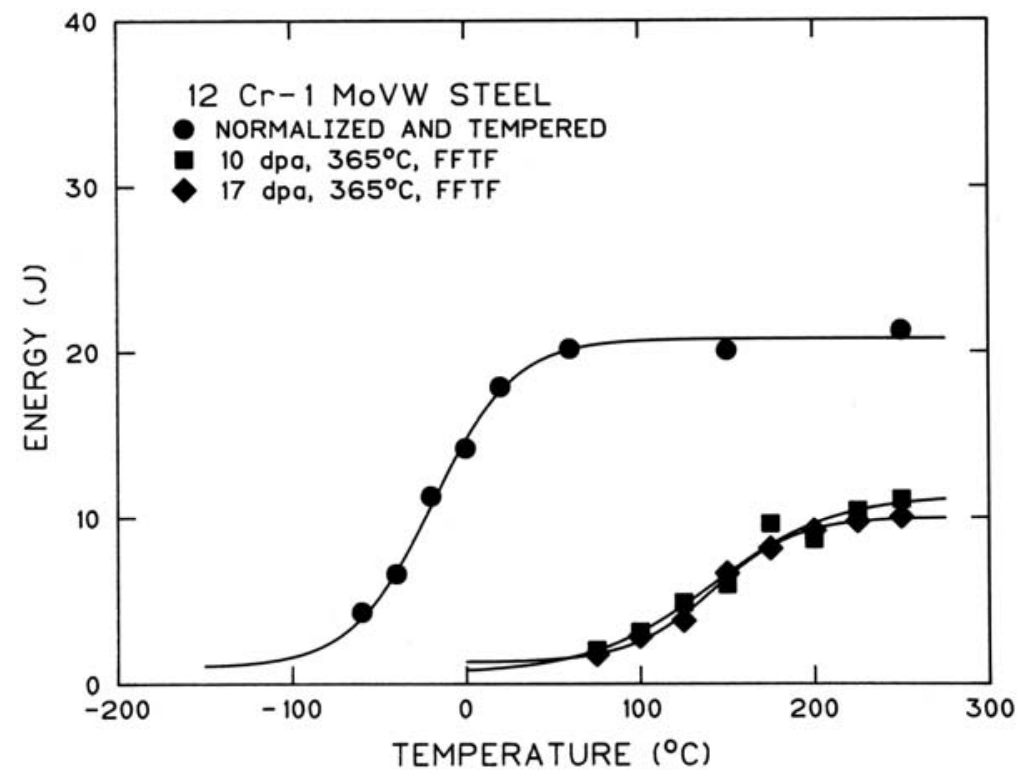

Fig. 4. Charpy curves for half-size specimens of Sandvik HT9 (12Cr-1MoVW) steel before and after irradiation to 10 and $17 \mathrm{dpa}$ at $365^{\circ} \mathrm{C}$ in FFTF. ${ }^{45}$

in the figure, the shift saturates with fluence (the shift is the same after 10 and $17 \mathrm{dpa}$ ). The magnitude of the shift varies inversely with irradiation temperature.

Although all $7-12 \% \mathrm{Cr}$ conventional and reduced-activation steels irradiated to date to high displacement damage ( $>100 \mathrm{dpa}$ ) demonstrate this effect on toughness, there are differences among different steels, as shown in Fig. 5, where the shift in DBTT for HT9 is compared with the shift for reduced-activation ORNL 9Cr-2WVTa steel. ${ }^{6}$ The reduced-activation steel showed much less shift (about $10^{\circ} \mathrm{C}$ vs. $\left.125^{\circ} \mathrm{C}\right)$. Part of this difference was attributed to the larger carbon concentration in the HT9 $(0.2 \%)$ than the $9 \mathrm{Cr}-2 \mathrm{WVTa}(0.1 \%)$; the tantalum in the $9 \mathrm{Cr}-2 \mathrm{WVTa}$ has also been shown to have a favorable effect on the impact properties. Modified 9Cr-1Mo (T91) has a DBTT shift about half as large as HT9 for similar test conditions, which is still more than twice that for the 9Cr-2WVTa steel.

The effect of irradiation on the shift can be affected by the normalizing-andtempering treatment ${ }^{49}$ and by the processing used on the steel during manufacture. ${ }^{47}$ It has been demonstrated that part of the reduction in USE on the MANET steel can be recovered by annealing $0.5 \mathrm{~h}$ at $535^{\circ} \mathrm{C} .{ }^{49}$ Such an anneal would dissolve irradiationinduced defects (particularly tiny clusters and the dislocation loops) that lead to hardening. ${ }^{30}$

The above discussion on embrittlement concerned high-chromium steels and irradiations to high displacement damage ( $>1 \mathrm{dpa})$. In the pressure vessel steels of the light-water reactors (e.g., A533B) operating today, hardening and embrittlement in these low-alloy steels are observed for irradiations of $<1 \mathrm{dpa}^{51}$ where there is little effect on the high-alloy steels.

As measured by a shift in DBTT in Charpy tests, there are indications that transmutation helium increases the embrittlement of the higher-chromium steels in a 


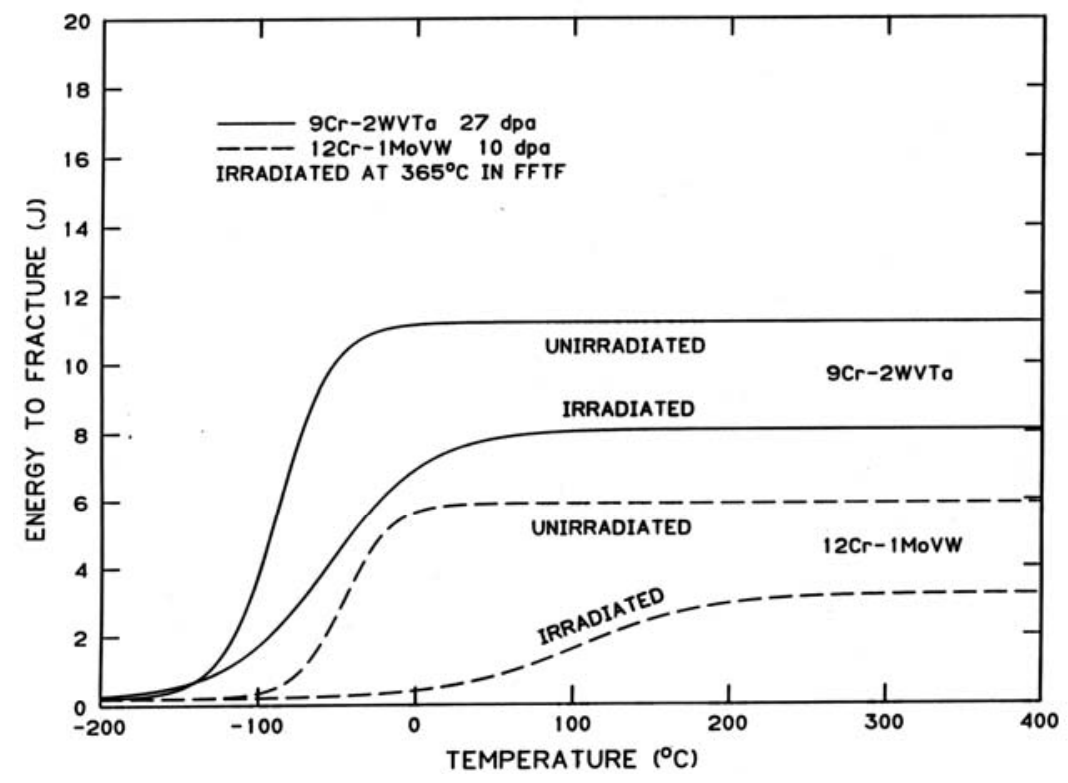

Fig. 5. Comparison of the unirradiated and irradiated Charpy curves for one-third-size specimens of HT9 and ORNL 9Cr-2WVTa steels irradiated in FFTF at $365^{\circ} \mathrm{C} .^{6}$

fusion neutron environment ${ }^{50}$ after irradiation in the hardening range (below $\approx 425^{\circ} \mathrm{C}$ ). However, because of the much lower amount of helium formed in fission light-water and fast reactors, such as the Generation IV designs, helium should not be a factor for this type of embrittlement in those reactors, and it will not be discussed.

Intergranular low-ductility fractures attributed to helium effects are observed in tensile tests of austenitic stainless steels for irradiation temperatures $T_{i} \approx 0.5 T_{m}$, where $T_{m}$ is the melting temperature (temperatures in Kelvin). Such elevated-temperature helium embrittlement in austenitic stainless steels can occur with as little as 1 appm He or less, depending on the composition, thermomechanical processing, irradiation conditions, and test conditions (temperature, strain rate, etc.). All indications are that the ferritic/martensitic steels are relatively immune to this type of embrittlement. ${ }^{6}$ 


\section{HIGH-CHROMIUM (9-12\% CR) STEELS}

Despite the fact that numerous steels have been developed that are improvements over HT9, FV448, EM-12, DIN 1.4914, and JFMS, some of these compositions are still under consideration for Generation IV reactors. ${ }^{1}$ Most of these steels were developed for conventional fossil-fuel power plant applications. Since the 1970s when these steels were first considered for nuclear applications, improved steels for conventional power plant applications have been developed. Although not as yet tested under irradiation, these steels need to be considered for nuclear applications. The evolution of the new steels will now be reviewed by considering the compositional changes that have led to improved microstructures and properties.

\subsection{EVOLUTION OF STEELS FOR POWER-GENERATION INDUSTRY}

The first Cr-Mo steels were used for conventional power-generation applications in the $1920 \mathrm{~s}$. The $2 \frac{1}{4} \mathrm{Cr}-1 \mathrm{Mo}$ (nominally Fe-2.25Cr-1.0 Mo-0.3 Si-0.45Mn-0.12C) steel, designated by ASTM as Grade $22,{ }^{*}$ was introduced in the 1940 s and is still widely used today. Along with Grade 22, 9Cr-1Mo (T9), and Fe-9.0Cr-1.0Mo-0.6Si-0.45Mn-0.12C composition, was an early development, the additional chromium added for corrosion resistance. Since then, there has been a continual push to increase operating temperatures of conventional fossil-fired power-generation systems. This led to the development of several "generations" of steels with improved elevated-temperature strengths. The evolution of steel compositions (Table 1), which began with T22 and T9 (zeroth generation) with $100,000 \mathrm{~h}$ creep-rupture strengths at $600^{\circ} \mathrm{C}$ of about $40 \mathrm{MPa}$ (Table 3), has allowed for increased operating steam temperatures and pressures. ${ }^{2-4}$ Three generations of steels have been introduced since the introduction of T22 and T9, and a fourth generation is in the development stage (Table 3).

Steels beyond the zeroth generation contained mainly $9-12 \% \mathrm{Cr}$ for improved corrosion and oxidation resistance for elevated-temperature operating conditions. The first generation, in addition to increased chromium, involved primarily the addition of the carbide formers vanadium and niobium to T22 and T9 compositions to add precipitate strengthening. In some cases, a small tungsten addition was made for further solidsolution strengthening, in addition to that provided by molybdenum. These steels, introduced in the 1960 s for applications to $565^{\circ} \mathrm{C}$, included $2 \frac{1}{4} \mathrm{Cr}-1 \mathrm{MoV}$, HT9 (Fe12.0Cr-1.0Mo-0.25V-0.5Ni-0.5W-0.6Mn-0.4Si-0.2C), HT91 (Fe-12.0Cr-1.0Mo-0.25V$0.5 \mathrm{Ni}-0.6 \mathrm{Mn}-0.4 \mathrm{Si}-0.2 \mathrm{C}$ ), and EM12 (Fe-9.5Cr-2.0Mo-0.30V-0.40Nb-1.1Mn-0.4Si$0.10 \mathrm{C}$ ). These steels, which included those later considered for fast reactor applications in the $1970 \mathrm{~s}$, had increased $10^{5} \mathrm{~h}$ rupture strengths at $600^{\circ} \mathrm{C}$ of up to $60 \mathrm{MPa}$.

\footnotetext{
* Grade 22 and the other commercial steels discussed here (Table 1) are given designations by ASTM (e.g., Grade 9 is $9 \mathrm{Cr}-1 \mathrm{Mo}$ and Grade 91 is modified $9 \mathrm{Cr}-1 \mathrm{Mo}$ ). The steels are further distinguished as T22 or T91 for tubing, P22 and P91 for piping, F22 and F91 for forgings, etc. The "T" designation will mainly be used in this paper, since many of the steels were developed for boiler tubing, although they are also used as other product forms.
} 
Table 3. Evolution of Ferritic/Martensitic Steels for Power-Generation Industry

\begin{tabular}{|c|c|c|c|c|c|}
\hline Generation & Years & Steel Modification & $\begin{array}{c}10^{5} \text { h Rupture } \\
\text { Strength, 600 } \\
\text { (MPa) }\end{array}$ & Steels & $\begin{array}{c}\text { Max Use } \\
\text { Temperature } \\
\left({ }^{\circ} \mathrm{C}\right)\end{array}$ \\
\hline 0 & $1940-60$ & & 40 & T22, T9 & $520-538$ \\
\hline 1 & $1960-70$ & $\begin{array}{l}\text { Addition of Mo, } \\
\text { Nb, V to Simple } \\
\text { Cr-Mo steels }\end{array}$ & 60 & $\begin{array}{c}\text { EM12, } \\
\text { HCM9M, } \\
\text { HT9, HT91 }\end{array}$ & 565 \\
\hline 2 & $1970-85$ & $\begin{array}{c}\text { Optimization of C, } \\
\mathrm{Nb}, \mathrm{V}, \mathrm{N}\end{array}$ & 100 & $\begin{array}{l}\text { HCM12, T91, } \\
\text { HCM } 2 S\end{array}$ & 593 \\
\hline 3 & $1985-95$ & $\begin{array}{l}\text { Partial Substitution } \\
\text { of W for Mo and } \\
\text { Add } \mathrm{Cu}, \mathrm{N}, \mathrm{B}\end{array}$ & 140 & $\begin{array}{l}\text { NF616, E911, } \\
\text { HCM12A }\end{array}$ & 620 \\
\hline 4 & Future & $\begin{array}{l}\text { Increase } \mathrm{W} \text { and } \\
\text { Add Co }\end{array}$ & 180 & $\begin{array}{l}\text { NF12, } \\
\text { SAVE12 }\end{array}$ & 650 \\
\hline
\end{tabular}

Generally, the microstructures of the 9 and $12 \% \mathrm{Cr}$ steels are designed by balancing austenite and ferrite stabilizers to produce $100 \%$ austenite during austenitization and $100 \%$ martensite during a normalizing (air cooling) or quenching treatment following austenitization, although a small amount of $\delta$-ferrite $(<1 \%)$ may be present in some cases, especially in the $12 \% \mathrm{Cr}$ steels. Some duplex steels containing martensite and $\delta$-ferrite have been developed and used. For example, because of the 2\% Mo in the EM12 composition (Table 1), it contains about $50 \% \delta$-ferrite. Unless otherwise stated, the microstructures discussed here are assumed to be $\approx 100 \%$ martensite.

For the second generation, developed in 1970-1985, carbon, niobium, and vanadium were optimized, nitrogen $(0.03-0.05 \%)$ was added, and the maximum operating temperature increased to $593^{\circ} \mathrm{C}$. The new steels included modified $9 \mathrm{Cr}-1 \mathrm{Mo}$, designated T91 (Fe-9.0Cr-1.0Mo-0.0.2 V-0.08Nb-0.05N-0.40Mn-0.40Si-0.10C) and HCM12 (Fe12.0Cr-1.0Mo-1.0W-0.25V-0.05Nb-0.55Mn-0.30Si-0.03N-0.10C), which has a duplex structure (tempered martensite and $\delta$-ferrite). These steels have $10^{5} \mathrm{~h}$ rupture strengths at $600^{\circ} \mathrm{C}$ of about $100 \mathrm{MPa}$. Of these latter steels, T91 has been used most extensively in the power-generation industry throughout the world. ${ }^{2-4}$

The third generation of steels was developed based on the previous generation, primarily by the substitution of tungsten for some of the molybdenum, although boron and nitrogen were also utilized. These steels, which will be discussed in detail below, are typified by NF616 (Fe-9.0Cr-1.8W-0.5Mo-0.20V-0.05Nb-0.45Mn-0.06Si-0.06N-0.004B0.07C), designated Grade 92, E911 (Fe-9.0Cr-1.0Mo-1.0W-0.20V-0.08Nb-0.40Mn$0.40 \mathrm{Si}-0.07 \mathrm{~N}-0.11 \mathrm{C}$ ), TB12 (Fe-12.0Cr-0.5Mo-1.8W-1.0Ni-0.20V-0.05Nb-0.50Mn$0.10 \mathrm{Ni}-0.06 \mathrm{Si}-0.06 \mathrm{~N}-0.004 \mathrm{~B}-0.10 \mathrm{C}$ ), and HCM12A (Fe-12.0Cr-0.5Mo-2.0W-1.0Cu$0.25 \mathrm{~V}-0.05 \mathrm{Nb}-0.30 \mathrm{Ni}-0.60 \mathrm{Mn}-0.10 \mathrm{Si}-0.06 \mathrm{~N}-0.003 \mathrm{~B}-0.10 \mathrm{C})$, designated Grade 122. They were developed and introduced in the $1990 \mathrm{~s}$ for $620^{\circ} \mathrm{C}$ operation with $10^{5} \mathrm{~h}$ creeprupture strengths at $600^{\circ} \mathrm{C}$ of $140 \mathrm{MPa}$.

Finally, the next generation of steels is being developed at present, where the intention is to push operating temperatures to $650^{\circ} \mathrm{C}$. These fourth-generation steels, SAVE12 (Fe-11.0Cr-3.0W-3.0Co-0.20V-0.07Nb-0.30Mn-0.30Si-0.04N-0.07Ta-0.04Nd$0.10 \mathrm{C}$ ) and NF12 (Fe-11.0Cr-2.6W-2.5Co-0.2Mo-0.2V-0.07Nb-0.50Mn-0.20Si-0.06N- 
0.004B-0.08C), differ from the previous generation primarily by the use of up to $3.0 \%$ cobalt; they have projected $10^{5} \mathrm{~h}$ creep-rupture strengths at $600^{\circ} \mathrm{C}$ of $180 \mathrm{MPa}^{2-4}$

The reduced-activation steel compositions were patterned after existing conventional steels being used or developed at the time the reduced-activation steels were being developed. The ORNL 9Cr-2WVTa, for example, was patterned after modified 9Cr-1Mo steel, with the molybdenum replaced by tungsten and niobium replaced by tantalum. ${ }^{12}$ As a result, most of these steels should, at best, be ranked as second generation. For the present discussion where elevated-temperature properties, especially creep, are of most importance, the steels generally have creep properties similar to those of modified 9Cr1Mo (T91). The possible exception is the EUROFER composition, which was developed most recently; ${ }^{29}$ the composition has characteristics of third-generation steels, in that it contains boron and nitrogen (Table 2). It remains to be seen if the steel has the properties of a third-generation steel.

The remainder of the discussion in this section on ferritic/martensitic steels will focus on the present (third) and next generation of steels developed for conventional power plants. The 9Cr steels of the third generation-NF616 (T92), developed in Japan, and E911, developed in Europe - are both simple modifications of T91 (Table 1). In the NF616, half the molybdenum was replaced by tungsten, whereas in the E911, 1\% W was added to the T91 composition. Both steels contain slightly more nitrogen $(0.06-0.07 \%)$ than T91 $(\approx 0.05 \%)$, and the NF616 contains a boron addition $(0.004 \%)$.

As operating temperatures were increased to $600^{\circ} \mathrm{C}$, emphasis shifted from 2.25 to 9 and $12 \% \mathrm{Cr}$ for oxidation and corrosion resistance. Chromium is a ferrite stabilizer, and when it is increased from 9 to $12 \%$, it is necessary to balance the effect of the addition of this ferrite stabilizer with an austenite stabilizer if complete austenitization is to be achieved and a 100\% martensitic structure is to be obtained. Carbon is the most potent austenite stabilizer, and it along with nickel was used in HT9 and HT91 for this purpose $(0.2 \% \mathrm{C}$ and $0.5 \% \mathrm{Ni})$. However, for the third-generation $12 \mathrm{Cr}$ steels, the carbon, in most cases, was kept to about $0.1 \%$ for better weldability, thus requiring some other austenite-stabilizing element to be added if $\delta$-ferrite was to be avoided. The HCM12 (Table 1) is a duplex steel because it has the same composition as modified 9Cr-1Mo except it contains 3\% more chromium, and there is an addition of $1 \% \mathrm{~W}$. Both $\mathrm{Cr}$ and $\mathrm{W}$ are ferrite stabilizers, and since no austenite stabilizers were added to compensate for these additions, the microstructure contains over $30 \% \delta$-ferrite.

The TB12 steel (Table 1), an advanced third-generation $12 \mathrm{Cr}$ steel, is a similar modification of T91 as NF616 with regard to the W, Mo, N, and B, and it has a duplex structure of $\delta$-ferrite and martensite because the extra ferrite-stabilizing element (chromium) is not offset by enough austenite-stabilizing element. It contains only $0.1 \%$ $\mathrm{Ni}$ to offset the $3 \% \mathrm{Cr}$ addition (it also contains $0.05 \% \mathrm{~N}$, an austenite stabilizer). In TB12M, up to $1 \% \mathrm{Ni}$ is added to produce a $100 \%$ martensitic steel. HCM12A is a somewhat similar $12 \mathrm{Cr}$ composition to that of $\mathrm{TB} 12 \mathrm{M}$, but with a $1 \% \mathrm{Cu}$ addition as the austenite stabilizer. Copper was used instead of nickel, which was generally used in the past (e.g., as it was for TB12M, HT9 and HT91), because nickel reduces creep strength (this nickel effect will be discussed below).

It should be noted that the replacement of molybdenum by tungsten was also used to develop T23 (HCM2S), an advanced 21/4Cr steel (Fe-2.25Cr-1.6W-0.1Mo-0.25V-0.05Nb$0.45 \mathrm{Mn}-0.20 \mathrm{Si}-0.003 \mathrm{~B}-0.06 \mathrm{C})$. The $100,000 \mathrm{~h}$ creep-rupture strength at $600^{\circ} \mathrm{C}$ of this 
steel is above that of first generation steels, and it can exceed that of T91 under some conditions. ${ }^{2-4}$ However, because of the lower chromium and, therefore, lower oxidation and corrosion resistance, its maximum operating temperature in most environments is similar to that of the second generation steels (e.g., T91).

For the fourth generation of high-chromium martensitic steels, two $12 \% \mathrm{Cr}$ compositions $\left(12 \% \mathrm{Cr}\right.$ is believed necessary for operation above $\left.600-620^{\circ} \mathrm{C}\right)$, designated NF12 and SAVE12, are in the development stage in Japan (Table 1). ${ }^{2-4}$ In these steels with about $0.1 \% \mathrm{C}$, molybdenum has been further reduced or eliminated, and tungsten (2.6-3.0\%) has been increased compared to third-generation compositions. Because of the adverse effect of nickel on creep, cobalt (2.5-3\%) has been used as an austenite stabilizer instead of nickel. Another reason for using cobalt instead of nickel for a steel with $0.1 \% \mathrm{C}$ is that nickel lowers the $\mathrm{A}_{1}$ temperature, the equilibrium temperature where ferrite transforms to austenite on heating. For the amount of nickel required for a steel with only $0.1 \% \mathrm{C}$ to insure complete austenitization (and thus a completely martensitic structure), a lower $\mathrm{A}_{1}$ (below $700^{\circ} \mathrm{C}$ ) reduces the effective tempering temperatures too much (tempering must be carried out below $\mathrm{A}_{1}$ to avoid untempered martensite). The SAVE 12 also has small additions of $\mathrm{Nd}(0.04 \%)$ and $\mathrm{Ta}(0.07 \%)$.

\subsection{MICROSTRUCTURE}

For the Generation IV reactors, high-chromium ferritic/martensitic steels are being considered for elevated-temperature in-core applications and, in some cases, out-of-core applications where the low-alloy steels do not have sufficient corrosion resistance. The effect of microstructure on creep and the change in microstructure during elevatedtemperature exposure will be discussed to demonstrate the difference between the early versions of the steels and the improvements that have been made. Generally, these steels contain $9-12 \% \mathrm{Cr}$, but similar conclusions probably apply if the chromium is reduced to $5-7 \%$. This is in contrast to the $2-3 \% \mathrm{Cr}$ steels (discussed below), which are expected to have mostly tempered bainite or bainite plus ferrite microstructures when in the normalized-and-tempered and quenched-and-tempered conditions.

\subsubsection{Normalized-and-Tempered and Quenched-and-Tempered Microstructure}

For this discussion, it is assumed that the steel will be used in the normalized-andtempered or quenched-and-tempered condition, and unless otherwise stated, a $100 \%$ tempered martensite microstructure (Fig. 6) is assumed for the 9-12\% Cr steels. For these conditions, the strength of the $9-12 \%$ Cr steels will depend on the tempered martensite microstructure and the precipitates therein. The general microstructures (prior-austenite grain boundaries, lath/subgrain boundaries, dislocations, and precipitates) of most of the new 9 and $12 \mathrm{Cr}$ steels are similar, and they are similar to the microstructures of the steels of earlier generations, as is the general change in microstructure that occurs during elevated-temperature exposure. ${ }^{52-60}$ Strengthening mechanisms in the steels will include solid-solution strengthening, dislocation-particle interactions, dislocation-dislocation interactions, and dislocation-boundary interactions. 


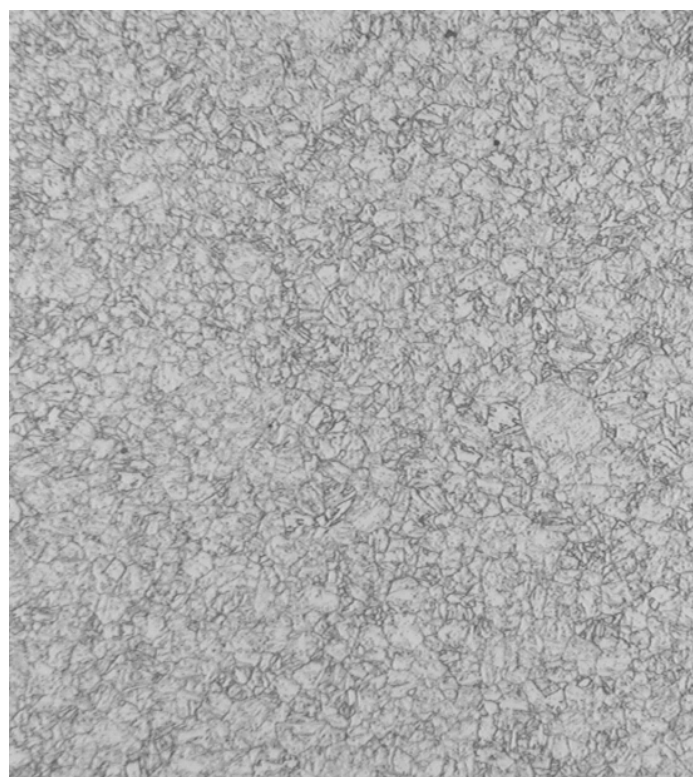

Fig. 6. Optical photomicrograph of normalized-and-tempered modified 9Cr-1Mo steel showing tempered martensite microstructure.

In the normalized or quenched conditions [Fig 7(a)], martensite laths with a high dislocation density are observed. When tempered, the dislocation structure recovers, and the laths become elongated subgrains with a typical average width of $0.25-0.5 \mu \mathrm{m}$ [Fig. 7(b)]. Laths are contained within the prior-austenite grain boundaries, and they contain a relatively high dislocation density $\left(10^{13}-10^{14} \mathrm{~m}^{-2}\right)$, depending on the tempering conditions. ${ }^{56}$ The dominant precipitates are large $(60-150 \mathrm{~nm}) \mathrm{M}_{23} \mathrm{C}_{6}$ particles that are mainly on lath boundaries and prior-austenite grain boundaries. ${ }^{59-62}$ If $\mathrm{V}$ and $\mathrm{Nb}$ are present in the composition, there will also be a fine distribution of small (20-80 $\mathrm{nm}) \mathrm{MX}$ particles that have generally been concluded to be vanadium nitrides and/or niobium carbonitrides, depending on the composition. ${ }^{56}$ Small amounts of $\mathrm{M}_{2} \mathrm{X}$ (a highchromium, high-nitrogen precipitate) are also found in some cases. The $\mathrm{M}_{23} \mathrm{C}_{6}$ helps stabilize the lath boundaries during elevated-temperature exposure, and the MX particles pin the dislocations, both processes helping to retard recovery. ${ }^{52-62}$

\subsubsection{Effect of Elevated-Temperature on Microstructure}

Significant microstructural changes of the $9-12 \% \mathrm{Cr}$ ferritic/martensitic steels occur when exposed to elevated temperatures during service, thermal aging, or in a creep test at typical service temperatures of $550-650^{\circ} \mathrm{C}$, with the of rate the changes increasing with increasing temperature. ${ }^{52-63}$ Elevated-temperature exposure causes a reduction in the dislocation density, with the reduction generally greater during a creep test than for thermal aging without a stress. This is reflected in the hardness, as there is a greater reduction in hardness in the gage section of a creep specimen than in the unstressed shoulder. ${ }^{60-63}$ Along with the reduction in dislocation density, the $\mathrm{M}_{23} \mathrm{C}_{6}$ particles coarsen (higher coarsening rate in the gage section), allowing the martensite laths to 

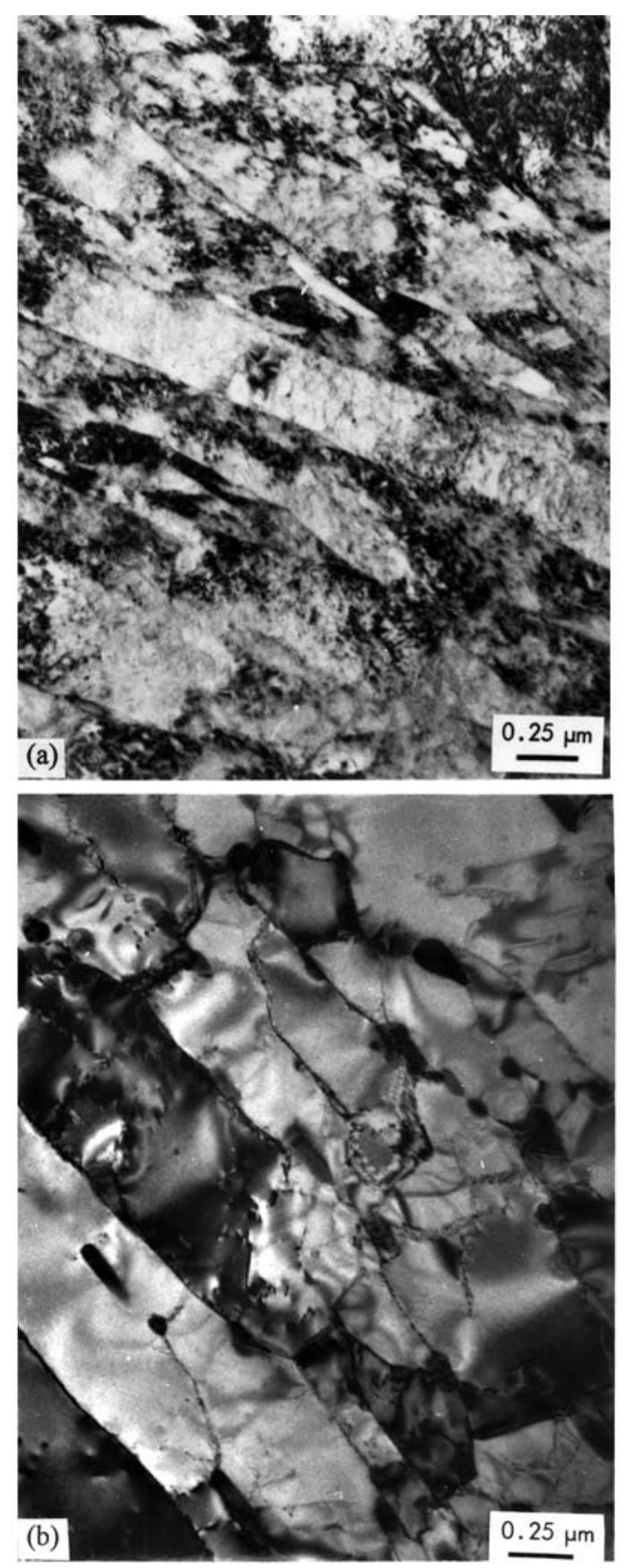

Fig. 7. Transmission electron micrographs of 12Cr-1MoVW (HT9) steel in (a) normalized and (b) normalized-and-tempered conditions. 
transform to more equiaxed subgrains, with the subgrains being fully recovered in a crept specimen after about $30,000 \mathrm{~h}$ at $600^{\circ} \mathrm{C}$. Along with the coarsening of the $\mathrm{M}_{23} \mathrm{C}_{6}$, there is also a coarsening in the MX precipitate distribution, although these particles coarsen much more slowly than $\mathrm{M}_{23} \mathrm{C}_{6}$. During coarsening, changes occur in the composition of the $\mathrm{M}$ (e.g., enrichment in chromium in the $\mathrm{M}_{23} \mathrm{C}_{6}$, etc.) in the precipitates as equilibrium is approached. ${ }^{52-63}$

In addition to the coarsening of $\mathrm{M}_{23} \mathrm{C}_{6}$ and $\mathrm{MX}$, another important effect of elevatedtemperature exposure is the formation of Laves phase, $(\mathrm{FeCr})_{2}(\mathrm{Mo}, \mathrm{W})$. Laves phase forms during thermal aging and creep, and at $600^{\circ} \mathrm{C}$ and above, it quickly coarsens, with the coarsening proceeding more quickly under stress. ${ }^{52-66}$ Laves phase formation is important because it removes the solid-solution strengthening elements tungsten and molybdenum from solution. In thermal aging studies of NF616, HCM12A, and TB12 for $10,000 \mathrm{~h}$ at 600 and $650^{\circ} \mathrm{C}$, particles up to $1 \mu \mathrm{m}$ were observed. ${ }^{52}$ The amount of tungsten and molybdenum in the alloy determines the amount of Laves that forms, as observed for T91 and E911, where smaller amounts of Laves formed at $600^{\circ} \mathrm{C}$ in T91 compared to E911, which contains $1 \% \mathrm{~W}$ and $1 \%$ Mo, compared to only $1 \%$ Mo for T91. Further, almost no Laves formed in $\mathrm{T} 91$ at $650^{\circ} \mathrm{C}$ compared to E911, where, because of the higher tungsten and molybdenum concentrations, Laves is stable at a much higher temperature. ${ }^{53}$

After exposure for long times at elevated temperatures, a large portion of the tungsten and/or molybdenum in the steels is contained in the precipitates (Laves and $\mathrm{M}_{23} \mathrm{C}_{6}$ ). For NF616 steel containing $1.84 \% \mathrm{~W}$, computational thermodynamics and kinetics calculations were used to estimate that at equilibrium approximately 0.6 and $0.85 \% \mathrm{~W}$ remained in solution at 600 and $650^{\circ} \mathrm{C}$, respectively, ${ }^{54}$ which was verified with tests at $600^{\circ} \mathrm{C}$. Measurements of precipitates from thermally aged steel $l^{65,66}$ combined with thermodynamics calculations ${ }^{65}$ indicated that the equilibrium concentration of tungsten in solution at $600^{\circ} \mathrm{C}$ will approach $0.5 \%$, regardless of the starting concentration.

Thus, elevated-temperature exposure pushes the evolution of the microstructure toward equilibrium, which will consist of large, relatively equiaxed subgrains within the prior austenite grain boundaries. The interior of the subgrains will contain a very low dislocation density. ${ }^{53}$ Ostwald ripening produces a lower density of large $\mathrm{M}_{23} \mathrm{C}_{6}$ and $\mathrm{MX}$ precipitates than in the tempered microstructure. Although a relatively fine distribution of Laves phase forms during the elevated-temperature exposure, it quickly coarsens at $550-600^{\circ} \mathrm{C}$. This general microstructural evolution will apply to all $9-12 \% \mathrm{Cr}-\mathrm{Mo}-\mathrm{W}-\mathrm{V}$ steels containing small amounts of $\mathrm{Nb}, \mathrm{B}, \mathrm{N}$, etc. (Table 1), and, with minor variations, to the $2-3 \%$ Cr Cr-Mo-W-V steels, although in the latter, the chromium-rich $\mathrm{M}_{7} \mathrm{C}_{3}$ precipitate may dominate instead of $\mathrm{M}_{23} \mathrm{C}_{6}$.

\subsubsection{Effect of Composition on Microstructure}

Although the overall microstructures of the $9-12 \% \mathrm{Cr}$ steels are quite similar for most compositions that have been developed, it is the compositional changes made over the years that have resulted in the improved properties. Generally, the developers of the new steels have used modified $9 \mathrm{Cr}-1 \mathrm{Mo}$, T91 (9Cr-1MoVNb), as a benchmark for comparison, and for this discussion, T91 will be used as a basis for comparison of the effects of the different elements that have been added to improve the properties. 


\subsubsection{Effect of Carbon and Nitrogen}

Carbon and nitrogen are strong austenite stabilizers with a relatively large solubility in austenite. They have a very small solubility in ferrite, which gives rise to the formation of carbides, nitrides, and carbonitrides, as discussed in the following sections.

\subsubsection{Effect of Chromium}

Chromium is a ferrite-stabilizing element that is generally added to steels for oxidation and corrosion resistance. It provides little solid-solution strengthening when added to iron. ${ }^{67}$ Chromium reacts with carbon to form carbides; the chromium-rich carbides usually encountered in the $2-12 \% \mathrm{Cr}$ steels are $\mathrm{M}_{7} \mathrm{C}_{3}$ and $\mathrm{M}_{23} \mathrm{C}_{6}$. The latter carbide dominates in the $9-12 \% \mathrm{Cr}$ steels; it forms during tempering and remains present throughout the elevated-temperature exposure. The $\mathrm{M}_{7} \mathrm{C}_{3}$ forms in lower-chromium steels $(\$ 7 \% \mathrm{Cr})$, although $\mathrm{M}_{23} \mathrm{C}_{6}$ may also form in these steels after prolonged exposure at elevated temperatures. ${ }^{68}$ In steels containing nitrogen, chromium-rich $\mathrm{M}_{2} \mathrm{X}\left(\mathrm{Cr}_{2} \mathrm{~N}\right)$ can also form.

\subsubsection{Effect of Tungsten and Molybdenum}

In developing steels beyond T91, tungsten was added to the modified $9 \mathrm{Cr}-1 \mathrm{Mo}$ composition (E911, HCM12) or substituted for part of the molybdenum (NF616, T23, TB12), which was based on work of Fujita et al. ${ }^{69}$ Independent of the Fujita work and at about the same time, molybdenum was replaced by tungsten for nuclear considerations in the development of reduced-activation steels for fusion applications. In this case, tungsten was a natural choice to replace molybdenum because it was in the same column of the periodic table and behaved similarly in steel (formed similar-type carbides, etc.). ${ }^{12}$

Molybdenum and tungsten are ferrite stabilizers, and depending on other ferrite stabilizers (i.e., Cr, V, Si, Nb) and austenite stabilizers (i.e., C, N, Ni, Co, and $\mathrm{Cu}$ ) present in a steel, the amount must be limited to avoid $\delta$-ferrite. In the tempered condition, Mo and $\mathrm{W}$ are distributed between the solid solution and that incorporated in the $\mathrm{M}_{23} \mathrm{C}_{6}$ and MX. The two elements provide relatively high solid-solution strengthening of iron. ${ }^{67-72}$ Tungsten diffuses more slowly than molybdenum, which slows recovery and Laves precipitation processes. ${ }^{64-66,73}$ The elements generally do not form carbides or nitrides in the $9-12 \% \mathrm{Cr}$ steels, although $\mathrm{M}_{2} \mathrm{C}\left(\mathrm{Mo}_{2} \mathrm{C}\right.$ or $\left.\mathrm{W}_{2} \mathrm{C}\right)$ does form in low-chromium steels (e.g., $\mathrm{Mo}_{2} \mathrm{C}$ in $2 \frac{1}{4} \mathrm{Cr}-1 \mathrm{Mo}$ ). ${ }^{68}$

A molybdenum equivalent, $\mathrm{Mo}_{\text {eq }}$, defined as $\mathrm{Mo}+0.5 \mathrm{~W}$ (concentrations in wt. \%) in solid solution, has been established, and a value of about $1.5 \%$ before thermal exposure has been found to be appropriate in one investigation. ${ }^{70}$ Because of Laves precipitation, it has been stated that at equilibrium the $\mathrm{Mo}_{\text {eq }}$ cannot be expected to exceed $1 \%{ }^{71}$ Exposure of the $9-12 \%$ Cr steels with Mo and/or W at a $\mathrm{Mo}_{\text {eq }} \geq 1$ at $600-650^{\circ} \mathrm{C}$ has been shown to result in the precipitation of Laves-phase, ${ }^{54,65,66}$ which removes the element from solid solution and reduces solid-solution strengthening. Other work indicated that the lowering of the $\mathrm{Mo}_{\mathrm{eq}}$ occurred for steels with an original $\mathrm{Mo}_{\mathrm{eq}}$ as small as $0.84 \%$ 
before thermal exposure, after which precipitation during thermal aging at $600^{\circ} \mathrm{C}$ for $10,000 \mathrm{~h}$ lowered the value to $\approx 0.5 \%$. $^{71}$

\subsubsection{Effect of Vanadium, Niobium, and Tantalum}

Vanadium and niobium are strong carbide, nitride, and carbonitride formers, and in the 9-12 Cr steels, they are expected to form $\mathrm{MX}$, where $\mathrm{V}$ and $\mathrm{Nb}$ are enriched in the $\mathrm{M}$, and $\mathrm{X}$ is either carbon, nitrogen, or a combination of the two, resulting in carbides (MC), nitrides $(\mathrm{MN})$, or carbonitrides $[\mathrm{M}(\mathrm{C}, \mathrm{N})]^{71}$ At one time it was believed that strengthening by vanadium was caused by the formation of vanadium carbide. More recent work indicated that the vanadium-rich $\mathrm{MX}$ is rich in nitrogen. ${ }^{71}$ Niobium carbides are extremely stable, and it is necessary to heat to temperatures beyond normal austenitizing temperatures for them to dissolve completely. However, undissolved niobium carbides restrict grain growth during austenitization, thus producing a refined prior-austenite grain size relative to a steel without niobium.

Tantalum is generally expected to behave like niobium. However, TEM ${ }^{74}$ and atomprobe analyses ${ }^{75}$ indicated that for the normalized-and-tempered 9Cr-2WVTa steel, 75$90 \%$ of the tantalum unexpectedly remained in solution after normalization.

Nevertheless, the tantalum did produce austenite grain refinement, ${ }^{22}$ similar to what is observed for niobium-containing steels.

\subsubsection{Effect of Boron and Phosphorus}

Boron is a surface-active element with a low solubility in ferrite, and it is often used to increase hardenability. In many of the $9-12 \% \mathrm{Cr}$ steels, about $0.005-0.01 \% \mathrm{~B}$ is added. It has been found to segregate to the surface of the $\mathrm{M}_{23} \mathrm{C}_{6}$ and decrease the rate at which the carbide can coarsen, thus stabilizing the microstructure, since the $\mathrm{M}_{23} \mathrm{C}_{6}$ helps pin the subgrain boundaries. ${ }^{58,59,76-79}$ Recent studies of P122 and P92 ${ }^{77}$ steels using secondary ion mass spectroscopy, energy filtered transmission electron microscopy, and atom probe field-ion microscopy revealed that the boron segregates to austenite grain boundaries during cooling after austenitizing, then during the first few minutes of tempering, it is incorporated into the $\mathrm{M}_{23} \mathrm{C}_{6}$. Boron slowed the coarsening rate during aging and creep to $10,000 \mathrm{~h}$. It was not found in any other precipitates when present at $\$ 0.005 \%{ }^{77-79}$ However, when present at levels of 0.0092 and $0.0139 \%$ in a $9 \mathrm{Cr}-3 \mathrm{~W}$ $3 \mathrm{Co}-\mathrm{VNb}$ steel, undissolved coarse $\mathrm{FeW}_{2} \mathrm{~B}_{2}$ was observed. ${ }^{79}$

Phosphorus can also segregate to the surface of $\mathrm{M}_{23} \mathrm{C}_{6}$, and a small amount of it is found in the Laves phase. ${ }^{58}$

\subsubsection{Effect of Nickel, Manganese, and Cobalt}

Nickel, manganese, and cobalt are austenite stabilizers. The main reason for adding them to $12 \mathrm{Cr}$ steels is to ensure $100 \%$ austenite formation (no $\delta$-ferrite) during the austenitization treatment, thus ensuring $100 \%$ martensite when cooled. ${ }^{54,55,59,70,80-83}$ Nickel and cobalt both increase the toughness of ferritic/martensitic steels. ${ }^{55,81,84}$

Although nickel has been the element most often used to prevent $\delta$-ferrite, indications are that it accelerates precipitate coarsening, thus lowering long-time creep 
strength. ${ }^{55,62,84,85}$ Nickel promotes the formation of $\mathrm{M}_{6} \mathrm{C},{ }^{55,84}$ thus destabilizing the $\mathrm{M}_{23} \mathrm{C}_{6}$, which stabilizes the subgrain structure. Manganese is a weaker austenite stabilizer than nickel, and it has a similar effect on carbide coarsening. ${ }^{70,72}$

In one investigation, cobalt was found to be a weaker austenite stabilizer than nickel in preventing $\delta$-ferrite formation in a $12 \% \mathrm{Cr}$ steel $(2 \mathrm{wt} . \% \mathrm{Co}$ was required compared to $1 \% \mathrm{Ni}),{ }^{81}$ while in another investigation, little difference was found between the two. ${ }^{85}$ Cobalt and nickel have similar weighting in some nickel-equivalent equations. ${ }^{72,80}$ Cobalt has been credited with being a solid solution strengthener ${ }^{86}$ and beneficial to creep strength by some investigators. ${ }^{73}$ However, this is contrary to earlier work that indicated cobalt contributed little to solid-solution strengthening in binary Fe-Co alloys. ${ }^{67,72}$ Nickel and manganese have been shown to have a much stronger solid-solution strengthening effect in iron than cobalt. ${ }^{67}$ Cobalt has also been grouped with $\mathrm{Ni}$ and $\mathrm{Mn}$ as having a negative effect on precipitate coarsening and creep strength by some investigators, ${ }^{87,88}$ who suggested $\mathrm{Pd}, \mathrm{Rh}, \mathrm{Pt}$, and Ir be used as austenite stabilizers, since they concluded that elements that raise the melting point of the steel strengthen it. ${ }^{88}$ Cobalt does have one advantage over nickel and manganese in that it does not lower the $\mathrm{A}_{1}{ }^{80}$

\subsubsection{Effect of Copper}

Copper is an austenite-stabilizing element, but it is different from $\mathrm{Ni}, \mathrm{Mn}$, and $\mathrm{Co}$ in that it has a low solubility in ferrite. ${ }^{58,59}$ It can remain in solution during a normalization or quenching treatment, but it will precipitate during tempering and aging. Copper precipitation can strengthen the steel and can play a role in the nucleation of other phases during thermal aging or creep. Several investigators have concluded that copper precipitates increase elevated-temperature strength, ${ }^{4,58,75,89}$ but other investigators grouped copper with nickel and cobalt as accelerating precipitate coarsening. ${ }^{88}$ A recent study of P122 concluded that the copper precipitates contribute to the production of, ${ }^{77}$ " a finer distribution and a faster growth time of Laves phase precipitates, which should be beneficial for the creep strength."

\subsection{CREEP AND MICROSTRUCTURAL EVOLUTION}

Creep-rupture curves (graphs of the log of stress vs. log of time to rupture) are commonly plotted as straight lines. However, for many materials this relationship only applies to short-time tests, and data deviate from a linear relationship at long times and low stresses. This is true for the Cr-Mo-W-V-type steels being discussed here. ${ }^{65,84,89-92}$ Thus, linear extrapolation of data from high stresses and short rupture times to low stresses and long rupture times will not produce reliable results. That is, the extrapolated rupture life will be an over estimate of the actual value.

Creep tests on Cr-Mo-W-V-type steels tested at low stresses and out to long rupture times have shown that the creep-rupture curves have a sigmoidal shape (Fig. 8). ${ }^{65,84,90}$ The change in shape with increasing rupture time (lower stress) is indicative of a change in microstructure brought on by stress and elevated-temperature exposure. 


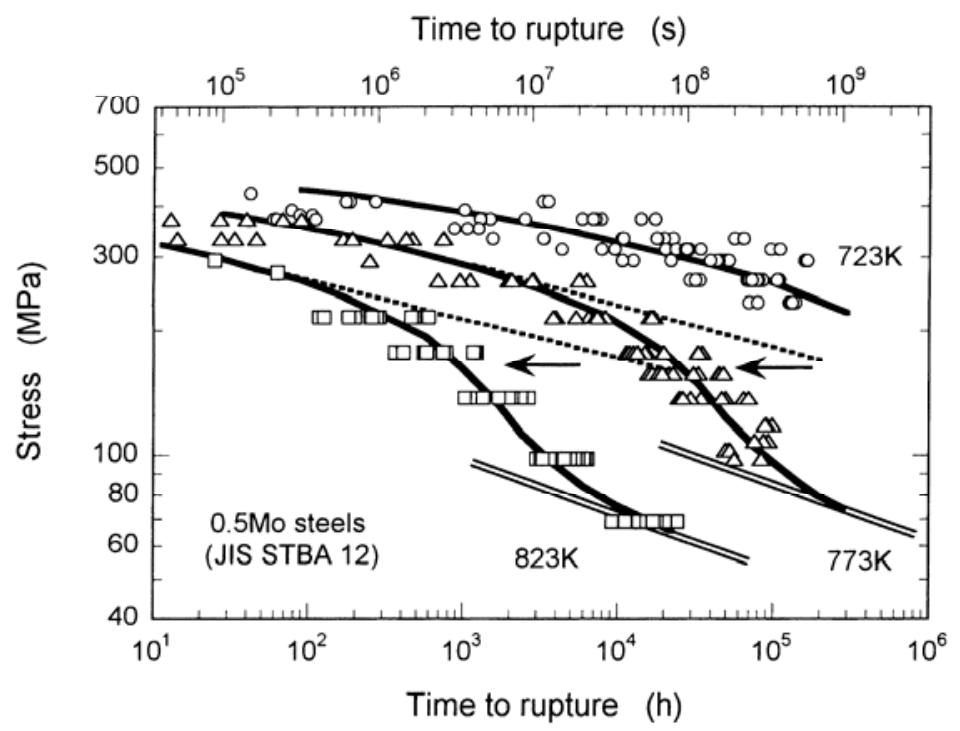

Fig. 8. Creep-rupture curves for heats of 0.5 Mo steels showing the sigmoidal shape of the curves for tests at 450,500 , and $550^{\circ} \mathrm{C} .^{90}$

To explain sigmoidal behavior, it was postulated that every steel has an "inherent" creep strength (Fig. 9). ${ }^{90}$ This is essentially the rupture strength of the equilibrium microstructure at the creep temperature. For the steels under discussion, the equilibrium microstructure consists of coarsened $\mathrm{M}_{23} \mathrm{C}_{6}, \mathrm{MX}$, and Laves-phase precipitates in a recovered matrix of large subgrains containing a low dislocation density, with the precipitates in equilibrium with the elements in solid solution. At this stage in the microstructural evolution, it can be assumed that the large precipitates and low dislocation density will have only a minimal effect on creep strength. Therefore, inherent strength is determined primarily by solid-solution strengthening. The rate of approach to the inherent strength will increase with an increase in temperature.

As proof of an inherent strength, Larson-Miller plots of data for low-alloy Cr-Mo steels $\left(0.5 \mathrm{Cr}-0.5 \mathrm{Mo}, 1 \mathrm{Cr}-0.5 \mathrm{Mo}, 2.25 \mathrm{Cr}-1 \mathrm{Mo}\right.$, etc.) were cited. ${ }^{90}$ Creep-rupture tests on these steels showed large data scatter at high creep stresses and low temperatures, but as the stress decreased and the temperature increased, the scatter was greatly reduced (Fig. 10). Larson-Miller plots of Vickers hardness of crept specimens of 12Cr-1Mo-1W$0.3 \mathrm{~V}$ and modified $9 \mathrm{Cr}-1 \mathrm{Mo}$ steels were presented as a vivid illustration of this effect (Fig. 11). ${ }^{90}$ The $9 \mathrm{Cr}$ steel was significantly harder than the $12 \mathrm{Cr}$ steel for short time/high temperature tests (low Larson-Miller parameter), but the two had similar hardness values for high Larson-Miller parameters. Thus, despite differences at high stresses due to different compositions, once hardening due to the high number density of dislocations and fine precipitate distribution of the original microstructure ceased to have a dominant effect on strength, the solid solution strength at equilibrium approached a similar value for the different steels (chromium is not a potent solid-solution strengthener). 


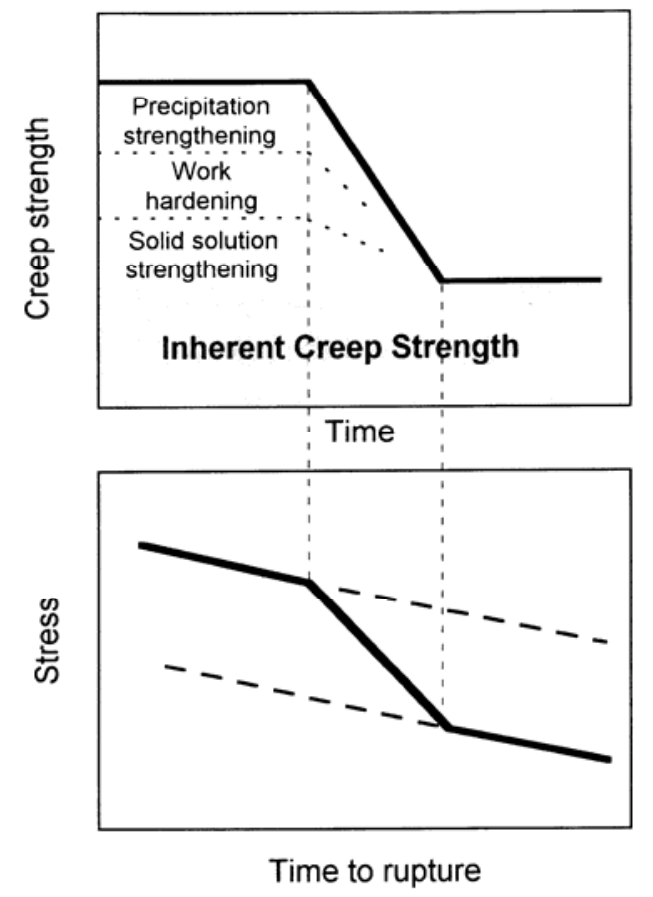

Fig. 9. Schematic illustration taken from Kimura et al. for an explanation of the mechanism for sigmoidal creep-rupture curves. ${ }^{90}$

A similar observation and conclusion was made for $2 \frac{1}{4} \mathrm{Cr}-1 \mathrm{Mo}$ steel tested in the normalized-and-tempered (bainitic microstructure) and annealed (mainly polygonal ferrite and pearlite microstructure) conditions. ${ }^{91}$ Although the normalized-and-tempered steel was stronger at short times because of the higher dislocation density and finer precipitates, the properties approached a common curve as stress was lowered or temperature increased. This observation was also attributed to the approach of a common equilibrium structure for $2 \frac{1}{4} \mathrm{Cr}-1 \mathrm{Mo}$ steel, which is determined primarily by the solidsolution strength, regardless of the starting strength and microstructure. ${ }^{91}$ In this case, as in many cases, sigmoidal curves were not observed. Data were fit by lines that appeared to merge as the stress decreased. In most cases, the sigmoidal shape will not be observed because of limited data and/or the lack of long-time data. Instead straight lines will be assumed, or there will appear to be a gradual change in slope in the creep-rupture curve, indicating that the transition to the inherent strength stage is beginning, as illustrated in Fig. 12 for E911. ${ }^{92}$ (Note in Fig. 12 how curvature in the creep-rupture curves increases with test temperature.) 


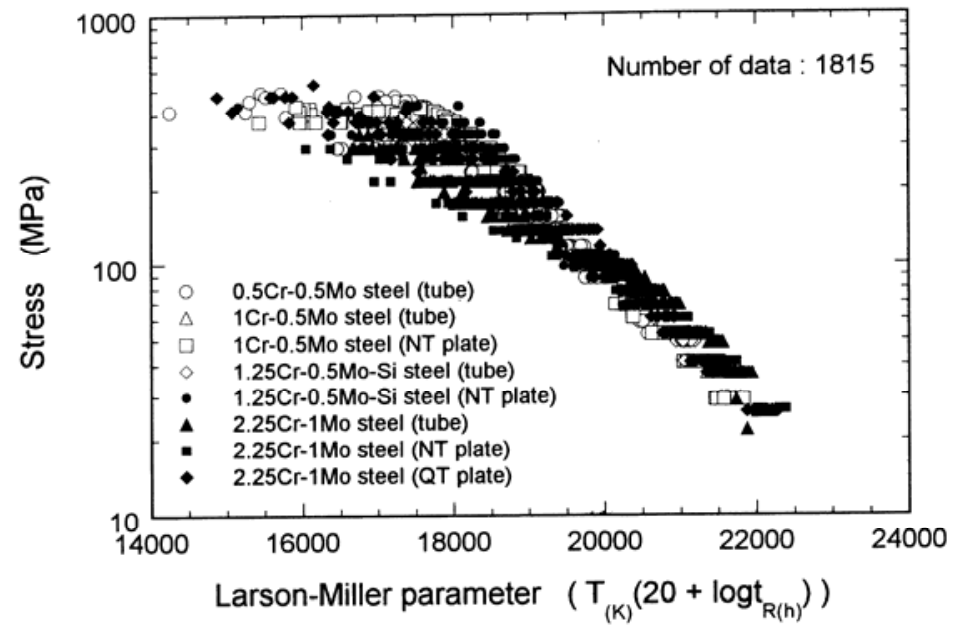

Fig. 10. Larson-Miller plots for creep-rupture stress of low-alloy $\mathrm{Cr}$-Mo steels that show a large variation for the different steels at low Larson-Miller parameters (short-time tests, low temperatures), but differences narrow at high Larson-Miller parameters (long-time tests, high temperatures). ${ }^{90}$

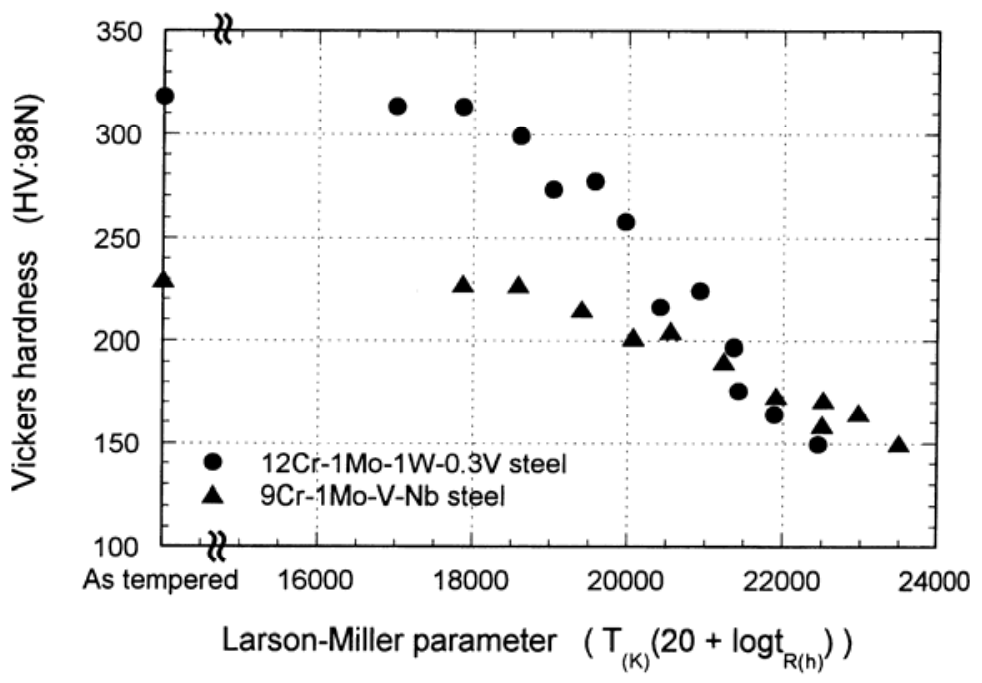

Fig. 11. Larson-Miller plots for Vickers hardness of creep specimens of $12 \mathrm{Cr}-1 \mathrm{Mo}-1 \mathrm{~W}-0.3 \mathrm{~V}$ and 9Cr-1Mo-V-Nb steels that show how the steels have a large difference in hardness for low LarsonMiller parameters but similar values for high parameters. ${ }^{90}$ 


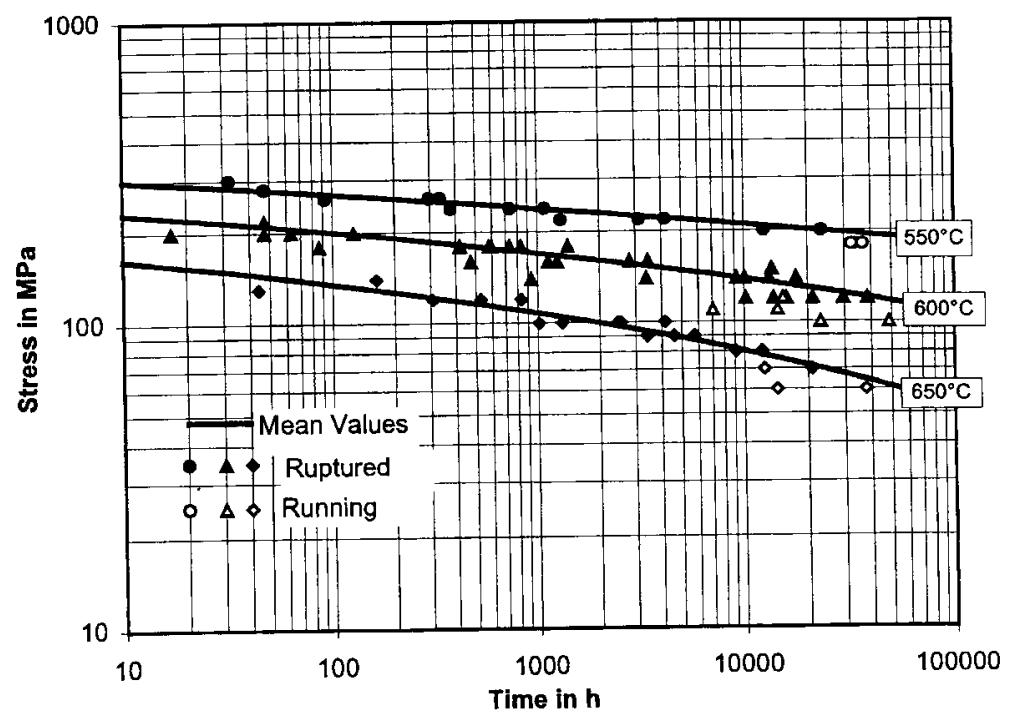

Fig. 12. Creep-rupture curves for E911 steel showing the downward curvature for low-stress tests at high temperatures. ${ }^{92}$

If it is accepted that at long rupture times at high temperature-low stresses-creeprupture life of any steel is ultimately determined by the inherent strength, which depends basically on the solid-solution strength, then there are obvious ways to increase the useful elevated-temperature strength. The difference in creep-rupture strength of different steels at high stresses (short rupture times) will be determined by differences in dislocation density, dispersion strengthening due to precipitates, and solid-solution strengthening. Differences in any of these three processes could lead to differences in rupture life at a given stress. The level of the short-time strength will be determined by the composition and heat treatment (i.e., different tempering treatments lead to different strengths). Therefore, one way to increase the strength is to develop a combination of heat treatment and composition that increases the initial strength and prolongs the early stage of the sigmoidal curve. Increased creep-rupture strength is also promoted by a prolonged transition to the final stage. It does not necessarily follow that a steel with high strength at high stresses (short time) will also have a long transition period, since the transition will be determined by the stability of the microstructure. Finally, the third strengthening possibility is to produce a steel that has a high inherent creep strength (high solid-solution strengthening). All of these procedures have been cited by developers of the advanced martensitic steels as reasons for improved properties.

Based on the discussion of the microstructural evolution when steels are exposed at high temperatures, the dislocation structure begins to recover, and the precipitate structure established during tempering begins to coarsen. With the coarsening of the $\mathrm{M}_{23} \mathrm{C}_{6}$ precipitates, they are no longer able to stabilize the subgrains, and they begin to grow. Likewise, the coarsening of the fine MX precipitates, although much slower under most conditions, hastens the recovery of the dislocation structure within the grains. If Laves phase forms, this can temporarily strengthen the steel and offset the effect of the 
coarsening of the $\mathrm{M}_{23} \mathrm{C}_{6}$, but Laves coarsens rapidly, ${ }^{93,94}$ thus eliminating its initial strengthening effect.

Work by Ennis et al. ${ }^{56}$ on $12 \mathrm{Cr} 1 \mathrm{MoV}$, modified 9Cr-1Mo (P91), and NF616 (P92) demonstrated the effect of some of these microstructural elements. Creep-rupture curves for the steels (Fig. 13) indicated that the P91 and P92 had similar rupture stresses at short times, both of which were larger than for $12 \mathrm{Cr} 1 \mathrm{MoV}$. The difference between P91 and P92 increased with rupture time (the longest rupture time mentioned was 17,551 h). Literature data for $9 \mathrm{Cr}-1 \mathrm{Mo}(\mathrm{P} 9)$ in the figure show it to have significantly lower creeprupture strength than the other steels.

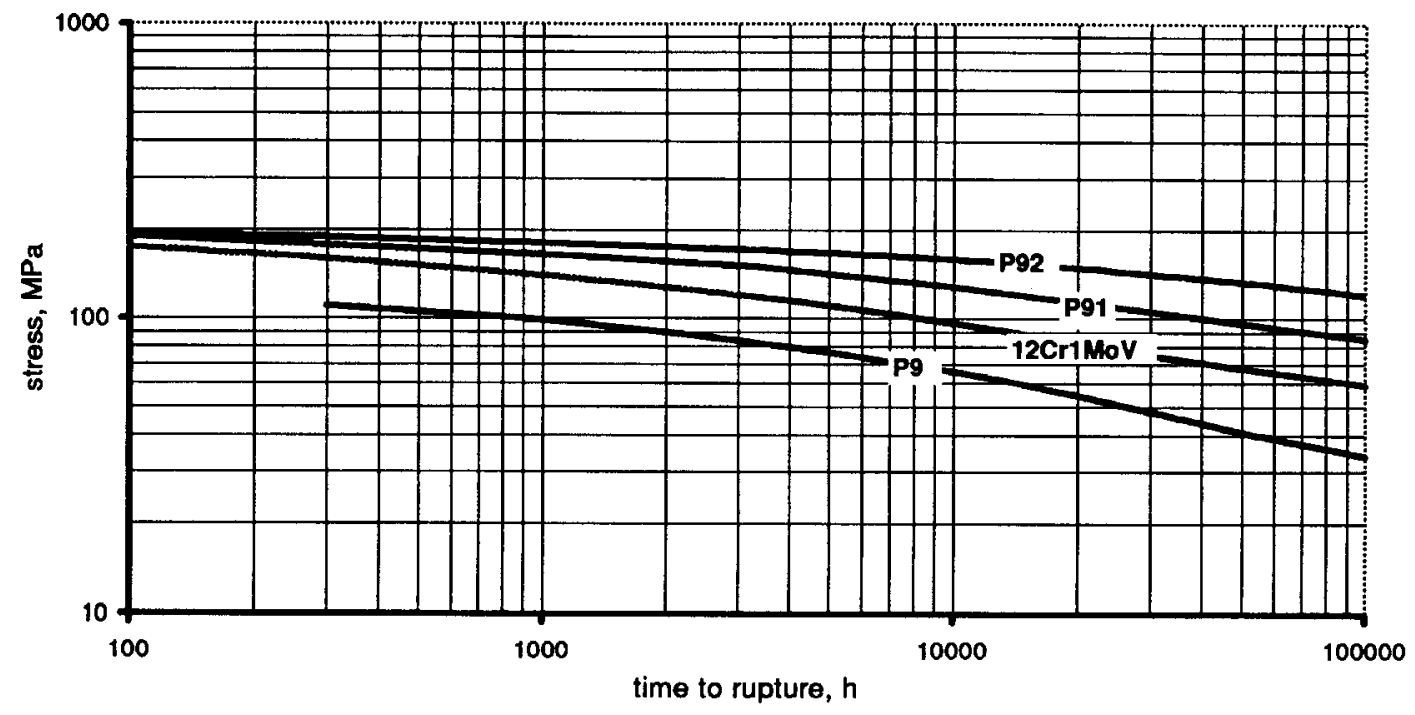

Fig. 13. Creep-rupture curves for P9, P91, P92, and $12 \mathrm{Cr} 1 \mathrm{MoV}$ steels tested at $600{ }^{\circ} \mathrm{C} .{ }^{56}$

As normalized and tempered, the $12 \mathrm{Cr} 1 \mathrm{MoV}$, P91, and P92 steels had similar dislocation densities $\left(7-7.5 \times 10^{14} \mathrm{~m}^{-2}\right)$ and mean subgrain sizes $(0.35-0.42 \mu \mathrm{m})$ (Fig. 14). ${ }^{56}$ The average diameter of the $\mathrm{M}_{23} \mathrm{C}_{6}$ particles were estimated at 170,99 , and $90 \mathrm{~nm}$ for the $12 \mathrm{Cr} 1 \mathrm{MoV}$, P91, and P92, respectively; average diameters of the smaller MX carbides were estimated at 63, 16, and $22 \mathrm{~nm}$, respectively. The P92 also contained complex $\mathrm{M}(\mathrm{C}, \mathrm{N})$ particles $(78 \mathrm{~nm})$ that were not present in the other steels, and Laves phase precipitated in this steel after testing for longer times at 600 and $650^{\circ} \mathrm{C}$.

The different behavior of the four steels in Fig. 13 can be attributed to differences in chemical composition (Table 4 gives nominal compositions of important elements) and the subsequent different microstructures and microstructural evolution that resulted therefrom. The P9 is expected to have the lowest strength, since it contains no strong carbide former (i.e., $\mathrm{Nb}, \mathrm{V}$, etc.). Thus, only the large globular $\mathrm{M}_{23} \mathrm{C}_{6}$ precipitates are expected to form during tempering, and this precipitate morphology has little strengthening effect and coarsens quickly at $600-650^{\circ} \mathrm{C}$, speeding the approach to the 

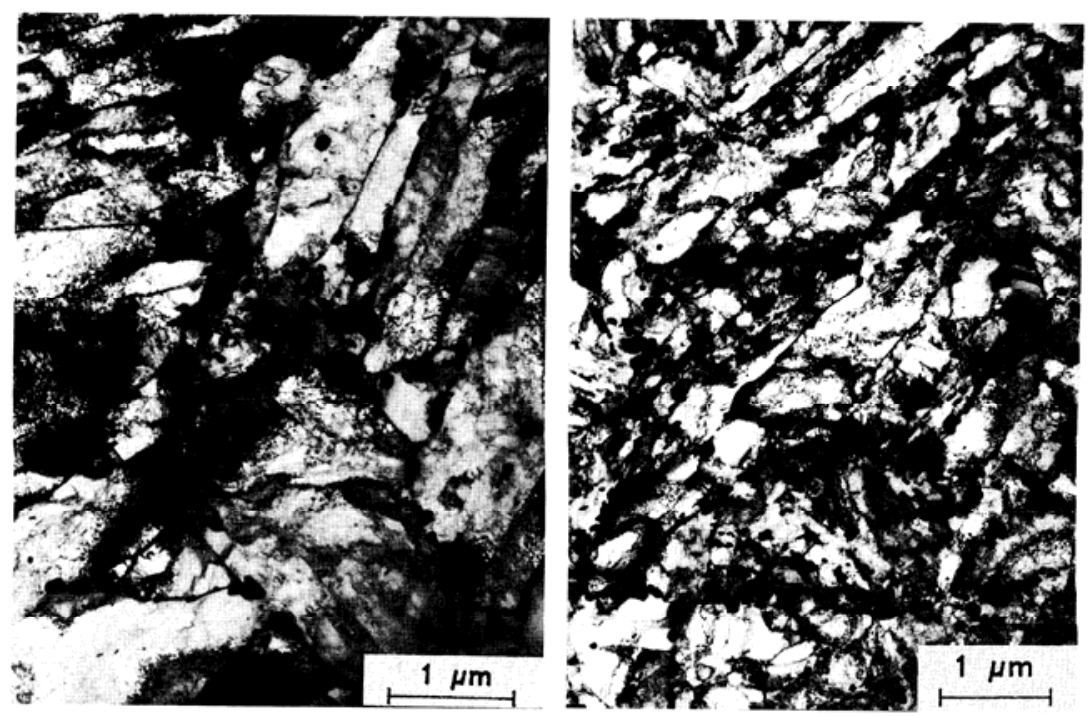

(a)

(b)

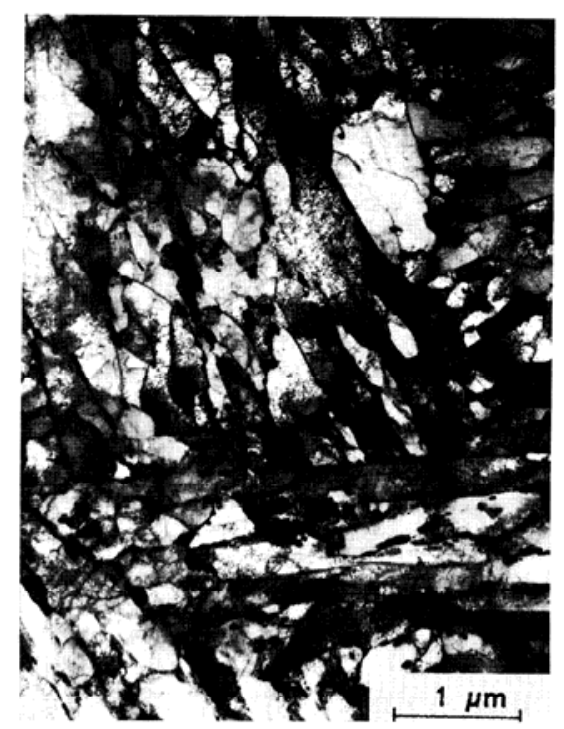

(c)

Fig. 14. Transmission electron micrographs of (a) P91, (b) P92, and (c) $12 \mathrm{Cr} 1 \mathrm{MoV}$ steels. ${ }^{56}$ 
inherent strength. In the case of the $12 \mathrm{Cr} 1 \mathrm{MoV}$ steel, $\mathrm{M}_{23} \mathrm{C}_{6}$ is also the dominant precipitate, because although the presence of vanadium gives rise to some $\mathrm{MX}$, there is less MX present than in a steel like P91 and P92. ${ }^{95,96}$ One difference between the $12 \mathrm{CrMoV}$ and the other steels is that the $12 \mathrm{Cr}$ steel contains about $0.20 \% \mathrm{C}$. As a result, considerably more $\mathrm{M}_{23} \mathrm{C}_{6}$ forms than in the other three steels that contain $0.1-0.12 \% \mathrm{C}$. For example, HT9 steel, a $12 \mathrm{Cr}$ steel which also contains $0.2 \% \mathrm{C}$, was shown to contain over twice as much precipitate (mostly $\left.\mathrm{M}_{23} \mathrm{C}_{6}\right)$ as modified $9 \mathrm{Cr}-1 \mathrm{Mo}$ steel $(0.1 \% \mathrm{C}){ }^{96} \mathrm{It}$ is the larger amount of $\mathrm{M}_{23} \mathrm{C}_{6}$ precipitate and the presence of some $\mathrm{MX}$ that gives the $12 \mathrm{CrMoV}$ an advantage over P9.

Table 4. Nominal Compositions of Steels for Microstructural Studies ${ }^{56}$

\begin{tabular}{ccccc}
\hline Element & P9 & 12Cr1MoV & P91 & P92 \\
\hline $\mathrm{C}$ & 0.12 & 0.20 & 0.10 & 0.12 \\
$\mathrm{Cr}$ & 9.0 & 11.60 & 8.10 & 9.10 \\
$\mathrm{Mo}$ & 1.0 & 0.90 & 0.90 & 0.50 \\
$\mathrm{~W}$ & & & & 1.80 \\
$\mathrm{~V}$ & & 0.25 & 0.20 & 0.20 \\
$\mathrm{Nb}$ & & & 0.07 & 0.06 \\
$\mathrm{~B}$ & & & & 0.003 \\
$\mathrm{~N}$ & & & 0.05 & 0.04 \\
$\mathrm{Ni}$ & & 0.70 & 0.30 & 0.10 \\
\hline
\end{tabular}

The difference between P91 and 12CrMoV and P9 involves the presence of nitrogen and niobium in P91. These elements along with the vanadium promote fine MX precipitates that initially stabilize the dislocation and subgrain structure. Finally, the superiority of the P92 over P91 has to be attributed to the tungsten and boron present in the P92 and not in P91, since this is the main difference in the two steels. Minor differences in nickel (0.06\% in P92 and 0.33\% in P91) and Si (0.02 in P92 and 0.4 in P91) may play a secondary role in the differences. Nickel could play a role in the difference, since it has been observed to cause an increase in the rate of coarsening of the $\mathrm{M}_{23} \mathrm{C}_{6}$ precipitates, but the effect of nickel has been seen generally for higher nickel concentrations, ${ }^{55,84,85}$ although in one study an effect of $0.4 \% \mathrm{Ni}$ was observed. ${ }^{97}$

Boron makes a difference in the creep behavior of P92 and P91 because it has been found to lower the rate of $\mathrm{M}_{23} \mathrm{C}_{6}$ precipitate coarsening, which, in turn, slows recovery due to subgrain coarsening. ${ }^{58,59,73,77,80,82,88,89,98-102}$ In one study where boron-alloyed variants of $\mathrm{Cr}-\mathrm{Mo}-\mathrm{W}-\mathrm{V}$ steels were tested, the boron-containing steel exhibited the greatest stability in the low-stress (long-time) regime. ${ }^{73}$ Another mechanism for a boron effect, termed "latent creep resistance," has been proposed, ${ }^{61}$ where it was suggested that boron causes precipitation and dissolution of MX to occur continuously during creep. Precipitates are envisioned to form on and pin the dislocations. When the dislocations pull away from the MX precipitates, they dissolve, after which new precipitates form on other dislocations, and the process is repeated continuously. ${ }^{61}$

Some investigators have attributed the superiority of tungsten-bearing steels to an artifact of the extrapolation from short-time tests. ${ }^{61}$ That is, for the short-time tests ( $\$ 10000 \mathrm{~h}$ ), the tungsten still contributes to the solid-solution strengthening, and precipitation hardening by Laves phase contributes to the strength, even though Laves removes tungsten from solution. In a study where experimental heats containing Mo and 
W were creep tested, it was found that all the tungsten-alloyed heats showed high strength below $10000 \mathrm{~h}$, after which the tungsten-containing steels declined to the level of P91. ${ }^{61}$ In another study, a $1 \% \mathrm{~W}$ addition to a $10.50 \% \mathrm{Cr}$ steel containing $1 \% \mathrm{Mo}$ showed the steel with tungsten to have improved creep properties, although in another study, the tungsten was concluded not to have an added effect as a solid-solution strengthener.

Laves-phase precipitation caused by the presence of tungsten has an initial strengthening effect, although this is a short-lived effect, since Laves coarsens quickly. ${ }^{61,71,82}$ For P92 and P91, a greater effect of Laves on the P92 might be expected, because of the larger molybdenum equivalent before thermal exposure-approximately 1.4 and 0.9 for P92 and P91, respectively. ${ }^{56}$ It has been suggested that tungsten and molybdenum additions are not effective beyond a $\mathrm{Mo}_{\mathrm{eq}}$ of $1 \%$, because they are solidsolution strengtheners, and they are removed from solution by the formation of Laves phase and $\mathrm{M}_{6} \mathrm{C}$ by about $10^{4} \mathrm{~h} .^{71}$ Another investigation concluded a $\mathrm{Mo}_{\mathrm{eq}}$ of $1.5 \mathrm{was}$ optimum. ${ }^{65}$ A $2 \% \mathrm{~W}$ composition similar to P92 was concluded to be optimum in another study, ${ }^{100}$ where it was found that increasing chromium from 9 to $12 \%$ accelerates Laves-phase formation, because higher chromium can replace tungsten in the $\mathrm{M}_{23} \mathrm{C}_{6}$.

Solid-solution strengthening by tungsten has been cited most often as the reason tungsten-containing steels are superior to those with just molybdenum, ${ }^{56,66,70,82,87}$ although molybdenum is also known to be a potent solid-solution strengthener. ${ }^{67,72,80}$ It may be that the lower diffusion coefficient for tungsten means that the equilibrium tungsten concentration in solution just takes longer to be reached. If so, this difference should give the P92 in Fig. 13 longer short-time and transition stages in the sigmoidal creep-rupture curve than the P91. The other advantage in the short time is the Laves phase that appears in the P92 and gives short-time strengthening. The boron effect discussed above also provides a short-time advantage for P92.

The difference between P91 and P92 is explained by the Ennis et al. ${ }^{56}$ to involve two effects. The first effect is a slower recovery of the martensitic structure of P92, which was illustrated by the change in dislocation density as a function of creep-test duration, with the density for the P92 decreasing more slowly (Fig. 15). ${ }^{56}$ They attribute this to tungsten increasing the $A_{1}$ temperature, although it could also be attributed to the slower diffusion of tungsten versus molybdenum. Obviously, the figure indicates that the dislocation densities in the two steels are approaching a common value somewhere beyond $10,000 \mathrm{~h}$. The second enhancement was attributed to strengthening by Laves phase, which is transitory. ${ }^{56}$ Therefore, it is probably the short-time stage being seen in the tests illustrated in Fig. 13, which indicates that the difference in the two steels is significant under the test conditions illustrated. However, long-term tests are required to determine whether this advantage persists (no creep data were presented, but it is not clear if tests beyond $10,000 \mathrm{~h}$ were conducted). ${ }^{56}$

There is no information on the length of the transition region of the creep-rupture curve or how it will differ for different steels. This transition must be caused mainly by precipitate coarsening, dislocation recovery, and loss of solid-solution-hardening elements from solution. If the initial linear and the transition regimes of the sigmoidal creep-rupture curve do not last the service lifetime, then the inherent strength of the steel 


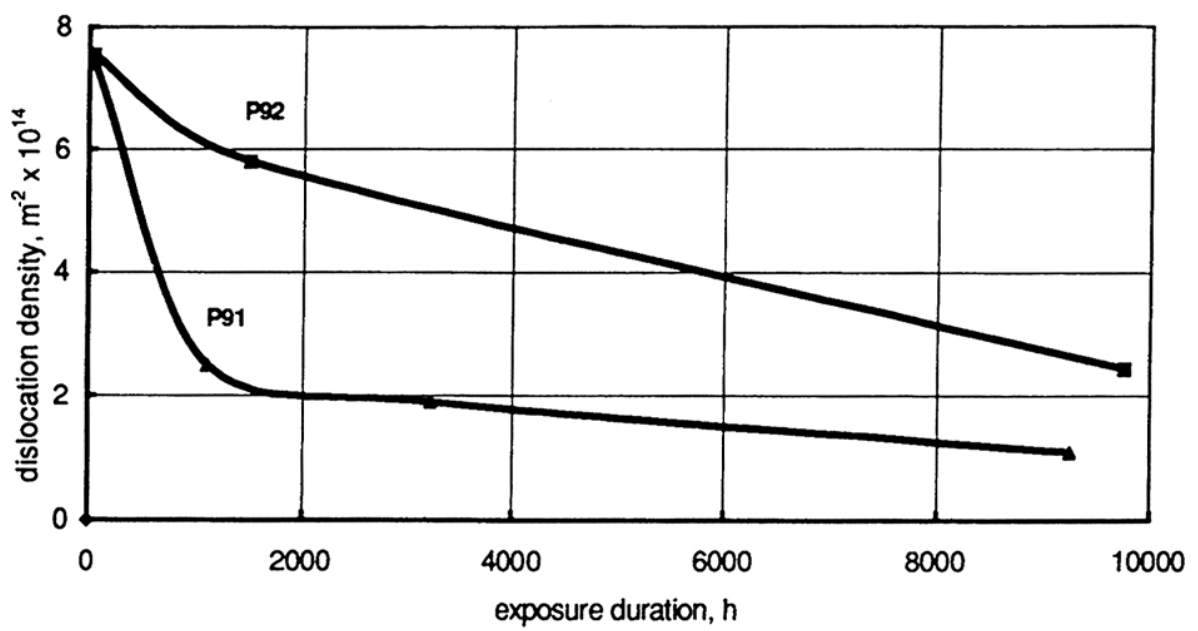
$600^{\circ} \mathrm{C} .^{56}$

Fig. 15. Dislocation density for P91 and P92 as a function of exposure time in a creep test at

will ultimately determine the conditions at which the steel can be used (i.e., rupture behavior at $>300,000 \mathrm{~h}$, the expected lifetime of power plants).

The question then becomes: Is the inherent creep strength of the P92 significantly greater than that of the P91 under these conditions? Since the inherent creep strength is essentially the strength of the solid-solution, it is not clear that there would be a significant difference in the two steels. Although tungsten has been credited with adding solid-solution strengthening to the steels at equilibrium, ${ }^{66,70,89}$ only $0.5-0.8 \% \mathrm{~W}$ will remain in solution, ${ }^{52,66,71}$ and its solid-solution strengthening effect may therefore be small. ${ }^{101}$ Furthermore, molybdenum also produces solid-solution strengthening, so it is not clear that there should be a large difference in the inherent creep strength of the two steels - especially since less Laves may form in the P91, thus perhaps leaving the two steels with similar amounts (atom percent) of solid-solution strengthening elements.

The fourth-generation steels, NF12 and SAVE12, have been developed based on the experience of the previous generations. Both are $11 \mathrm{Cr}$ steels, with the major compositional changes involving more tungsten $(2.6 \%$ in NF12 and 3.0\% in SAVE 12$)$, less molybdenum $(0.2 \%$ in NF12 and $0 \%$ in SAVE 12$)$, and the addition of cobalt $(2.5 \%$ in NF12 and 3.0\% in SAVE 12). The NF12 contains $0.004 \mathrm{~B}, 0.06 \% \mathrm{~N}$, and $1.0 \% \mathrm{Cu}$, while the SAVE 12 does not contain boron and only $0.04 \% \mathrm{~N}$; it also contains $0.07 \% \mathrm{Ta}$ and $0.04 \% \mathrm{Nd}$. The tantalum and neodymium are added because they are expected to form fine carbides. ${ }^{4}$ The copper used to stabilize the austenite will precipitate, and it can affect the strength and the nucleation of the Laves phase, as discussed above.

The exact effect of cobalt on mechanical properties still appears to be an open question, as discussed above. It does not contribute to solid-solution strengthening in iron binary alloys, ${ }^{67,72}$ and it may act like nickel with respect to the coarsening of the $\mathrm{M}_{23} \mathrm{C}_{6}{ }^{88}$ or, perhaps at best, does not affect the coarsening. If this is the case, then its function might be solely as an austenite stabilizer that does not lower the $A_{1}$ as much as nickel and improves the toughness as nickel does. In recent creep tests, the creep-rupture 
behavior of a cobalt-containing $11 \mathrm{Cr}-2 \mathrm{~W}-2 \mathrm{Co}-0.3 \mathrm{MoVNbB}$ steel was compared with one without cobalt (P92), and it was found that the $\mathrm{P} 92$ properties were better than those of the cobalt-containing steel. ${ }^{87}$ The observation was explained by the statement that, “... this is probably due to the presence of cobalt which reduces the solubility of molybdenum and tungsten, thus accelerating the precipitation kinetics of Laves phase."

This conclusion adds to the questions concerning the effectiveness of cobalt. One reason for the improved properties of the NF12 and SAVE12 then might be the increased tungsten concentration, which produces a longer initial segment of the sigmoidal creeprupture curve. This would follow because of a larger amount of tungsten in solution at the start and a larger amount of Laves phase formed to give more interim precipitation strengthening. Both of these effects are transitory, as discussed above. The other innovation in these steels is the addition of the tantalum and neodymium. Off hand, it is not clear how these strong carbide formers differ substantially from niobium, which has been applied extensively in the steels under discussion.

This discussion on the creep behavior of the advanced steels leads to several interesting observations. Based on the creep data obtained to date, the advanced ferritic/martensitic steels have a significant strength advantage over the first- and secondgeneration steels. However, if the creep-rupture curves of these steels have the sigmoidal shape postulated by Kimura et al. (Fig. 9),${ }^{90}$ then the ultimate creep-strength advantage for the advanced steels must depend on the advantage developed in the first two portions of the sigmoidal curve, for it is not expected that the inherent strength of the different steels being discussed will be all that different. The latter conclusion follows because it is believed that the solid-solution strength, which determines the strength in the last portion of the sigmoidal curve, is derived primarily from tungsten and molybdenum. However, as discussed above, the concentration of these elements is reduced by Lavesphase formation to an equilibrium concentration that is significantly below that of the starting concentration, and the final concentrations should not vary much for the different steels.

It appears that the advantage of the first portion of the sigmoidal curve can provide a significant advantage for the advanced steels (e.g., see Fig. 13). Depending on the composition of a given steel, the second portion - the transition — of the curve can also provide a strength advantage for the advanced steels. The transition will be determined by the coarsening of the $\mathrm{M}_{23} \mathrm{C}_{6}, \mathrm{MX}$, and Laves phase. Therefore, anything that retards coarsening will enhance the strength advantage of a given steel. As discussed above, boron has been demonstrated to do this for the $\mathrm{M}_{23} \mathrm{C}_{6}$ and maybe the MX. It appears that decreasing the rate of coarsening of the $\mathrm{M}_{23} \mathrm{C}_{6}$ and Laves phase and improving the original strength advantage of the advanced steels is the best way to develop an advanced steel. The latter may be achieved by increasing the number density and reducing the size of the MX precipitate particles. However, because of sigmoidal creep-rupture curves, extrapolation of the data to proposed structure lifetimes $(>300,000 \mathrm{~h})$ is fraught with difficulties. Longtime $(>100,000 \mathrm{~h})$ data for the new steels is urgently needed to resolve these uncertainties. 


\subsection{CREEP MECHANISMS}

In the above discussion on creep of the high-chromium tempered martensitic steels, a creep mechanism was not generally identified, although a power-law mechanism was implied. In most of the referenced papers, mechanisms are rarely discussed, but it appears that power-law creep controlled by a dislocation-climb or dislocation-climb-plusglide mechanism is generally implied, if not specifically stated. Power-law creep is the expected mechanism for these steels for most of the test conditions used. This mechanism applies at relatively high stresses and/or the lower test temperatures in the creep range. However, with decreasing stress and/or increasing temperature, the possibility of diffusion or viscous creep (e.g., Coble Creep and Nabarro-Herring Creep), Harper-Dorn Creep, or grain-boundary sliding mechanisms become possible. The mechanism is important, especially for the "inherent stress" concept, since this involves low stresses and high temperatures. It is also very important because extrapolation from tests at high stresses to the low-stress regime is required to determine allowable stresses.

In a detailed study of the NF616 (P92) steel at 600 and $650^{\circ} \mathrm{C}$ over the range 180 to $81 \mathrm{MPa}$, Ennis et al. ${ }^{103}$ identified power-law creep as the creep mechanism, namely,

$$
\dot{\varepsilon}=\mathrm{k} \sigma^{n}
$$

where $\dot{\varepsilon}$ is the creep rate, $\sigma$ is the stress, and $\mathrm{k}$ and $n$ are constants. The exponent $n$ was not constant across the entire stress range, but changed from 16 at high stresses to 6 at low stresses, the change occurring at a lower stress at 650 than $600^{\circ} \mathrm{C}$ (Fig 16).

Therefore, for these tests, there was no change to diffusion creep, since diffusion creep produces an $n$ of 1 . The change from an $n$ of 16 to 6 occurred at about 160 and $120 \mathrm{MPa}$, at 600 and $650^{\circ} \mathrm{C}$, respectively. It is obvious from Fig. 16 that the extrapolation of the high-stress creep-rate data will lead to an overestimate of the creep strength.

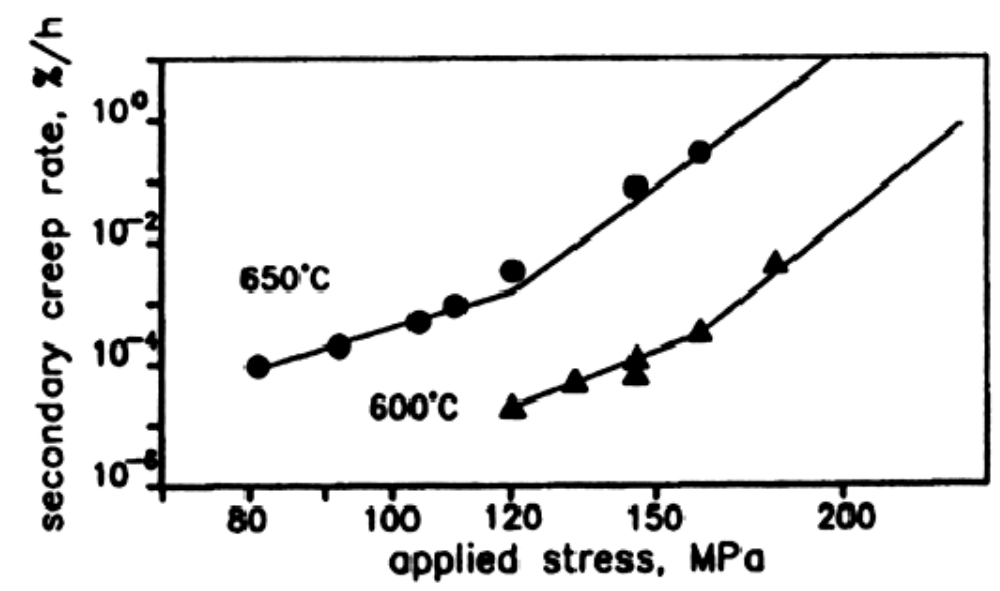

Fig. 16. Dependence of steady-state creep on stress for NF616 (P92) steel tested at 600 and $650^{\circ} \mathrm{C} .{ }^{103}$

The authors used the slope change to demonstrate how extrapolating creep data to low stresses from short-time data can grossly overestimate creep strength. They used the high-stress data to estimate a $1 \%$ strain in $10^{5} \mathrm{~h}$ at 600 and $650^{\circ} \mathrm{C}$ of 130 and $83 \mathrm{MPa}$, 
respectively. When the low-stress data were used for the extrapolation, values of 110 and $56 \mathrm{MPa}$ were obtained. ${ }^{103}$

Using the Monkman-Grant equation ${ }^{104}$ - a relationship between the creep rate and rupture life - Ennis et al. used the creep-rate data in Fig. 16 to estimate $10^{5} \mathrm{~h}$ rupture strengths for $\mathrm{P} 92$ of 115 and $55 \mathrm{MPa}$ at 600 and $650^{\circ} \mathrm{C}$, respectively, somewhat lower values than those obtained by other investigators. ${ }^{2}$

The transient strengthening that caused the high stress exponent of 16 was attributed to the effectiveness of precipitates acting as barriers to dislocation motion and to the original high dislocation density in the tempered martensite when the steel is first put into test. ${ }^{103}$ The effect of the initial high density of dislocations was demonstrated by heat treating the steel to a lower dislocation density without changing the precipitate size and distribution. Based on the extrapolation to low stresses, power-law creep was implied at least to $110 \mathrm{MPa}$ at $600^{\circ} \mathrm{C}$ and $55 \mathrm{MPa}$ at $650^{\circ} \mathrm{C} .^{103}$

In a study of the creep behavior of modified $9 \mathrm{Cr}-1 \mathrm{Mo}$ steel over the range $600-650^{\circ} \mathrm{C}$ and 1 to $300 \mathrm{MPa}$, Kloc et al. identified a regime of "viscous" creep below the power-law regime (Fig. 17). ${ }^{105}$ Uniaxial tensile creep tests were conducted above $100 \mathrm{MPa}$, and helical springs were used below this stress. The stress exponent was approximately unity for the low-stress tests up to $\approx 100 \mathrm{MPa}$. Above this stress, the exponent increased to 10 and higher. The authors pointed out that other work ${ }^{106}$ indicated that the two different creep-testing techniques did not always produce similar results. Although the two testing

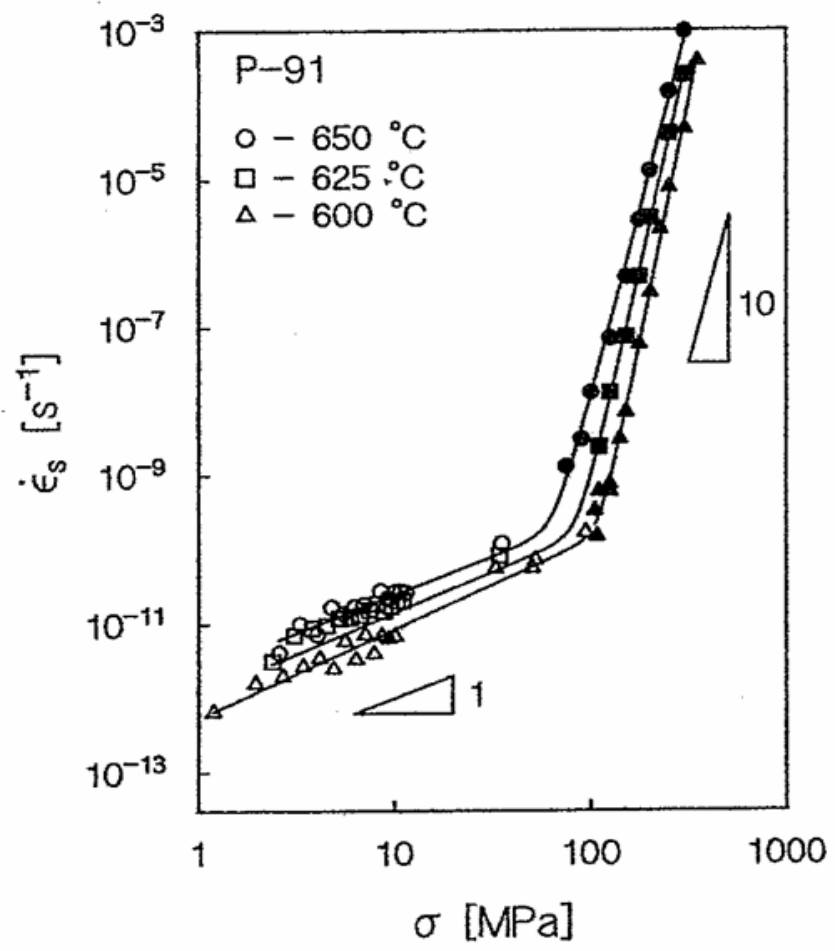

Fig. 17. Dependence of steady-state creep on stress for modified $9 \mathrm{Cr}-1 \mathrm{Mo}$ steel at $600-625^{\circ} \mathrm{C}$. Open symbols at the low stresses are data obtained by helical springs; data with closed symbols were uniaxial tests. ${ }^{105}$ 
techniques were used in the different mechanistic regimes, the authors concluded, "... creep curves obtained by both techniques at similar conditions do not justify hesitations about the influence of testing technique on the presented results." Since the results were obtained on material with only one grain size, it was not possible to determine if the lowstress results were due to Nabarro-Herring, Coble, or Harper-Dorn creep. ${ }^{105}$

Based on Fig. 16 and extrapolations therefrom, the conclusions of Ennis et al. ${ }^{103}$ at $650^{\circ} \mathrm{C}$ do not agree with the conclusion on viscous creep by Kloc et al. ${ }^{105}$ Other results that contradict this latter conclusion involve modified 9Cr-1Mo superheater tubes that were removed from service after 130,000 hours at a stress estimated to be $33 \mathrm{MPa}$ and a metal temperature of $593-600^{\circ} \mathrm{C} .{ }^{107}$ These tubes showed essentially no indication of creep deformation. Deformation would be expected if diffusion creep at $600^{\circ} \mathrm{C}$ occurred in accordance with Fig. 17.

Similarly, no indication of diffusion creep was observed for creep tests on modified $9 \mathrm{Cr}-1 \mathrm{Mo}$ steel thermally aged up to $75,000 \mathrm{~h}$ at 482 to $704^{\circ} \mathrm{C}$ and tested at the aging temperature. ${ }^{108}$ For these tests, a change in the exponent $n$ was observed, going from a value of about 10 to 3 as stress was decreased.

Although the transition from power-law creep to diffusion (viscous) creep will occur as stress is decreased and/or temperature is increased, these results do not clarify when that transition occurs in these steels. It would be helpful if tests were conducted on this class of steel that would allow the production of a deformation mechanism map. ${ }^{109}$ Such a map would be helpful, because as pointed out by Kloc et al., ${ }^{109}$ "Therefore, viscous creep should be taken into consideration, mainly for the applications where the dimension stability is critical."

\subsection{HIGH-CHROMIUM STEELS FOR NUCLEAR APPLICATIONS}

Although there are uncertainties concerning the long-time stability and creep properties of the third and fourth generation of the $9-12 \% \mathrm{Cr}$ martensitic steels, there appears to be no question that there are significant improvements over the first- and second-generation steels, at least for $\approx 100,000 \mathrm{~h}$ based on present experimental data from which lifetimes are extrapolated. Given the increased operating temperatures of the new reactor designs, steels with increased elevated-temperature strength will be required if the advantages of ferritic/martensitic steels are to be available to the reactor designer. It should be noted that for some in-core applications (e.g., cladding) the service lifetimes are very much less than the $>300,000 \mathrm{~h}$ envisioned for conventional power plants.

Obviously, irradiation studies of the steels will be required. However, it would not be expected that these steels should be significantly less irradiation resistant than the firstand second-generation steels, for which extensive irradiation studies have been conducted. Further, for the reactors for which the ferritic/martensitic steels are projected for cladding or other in-core applications (i. e., Na-LMR, Pb-LMR, SCWR-Th, and SCWR-F), an outlet temperature of $500-550^{\circ} \mathrm{C}$ is expected. Of course, the fuel cladding will operate at a higher temperature, but it should be within the upper operating temperature of the steels $\left(600-650^{\circ} \mathrm{C}\right)$, depending on the loading. At the upper temperature, creep, coolant corrosion, and/or fuel cladding chemical interactions (FCCI) will be the lifetime-limiting mechanisms for the steels. From studies on HT9 in the fast 
reactor program, ${ }^{110}$ the steel appeared to have adequate properties to $650^{\circ} \mathrm{C}$, which would mean that at the upper temperature of operation, the new steels will have an advantage over HT9. Swelling at these temperatures should not be a factor. ${ }^{33,44}$

The lowest temperature for in-core (duct, etc.) operation is estimated to be around $280^{\circ} \mathrm{C}$, and again, swelling, based on the work of the first and second generation steels, ${ }^{33,44}$ should not be limiting. At temperatures $\leqslant 400^{\circ} \mathrm{C}$, embrittlement due to irradiation hardening is of concern. Studies of the embrittlement of HT9 and modified $9 \mathrm{Cr}-1 \mathrm{Mo}$ indicated that the shift in DBTT of the latter steel $\left(54^{\circ} \mathrm{C}\right)$ was about half that of the former $\left(124^{\circ} \mathrm{C}\right)$ after irradiation in EBR-II and FFTF at $375-390^{\circ} \mathrm{C} .{ }^{46,111}$ The difference was attributed to the larger amount of carbide in the HT9, which contains twice as much carbon as modified $9 \mathrm{Cr}-\mathrm{Mo}(0.2 \%$ vs. $0.1 \%) .{ }^{111}$ Irradiation of the reduced-activation steel ORNL $9 \mathrm{Cr}-2 \mathrm{WVTa}$ resulted in an even smaller increase at these temperatures. $^{112}$

The steels are also envisioned for out-of-core applications (pressure vessels, piping, etc.), where the irradiation fluence may be much less than inside the core. In this application, temperatures would, in most cases, be below $600^{\circ} \mathrm{C}$, but reactor lifetimes are envisioned as 60 y $(>500,000 \mathrm{~h}),{ }^{1}$ making longtime creep tests even more important. 


\section{LOW-CHROMIUM (2-3\% CR) STEELS}

\subsection{ADVANTAGES OF 2-3\% CR STEELS}

In the previous sections, the discussion concerned microstructures and elevatedtemperature properties of high-chromium (mainly the $9-12 \% \mathrm{Cr}$ ) ferritic/martensitic steels developed since the 1970s, when such steels were first considered for in-core applications for liquid-metal reactors. Ferritic steels are also used for the pressure vessel of commercial light-water reactors operating today. Because the pressure vessel and other pressure-boundary structures do not operate at the elevated temperatures of the internals, it may be possible to use lower alloy steels than those discussed above for outof-core applications in future Generation IV reactors (others, because of higher operating temperatures, will require high-chromium steels). Some possible replacements for the pressure-vessel steels in use today in light-water reactors will be discussed in this section.

In the current generation of commercial pressurized-water reactors, the pressure vessels are constructed of low-alloy steels, such as A533B (Table 1). ${ }^{51}$ Reactor pressure vessels are 200-300 mm (8-12-in) thick. Most are fabricated from plates, which means that both axial and circumferential thick-section welds are required. Given the same design pressure, a steel with a 50\% higher strength would allow for more than a $30 \%$ reduction in shell thickness. In a steel mill, thinner sections allow smaller ingots to be cast; thinner plates or forgings allow the heat treatment and hot-rolling or forging process to ensure a more uniform composition in the final product. On the other hand, given the capacity, the same size of large ingots could be used to fabricate the even larger diameter forgings proposed for some Generation IV reactors.

The plates must be heat treated. Heat treatment of thinner plates and forgings is easier (more economical), and thinner sections can be cooled more rapidly, thus ensuring a more uniform through-thickness microstructure. During plant fabrication, thinner sections would offer advantages in material handling, welding, post-weld heat treatment, inspection, and vessel transportation. If extremely large vessels are designed, thinner sections would be more amenable to field fabrication.

Another significant advantage in this regard is the desire to manufacture the pressure vessel using a ring forging of sufficient size such that no circumferential welds are located in the beltline region (the region adjacent to the reactor core) of the vessel where the neutron exposure is the highest. For significantly larger reactor pressure vessels than currently used for LWRs, as proposed in some Generation IV reactor designs, the current steels (i.e., A533B and A508 Class 3) could be prohibitive to the manufacture of such large ring forgings.

\subsection{MICROSTRUCTURE OF LOW-CHROMIUM STEELS}

When the chromium concentration is reduced from $9 \%$ to $2-3 \%$, the hardenability is reduced. For a given section size, this means that for such a steel to form martensite, it must be cooled significantly faster from the austenitization temperature than a $9 \% \mathrm{Cr}$ steel. As a result, martensite is not expected to form in section thickness over a few 
millimeters. Instead, bainite forms. However, if the section thickness is large enough or the hardenability is small enough, the bainite will be accompanied by polygonal ferrite. The microstructure of the A533B plates used to construct the pressure vessels for the current generation of commercial pressurized-water reactors is usually a mixture of bainite and ferrite. Because of the different cooling rates in different parts of a thick plate, the microstructure will vary somewhat through the thickness. ${ }^{51}$

\subsection{BAINITIC STEELS}

The use of the stronger, higher-chromium 21/4Cr-1Mo steel instead of A533B has been mentioned for out-of-core applications in Generation IV reactors. ${ }^{1}$ However, as discussed above, the advanced $2.25 \mathrm{Cr}-1.6 \mathrm{WVNb}$ steel (T23) has strength approaching and exceeding that of some of the high-chromium steels. Similarly, the $2.25 \mathrm{Cr}-1 \mathrm{MoVTi}$ steel (T24) has improved properties over $2 \frac{1}{4} \mathrm{Cr}-1 \mathrm{Mo}$ steel. Obviously, these steels could be considered for pressure vessel and other out-of-core applications. A steel developed at ORNL also deserves consideration. Since little has been published on this latter steel, a brief review will be presented here.

\subsubsection{New 3Cr Steels}

Reduced-activation, low-alloy steels with improved strength and toughness were developed at ORNL in the U.S. Fusion Program ${ }^{113,114}$ based on observations on the microstructures developed during different heat treatments. ${ }^{115}$ As a result of these studies, a steel was produced with base composition nominally Fe-3.0Cr-3.0W-0.25V$0.10 \mathrm{C}(3 \mathrm{Cr}-3 \mathrm{WV})$. An addition of $0.07 \% \mathrm{Ta}$ (3Cr-3WVTa) to this base composition was found to further improve strength and toughness (see Table 1 for nominal compositions).

Some reactor designs in the Generation IV program will have pressure vessels that operate at temperatures above where low-alloy steels (e.g., A533B) can operate. Although $2 \frac{1}{4} \mathrm{Cr}-1$ Mo has been mentioned for this application, it appears that, like the T23 and T24 steels discussed in the previous section, the $3 \mathrm{Cr}-3 \mathrm{WV}$ and $3 \mathrm{Cr}-3 \mathrm{WVTa}$ steels would be better candidates for pressure vessels, piping, and other pressure boundary components of such a reactor. In the section sizes investigated to date, the $3 \mathrm{Cr}-3 \mathrm{WV}$ and 3Cr-3WVTa steels have strength over double the $345 \mathrm{MPa}$ (50 ksi) used to design with the A533B steel. It also has strength advantages over the commercial T23 and T24 steels, as discussed below. Work in progress at ORNL seeks to commercialize the steels: two 50-ton heats, one with tantalum and one without, have been produced for use in developing a database to be used for an ASME Code Case.

To demonstrate the excellent strength properties of the $3 \mathrm{Cr}-3 \mathrm{WV}$ and $3 \mathrm{Cr}-3 \mathrm{WVTa}$ steels, Fig. 18 shows the yield strength at room temperature and $600^{\circ} \mathrm{C} .{ }^{116} \mathrm{~A}$ comparison with the T23 and T24 is shown, demonstrating the advantage of the two $3 \mathrm{Cr}$ steels. A similar advantage is exhibited during creep at $600^{\circ} \mathrm{C}$ [Fig. 19(a)], especially for the $3 \mathrm{Cr}$ 3 WVTa steel. Creep at $650^{\circ} \mathrm{C}$ [Fig. 19(b)] shows the 3Cr-3WVTa steel has properties comparable to modified 9Cr-1Mo (T91) (no data were available for T23 at this temperature). For these test conditions, the 3Cr-3WVTa steel even has an advantage over the modified 9Cr-1Mo steel. In Fig. 20, a Larson-Miller parameter comparison is shown 


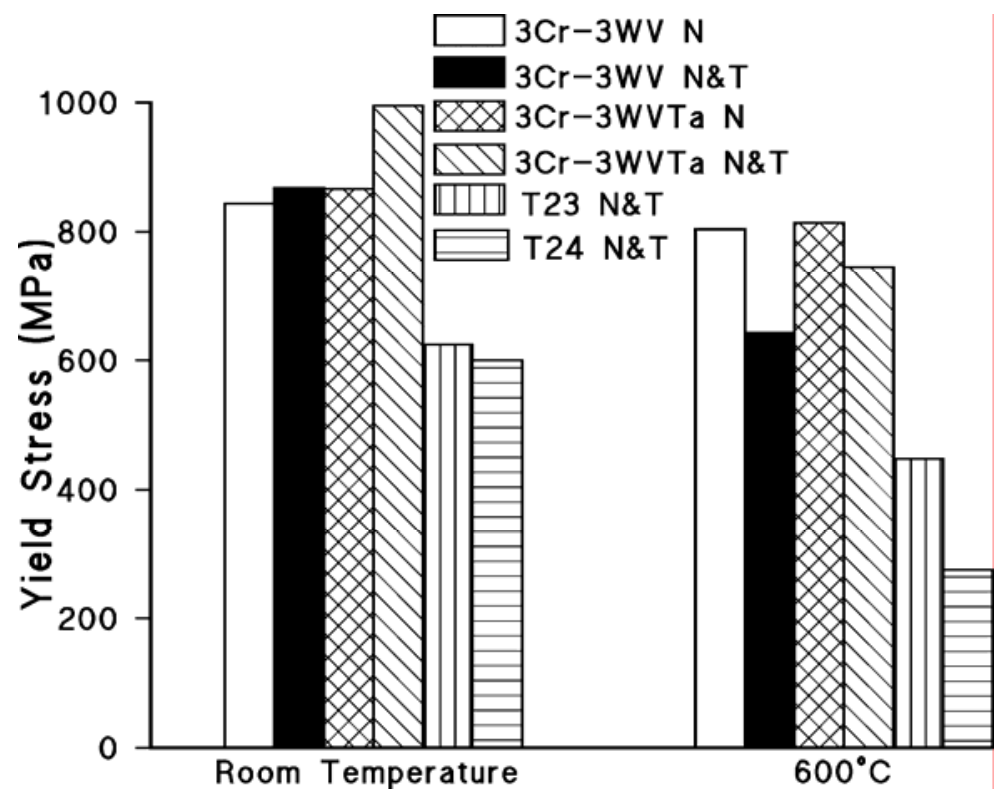

Fig. 18. Comparison of new $3 \mathrm{Cr}-3 \mathrm{WV}$ and $3 \mathrm{Cr}-3 \mathrm{WVT}$ a steels in the normalized $(\mathrm{N})$ and normalized-and-tempered conditions with normalized-and-tempered T23 (2.25Cr-1.6WVNb) and T24 (2.25Cr-1MoVTi) steels. ${ }^{116}$

for the $3 \mathrm{Cr}-3 \mathrm{WVTa}$ with $2 \frac{1}{4} \mathrm{Cr}-1 \mathrm{Mo}$ (T22) and $2.25 \mathrm{Cr}-1.6 \mathrm{WVNb}$ (T23); T23 is stronger than T24, which is not shown. ${ }^{116}$

The elevated-temperature strength properties of these steels is obtained from a bainitic microstructure (Fig. 21) ${ }^{116}$ with a high number density of fine MX precipitates in the matrix (Fig. 22). ${ }^{117}$ Both the $3 \mathrm{Cr}-3 \mathrm{WV}$ and $3 \mathrm{Cr}-3 \mathrm{WVTa}$ steels contain the needlelike precipitates, but the precipitates are considerably finer in the latter steel, indicating the effect of the tantalum. During creep, coarsening of these fine matrix precipitates is much more rapid in the steel without tantalum (Fig. 23). ${ }^{117}$

\subsection{LOW-CHROMIUM STEELS FOR OUT-OF-CORE NUCLEAR APPLICATIONS}

In addition to the advantages cited above for a higher-strength $2-3 \% \mathrm{Cr}$ steel in the steelmaking and pressure-vessel fabrication processes, a 3Cr-3WV-type steel would also offer advantages for nuclear plant operation. Present A533B vessels are clad with stainless steel to prevent corrosion products from contaminating the coolant. The higher chromium level of the $3 \mathrm{Cr}-3 \mathrm{WV}$ makes it more corrosion resistant, perhaps allowing it to be used without cladding. The higher chromium means the steel is also more resistant to hydrogen embrittlement. Based on observations on various higher alloyed ferritic steels (e.g., 21/4Cr-1Mo, modified 9Cr-1Mo, Sandvik HT9) irradiated to high doses (tens of dpa compared to $\approx 0.01 \mathrm{dpa}$ in an LWR) in fast reactors in the breeder reactor and fusion test programs, this $3 \mathrm{Cr}-3 \mathrm{WV}$ steel should be much more resistant to irradiation embrittlement compared to A533B. This might allow a reactor to be operated to a higher fluence with a 


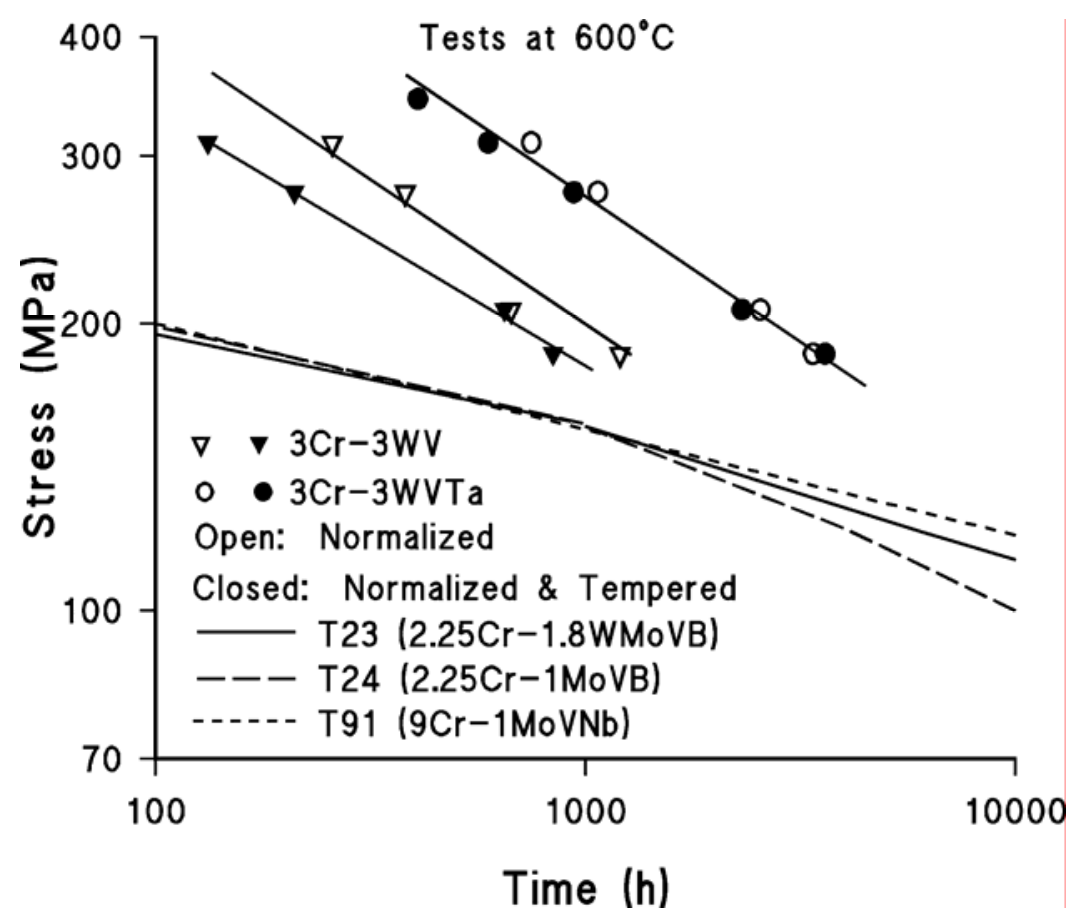

(a)

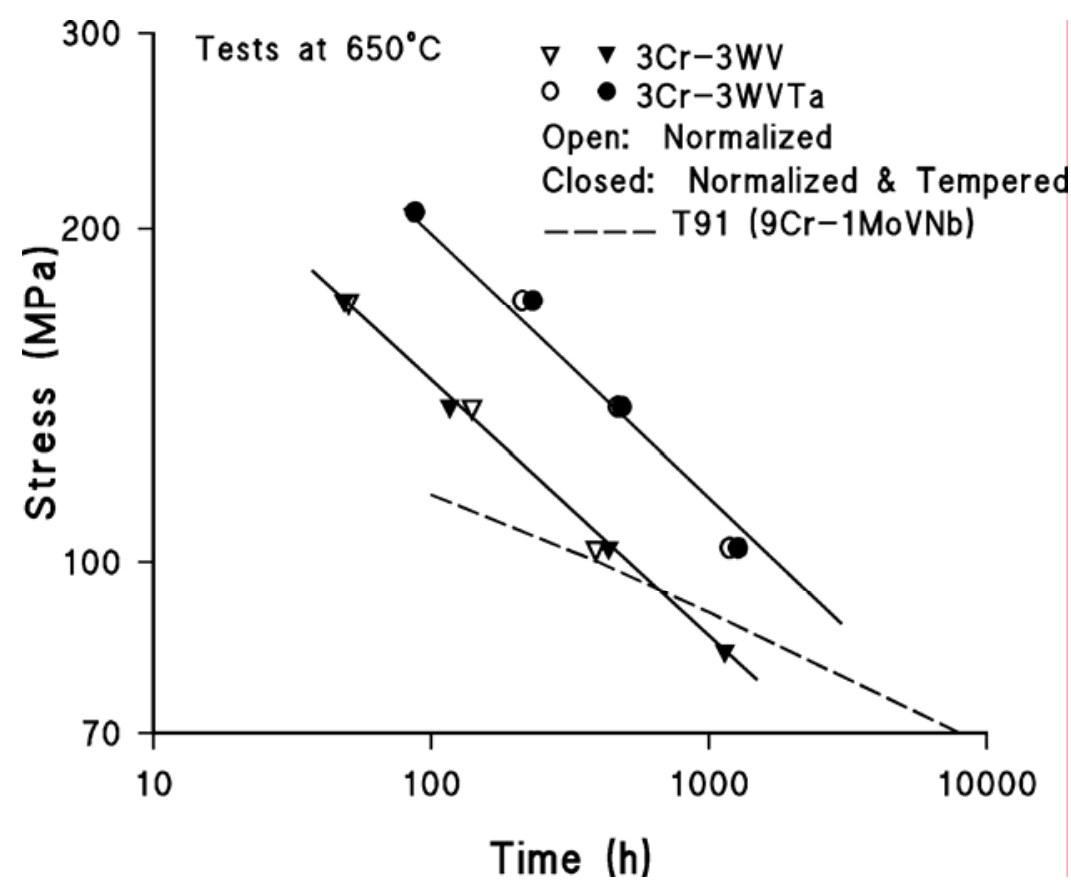

(b)

Fig. 19. Creep-rupture curves for $3 \mathrm{Cr}-3 \mathrm{WV}$ and $3 \mathrm{Cr}-3 \mathrm{WVT}$ a steels in the normalized and normalized-and-tempered conditions (a) at $600^{\circ} \mathrm{C}$ compared to T23 (2.25Cr-1.6WVNb), T24 (2.25Cr1MoVTi), and T91 (9Cr-1MoVNb) steels and (b) at $650^{\circ} \mathrm{C}$ compared to T91 steel. ${ }^{116}$ 


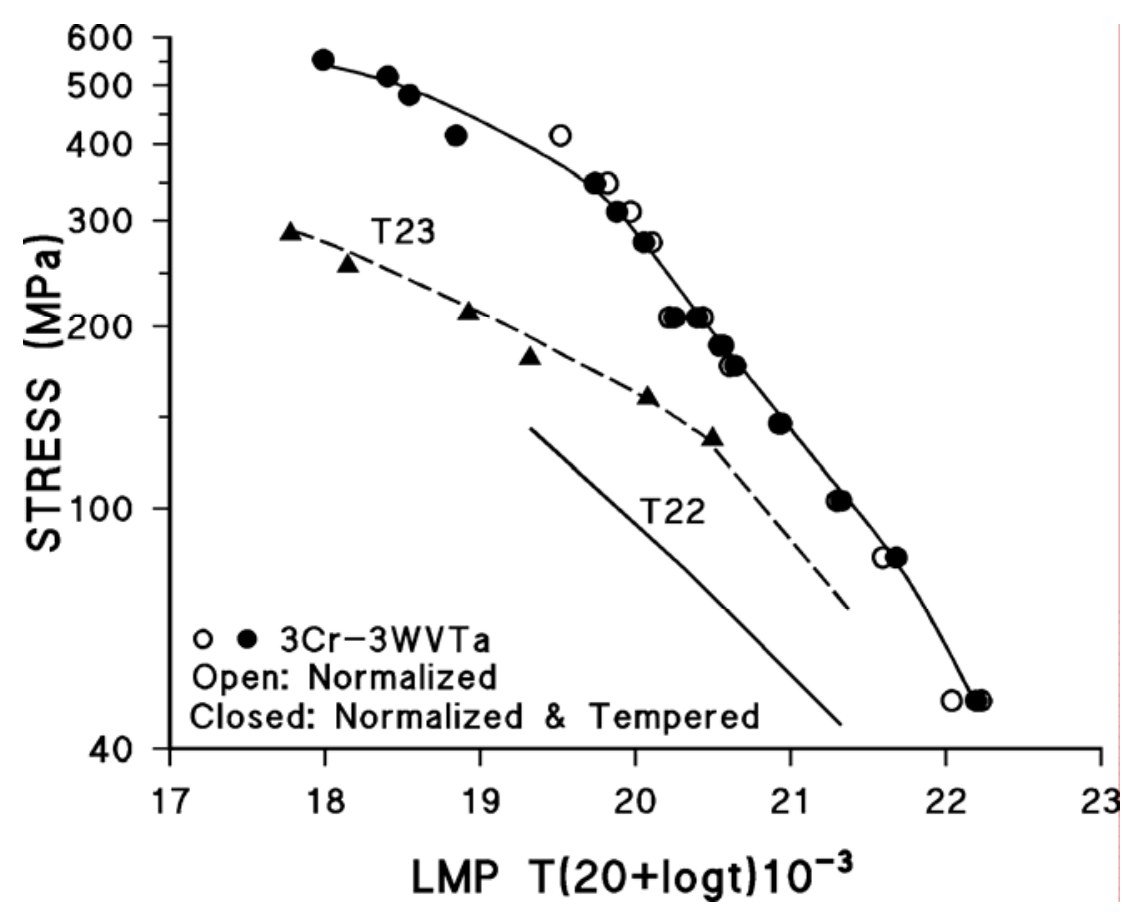

Fig. 20. Larson-Miller Parameter for 3Cr-3WVTa steel in the normalized and normalized-andtempered condition compared to T23 (2.25Cr-1.6WVNb) and T22 (2⿺辶/4-1Mo) steels. ${ }^{116}$

smaller coolant gap, which means a smaller-diameter vessel, all other conditions being equal for the two steels.

Furthermore, the composition of the $3 \mathrm{Cr}-3 \mathrm{WV}$ and $3 \mathrm{Cr}-3 \mathrm{WVTa}$ steels comply with the "reduced activation" criteria established in the fusion program. Current reactor pressure vessel steels contain significant amounts of radiation-sensitive elements, such as nickel and molybdenum, which result in significant activation of the steel. Reducedactivation materials contain only elements that, when activated during service, decay rapidly (typical long-decay-producing alloying elements $\mathrm{Ni}, \mathrm{Nb}, \mathrm{Cu}$, and $\mathrm{Mo}$ are eliminated from the composition). In the fusion program, the objective for these steels is to allow shallow land burial of components after service. Although shallow land burial of LWR pressure vessels is already allowed (due to lower doses than a fusion plant), these materials could provide a further safety margin for this procedure. 


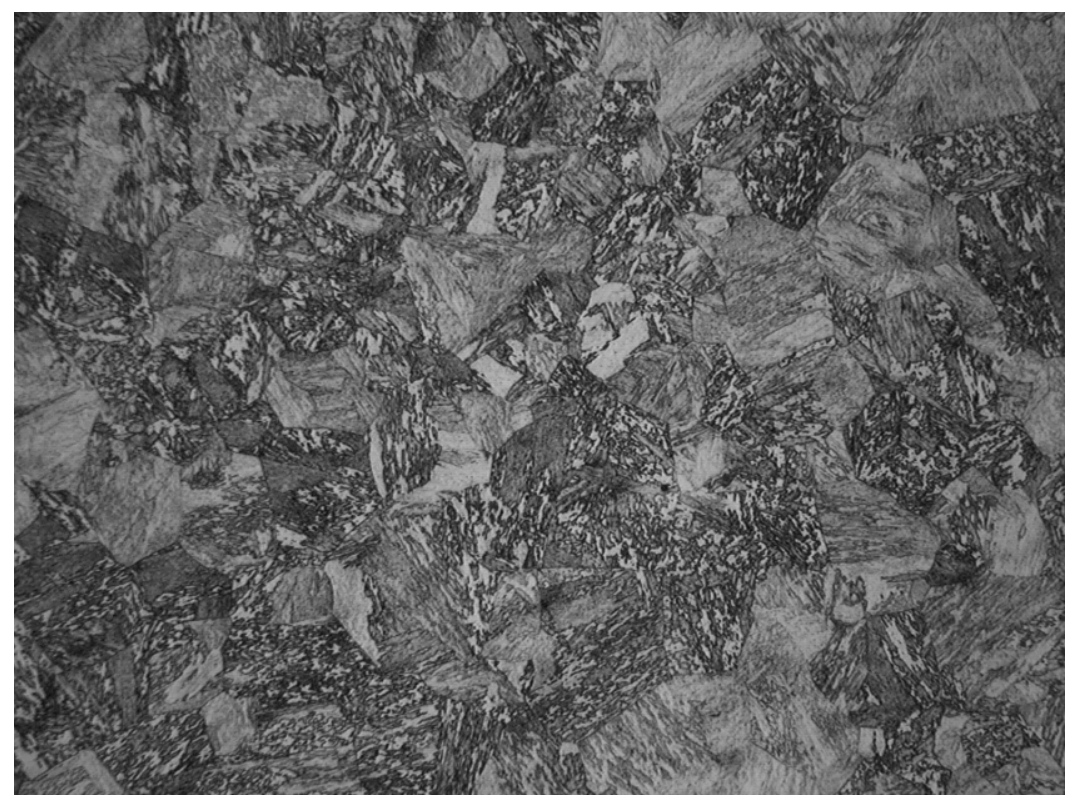

(a)

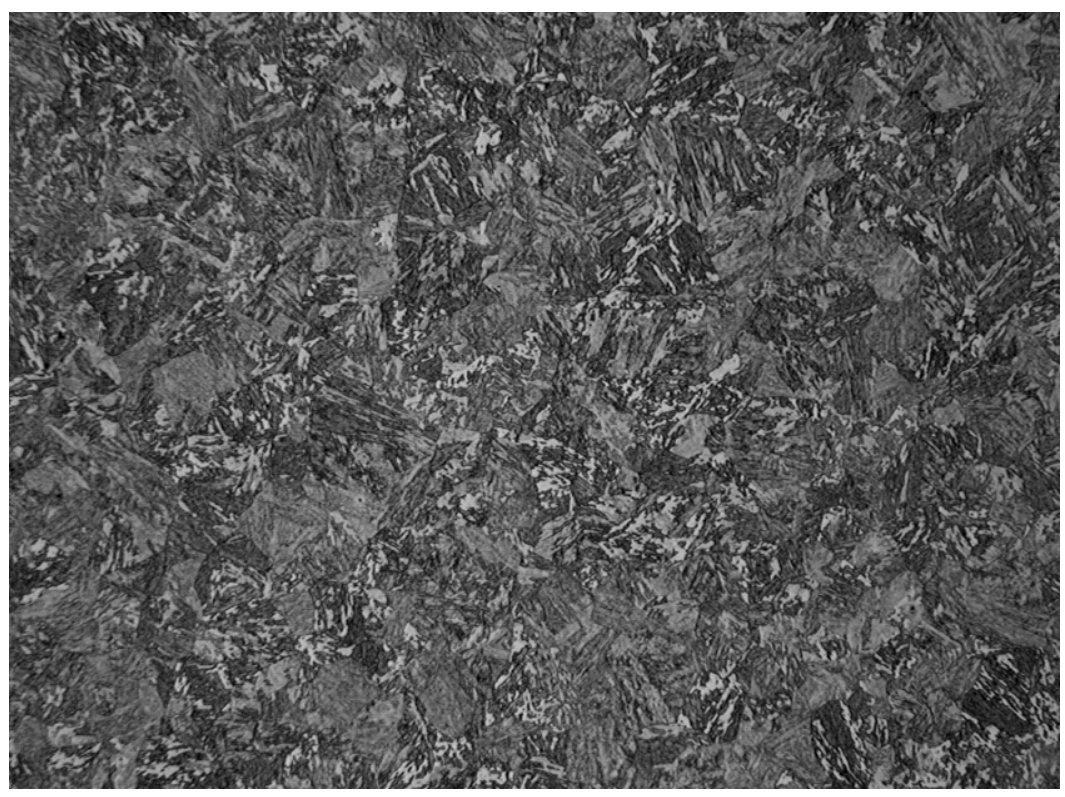

(b)

Fig. 21. Optical microstructure of (a) $3 \mathrm{Cr}-3 \mathrm{WV}$ and (b) $3 \mathrm{Cr}-3 \mathrm{WVTa}$ steels showing the bainite microstructure and grain refinement provided by tantalum. ${ }^{116}$ 


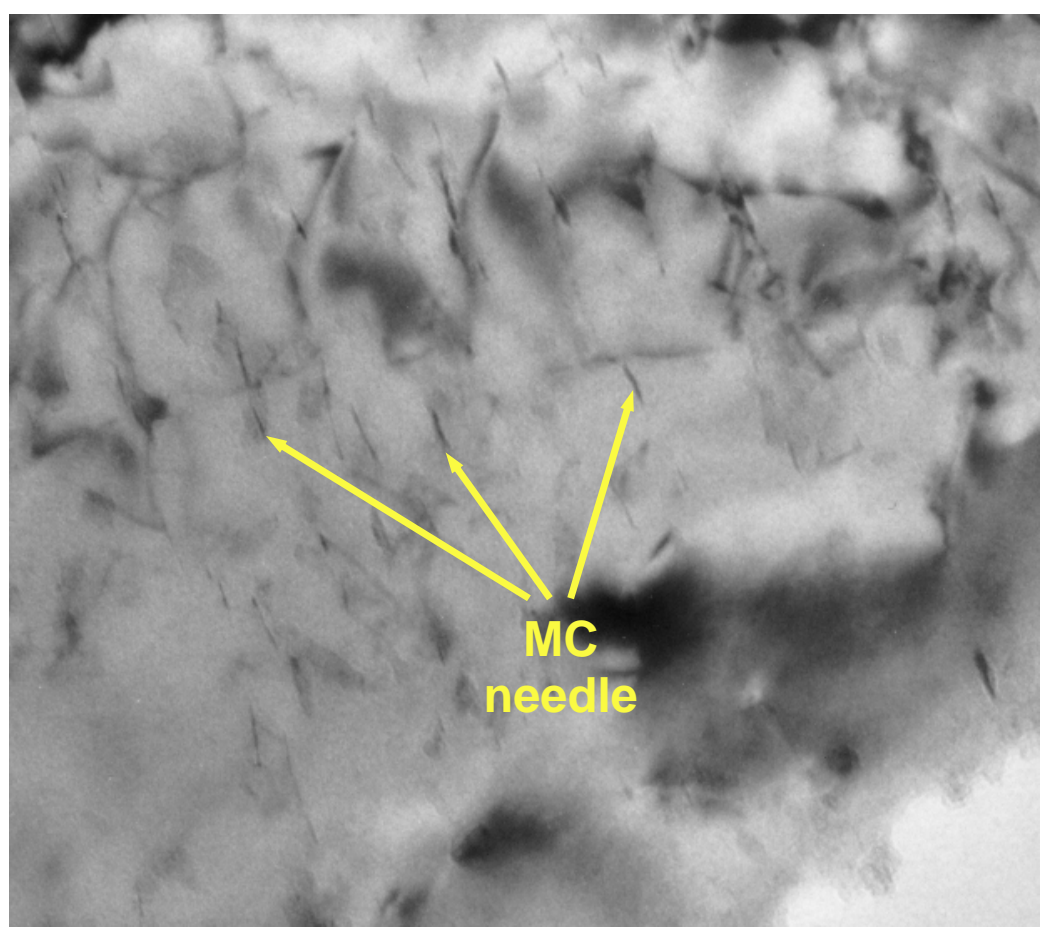

(a)

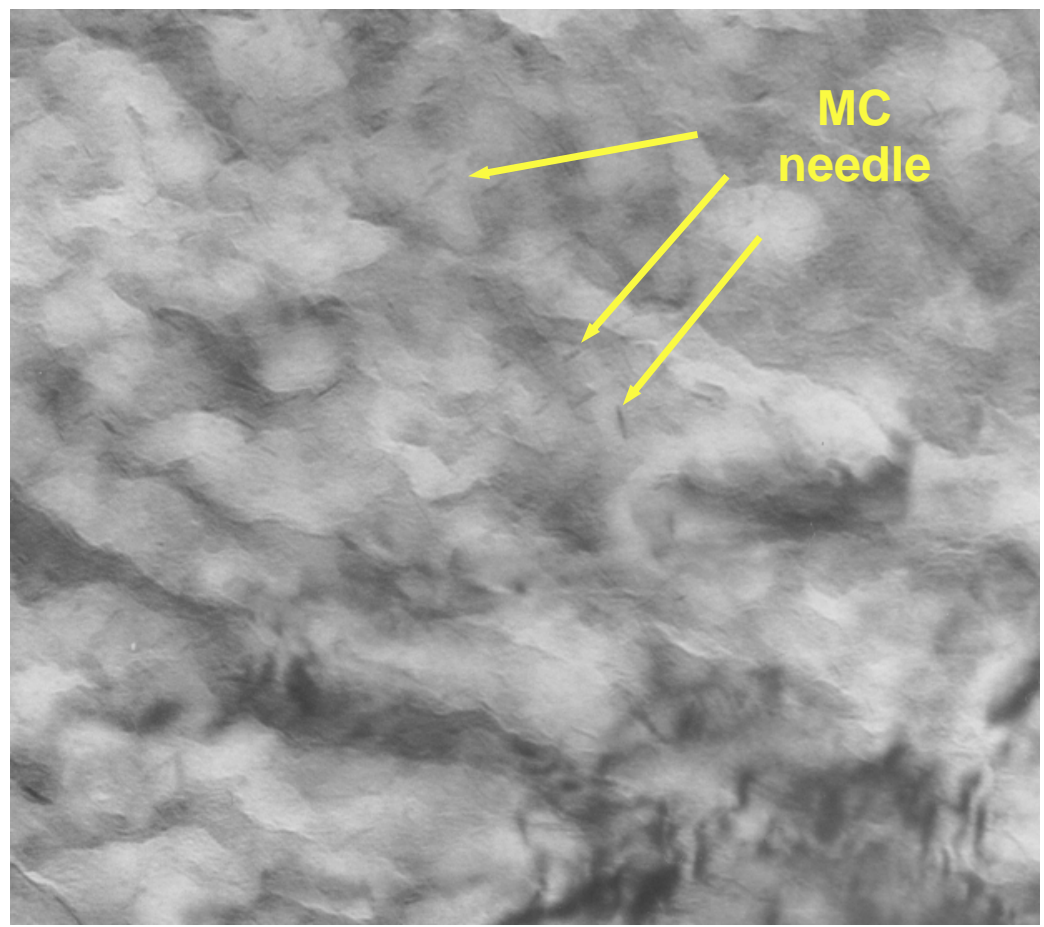

(b)

Fig. 22. Photomicrographs of (a) $3 \mathrm{Cr}-3 \mathrm{WV}$ and (b) $3 \mathrm{Cr}$-3WVTa steels showing the fine needle precipitates that provide the creep strength of the steels. ${ }^{117}$ 


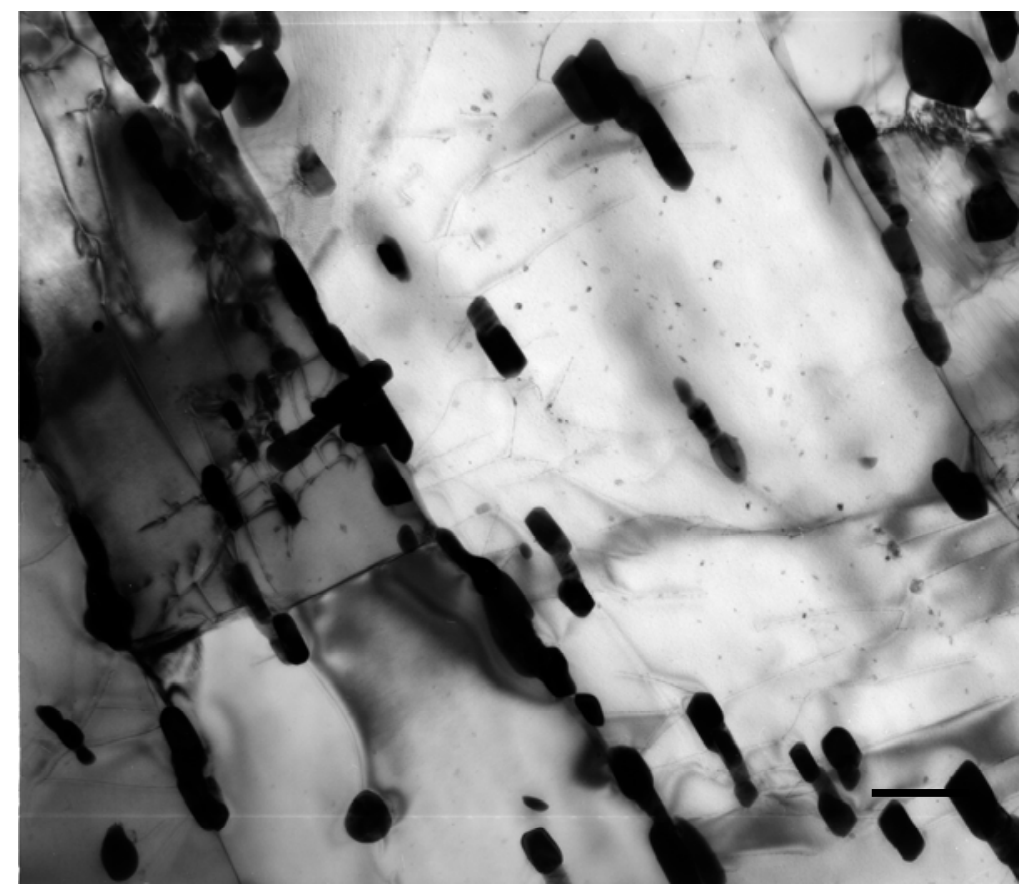

(a)

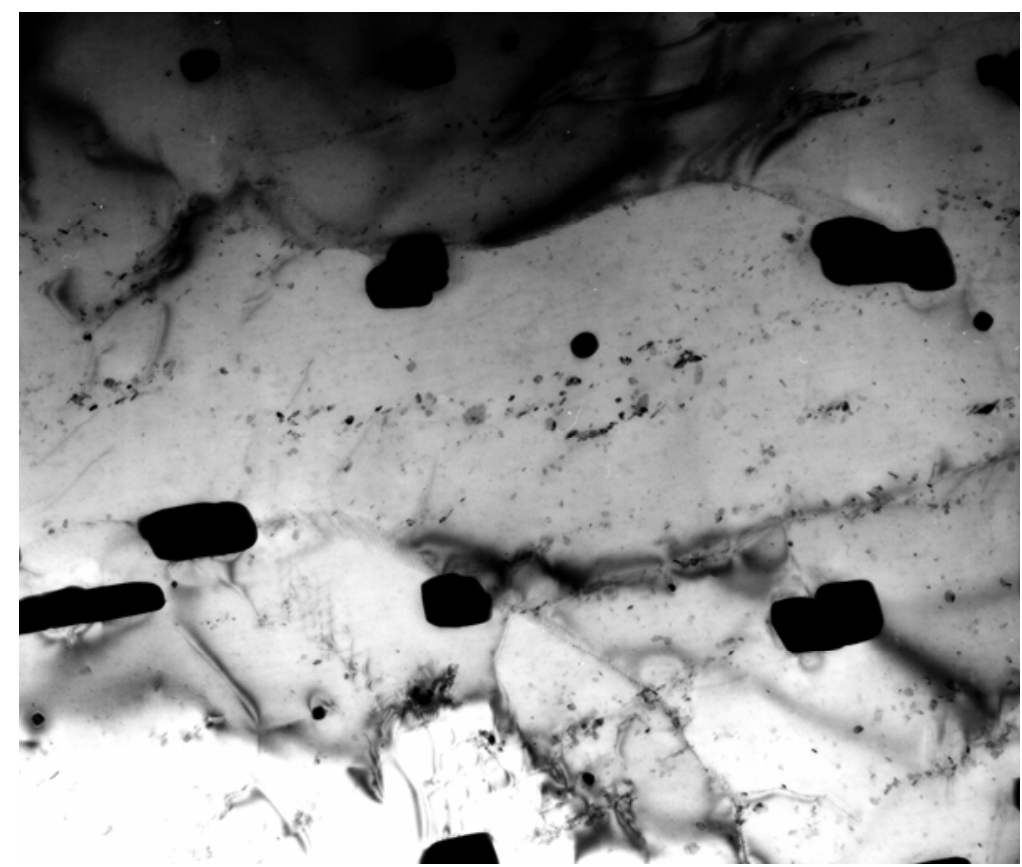

(b)

Fig. 23. Photomicrographs of (a) 3Cr-3WV steel and (b) 3Cr-3WVTa after creep-rupture test at $650^{\circ} \mathrm{C}, 83 \mathrm{MPa}$; $3 \mathrm{Cr}-3 \mathrm{WV}$ ruptured in $1141 \mathrm{~h}$ and $3 \mathrm{Cr}-3 \mathrm{WVTa}$ in $3086 \mathrm{~h}$. The fine needle precipitates in the matrix in the $3 \mathrm{Cr}-3 \mathrm{WVTa}$ appear more resistant to coarsening than those in the 3Cr-3WV. ${ }^{117}$ 


\section{FERRITIC AND MARTENSITIC STEELS FOR THE FUTURE}

Several investigators have looked beyond the typical Cr-Mo-W-V steels for novel compositions and processing routes to develop new ferritic and martensitic steels for service to $650^{\circ} \mathrm{C}$ and higher.

One such composition was a $9 \mathrm{Cr}-3.3 \mathrm{~W}-0.2 \mathrm{~V}-0.05 \mathrm{Nb}-0.05 \mathrm{~N}-0.08 \mathrm{C}$ steel containing $1-3 \% \mathrm{Pd}$, where the steel was hardened by an $\mathrm{Ll}_{0}$-type ordered phase that formed coherently in the matrix. ${ }^{118}$ In another study, a $15 \% \mathrm{Cr}$ ferritic steel with a base composition of Fe-0.1C-15Cr-1Mo-3W-0.2V-0.05Nb-0.07N-0.003B was alloyed with up to an additional $3 \% \mathrm{~W}$ and $3 \% \mathrm{Co}$. A combination of $6 \% \mathrm{~W}$ and $3 \%$ Co in the steel provided the best strength properties due to the precipitates (not identified) that formed. ${ }^{119,120}$ For nuclear considerations and subsequent activation, the cobalt alloys are probably not an option, although the class of steel may offer other non-cobalt-containing options.

Information on the development of a low-carbon $(0.002 \%) 9 \mathrm{Cr}-3 \mathrm{~W}-3 \mathrm{Co}-\mathrm{VNb}$ steel with $0.05 \% \mathrm{~N}$ has recently been published. ${ }^{121}$ Improved creep strength was attributed to nano-sized MX carbonitrides along prior-austenite grain boundaries and lath boundaries. ${ }^{79,121}$ Again, it may be possible to develop such a steel without cobalt, given the uncertainty of the effect of cobalt on creep strength, as discussed above. Another recent experimental steel development is a carbon-free martensitic alloy. ${ }^{122}$ The steel, an Fe-11.0Ni-5.0Cr-10.0Mo-0.20Ti-0.12Al-0.005B alloy, had excellent properties at $700^{\circ} \mathrm{C}$. All of these steels can only be considered experimental at this juncture.

Oxide dispersion-strengthened (ODS) ferritic steels are another alternative with the potential of having the advantage of a ferritic steel but being able to push operating temperatures to $650^{\circ} \mathrm{C}$ and beyond. These steels are presently receiving an everincreasing amount of attention as possible candidate materials for first wall and blanket structural materials for future fusion reactors ${ }^{6,123}$ and for fuel cladding for fast fission reactors. ${ }^{6,124}$ They have also been considered in the planning for Generation IV reactors, ${ }^{1}$ as well as for the conventional power-generation industry, as they push for operating temperatures beyond $650^{\circ} \mathrm{C}{ }^{125}$

ODS steels are not new to the nuclear industry, as they were first considered as fuel cladding for fast reactors in the 1960s. ${ }^{126}$ The problem that has hindered their widespread application is the anisotropy of mechanical properties due to the processing procedures used to form the steels. Processing generally starts by mechanically alloying the rapidly solidified metal alloy matrix and the ultra-fine oxide powders. This is followed by consolidation by hot extrusion, hot rolling, or hot isostatic pressing. Heat treatment at $1100^{\circ} \mathrm{C}$ and higher is used to recrystallize the structure in an effort to remove the anisotropy. ${ }^{127}$

The first ODS steels consisted of a low-carbon, high-chromium $(12-17 \% \mathrm{Cr})$ nontransformable ferrite matrix with a high number density of small titania $\left(\mathrm{TiO}_{2}\right)$ and/or yttria $\left(\mathrm{Y}_{2} \mathrm{O}_{3}\right)$ particles as the strengthening dispersion. Two early compositions studied extensively were: $\mathrm{Fe}-13 \mathrm{Cr}-1.5 \mathrm{Mo}-2.9 \mathrm{Ti}-1.8 \mathrm{Ti}_{2} \mathrm{O}_{3}$ (DT2906) and $\mathrm{Fe}-13 \mathrm{Cr}-1.5 \mathrm{Mo}-2.2 \mathrm{Ti}-$ $0.9 \mathrm{Ti}_{2} \mathrm{O}_{3}-0.5 \mathrm{Y}_{2} \mathrm{O}_{3}$ (DT2203Y05). ${ }^{126,128}$ Elevated-temperature strength is provided by a dispersion of fine titania and yttria particles and by $\chi$-phase $(70 \% \mathrm{Fe}, 15 \% \mathrm{Cr}, 7 \% \mathrm{Ti}, 6 \%$ Mo) that forms at grain boundaries. 
Over the last ten years or so, ODS steel development programs have been pursued in France ${ }^{129}$ and Japan, ${ }^{130,131}$ primarily in fast-reactor cladding programs. More recently, programs were begun in the fusion reactor programs in Japan, ${ }^{132}$ Europe, ${ }^{133}$ and the United States. ${ }^{134,135}$ A primary objective of these programs, as in the programs before them, is to solve the problem of the 127 "bamboo-like grain structure and a strong deformation texture" which gives rise to anisotropic mechanical properties, especially an inferior biaxial creep-rupture strength. The development programs seek to process the presently available steels (e.g., commercial MA 957-Fe-14Cr-1 Ti-0.3Mo-0.25 $\mathrm{Y}_{2} \mathrm{O}_{3}$ ) to produce an equiaxed structure and explore new alloy compositions. Many of the new alloys use tungsten instead of molybdenum, and they usually use $\mathrm{Y}_{2} \mathrm{O}_{3}$ dispersions with lower titanium concentrations than were used for the earlier versions. Aluminum and niobium additions have also been explored for grain refinement, but this has not solved the anisotropy problem completely.

A second approach to the anisotropy problem is to use a $9-11 \% \mathrm{Cr}, 2-3 \% \mathrm{~W}$ base with the yttria dispersion. ${ }^{124,131,133}$ The objective here is to develop an equiaxed structure through the austenite-to-martensite transformation when the steel is cooled from the austenitization temperature. This approach has produced steels with excellent tensile properties and a significant decrease in the anisotropy. ${ }^{131,132}$ However, the creep-rupture properties were reduced from those of the high-chromium ODS steels. ${ }^{131}$ It would also appear that a problem with a martensitic ODS steel is that it will have to contain sufficient carbon to produce the austenite that is transformed to martensite. When the steel is tempered to impart toughness, $\mathrm{M}_{23} \mathrm{C}_{6}$ will form. As noted earlier, $\mathrm{M}_{23} \mathrm{C}_{6}$ can reduce the properties of the high-chromium ferritic/martensitic steels-especially the impact toughness - and it would probably do the same in a martensitic ODS steel, since these steels already have low toughness because of their high strength. High-chromium ODS steels avoid the $\mathrm{M}_{23} \mathrm{C}_{6}$ by keeping the carbon concentration low (0.01-0.03\%).

There are other problems with the ODS steels besides anisotropy. At present, the literature is devoid of information on the production of thick-walled parts or largediameter tubing. Fabrication processes for these materials for heavy sections still need to be established, and this means addressing the problem of joining the materials.

Therefore, much research and development is still required before ODS steels will be ready for structural applications.

The Central Research Institute of the Electric Power Industry of Japan and Kobe Steel Ltd. have presented information on $12 \mathrm{Cr}-8 \mathrm{Mo}$ and $12 \mathrm{Cr}-8 \mathrm{Mo}-0.1 \mathrm{Y}_{2} \mathrm{O}_{3}$ steels fabricated for cladding of metallic fuel for fast breeder reactors. ${ }^{136}$ The steels, fabricated by mechanical alloying/powder metallurgy techniques, were shown "to have two-to-three times the creep-rupture strength of a conventional 12Cr (HT9) steel." The steels showed no void formation after $350 \mathrm{dpa}$ of $\mathrm{Ni}^{3+}$-ion irradiation. Again, this work appears to be in the early development stage, and it remains to be determined if these steels have the same problems as more conventional ODS steels and whether they would have any advantage over conventional ODS steels.

Two attempts have been made to produce dispersion-strengthened steels by more conventional techniques than mechanical alloying/power metallurgy techniques. The first has good creep strength to $650-700^{\circ} \mathrm{C}$, and it achieves its excellent elevatedtemperature properties by dispersion strengthening. ${ }^{137,138}$ The steel, designated A-21, has a nominal composition of Fe-9.5Cr-3Co- $1 \mathrm{Ni}-0.6 \mathrm{Mo}-0.3 \mathrm{Ti}-0.07 \mathrm{C}$ that is strengthened by 
a fine dispersion of tiny titanium carbides produced by austenitizing to dissolve all precipitates and then hot working the austenite (ausforming) prior to cooling to form martensite. Hot working generates dislocations that provide nucleation sites for many fine $\mathrm{TiC}$ particles to produce dispersion-strengthened martensite with high creep strength but without the anisotropy of the extruded ODS steels. By balancing the composition between the titanium and carbon and using up essentially all of the carbon to form $\mathrm{TiC}$, it is possible to avoid the large $\mathrm{M}_{23} \mathrm{C}_{6}$ precipitates that can be detrimental to the toughness.

A somewhat similar approach to the A-21 but without the hot working is the development of a steel designed to use precipitation strengthening with vanadium nitrides and carbonitrides. ${ }^{139}$ In this case, the steel with the complicated nominal composition of Fe-12Cr-0.5Ni-2Mn-10Co-1.5Mo-0.7V-0.06Nb-0.04Ta-0.04Ti-0.15N-0.03C was austenitized at $1180^{\circ} \mathrm{C}$ for $1 \mathrm{~h}$ and then ausaged at $700^{\circ} \mathrm{C}$ for $120 \mathrm{~h}$, after which it was cooled to room temperature, and finally tempered at $700^{\circ} \mathrm{C}$ for $4 \mathrm{~h}$. The objective was to form a high number density of fine precipitates. The properties of the steels produced by the initial attempts at this process were less-than desired, and further work is required.

A final example is the attempt to add a WTiC carbide directly to molten steel by encasing the carbide in iron as FeWTiC to be added to the melt. ${ }^{140}$ The properties still left a lot to be desired, as the strength for steels containing 1, 3, and 5\% FeWTiC did not reach those of a base composition without the carbides added. However, the work did demonstrate the feasibility of the process, thus giving hope that future improvements can be made. 


\section{SUMMARY}

Significant advances have been made in developing conventional ferritic/martensitic steels that are improvements over the HT9, EM-12, FV448, and DIN 1.4914 steels originally considered candidates for cladding and duct applications in international fast reactor programs in the 1970s. Although the effect of irradiation on most of these new steels is unknown, the steels offer the prospect of operating temperatures of $50-100^{\circ} \mathrm{C}$ higher than for the older steels. Additionally, ODS steels and other developmental steels offer the possibility of over $200^{\circ} \mathrm{C}$ higher maximum operating temperatures than the steels originally considered for nuclear applications. 


\section{ACKNOWLEDGMENTS}

Thanks are extended to Drs. L. K. Mansur, M. K. Santella, R. W. Swindeman, R. K. Nanstad, and S. J. Zinkle for reviewing the manuscript and helpful discussions of the subject.

Research was sponsored by the Office of Nuclear Energy, Science, and Technology, U.S. Department of Energy, under contract DE-AC05-00OR22725 with UT-Battelle, LLC. 


\section{REFERENCES}

1. A Technology Roadmap for Generation IV Nuclear Energy Systems, GIF-002-00, U.S. DOE Nuclear Energy Research Advisory Committee and the Generation IV International Forum, December 2002.

2. F. Masuyama, Advanced Heat Resistant Steel for Power Generation, eds. R. Viswanathan and J. Nutting, The Institute of Materials, London, 33-48, 1999.

3. R. Viswanathan and W. Bakker, J. Mater. Eng. Perf. 10, 81-95 (2001).

4. R. Viswanathan and W. Bakker, J. Mater. Eng. Perf. 10, 96-101 (2001).

5. R. T. King et al., Symposium on Structural Material for Service at Elevated Temperatures in Nuclear Power Generation, ed. A. O. Schaefer, Am. Soc. Mech. Eng., New York, 375-385, 1975.

6. R. L. Klueh and D. R. Harries, High-Chromium Ferritic and Martensitic Steels for Nuclear Applications, ASTM, West Conshohocken, Pa., 2001.

7. S. N. Rosenwasser, et al., J. Nucl. Mater., 85-86, 177-182 (1979).

8. R. L. Klueh, K. Ehrlich, and F. Abe, J. Nucl. Mater., 191-194, 116-124 (1992).

9. R. W. Conn et al., Panel Report on Low Activation Materials for Fusion Applications, UCLA Report PPG-778, University of California at Los Angeles, 1983.

10. G. J. Butterworth and O. N. Jarvis, J. Nucl. Mater., 122-123, 982-988 (1984).

11. N. M. Ghoniem, A. Shabaik, and M. Z. Youssef, Proceedings of Topical Conference for Ferritic Steels for Use in Nuclear Energy Technologies, eds. J. W. Davis and D. J. Michel, The Metallurgical Society of AIME, Warrendale, Pa., 201-208, 1984.

12. R. L. Klueh and E. E. Bloom, Nucl. Eng. Design/Fusion 2, 383-389 (1985).

13. D. S. Gelles, Optimizing Materials for Nuclear Applications, eds. F. A. Garner, D. S. Gelles, and F. W. Wiffen, The Metallurgical Society of AIME, Warrendale, Pa., 63$72,1985$.

14. D. Dulieu, K. W. Tupholme, and G. J. Butterworth, J. Nucl. Mater., 141-143, 10971101 (1986).

15. M. Tamura, H. Hayakawa, M. Tanimura, A. Hishinuma, and T. Kondo, J. Nucl. Mater., 141-143, 1067-1073 (1986).

16. T. Noda, F. Abe, H. Araki, and M. Okada, J. Nucl. Mater., 141-143, 1102-1106 (1986).

17. R. L. Klueh, D. S. Gelles, and T. A. Lechtenberg, J. Nucl. Mater., 141-143, 10811087 (1986).

18. D. S. Gelles, Reduced Activation Materials for Fusion Reactors, ASTM STP 1047, eds. R. L. Klueh, D. S. Gelles, M. Okada, and N. H. Packan, ASTM, Philadelphia, 113-129, 1990.

19. C. Y. Hsu and T. A. Lechtenberg, J. Nucl. Mater., 141-143,1107-1112 (1986).

20. K. Anderko, K. Ehrlich, I. Schäfer, and M. Schirra, CETA-EinEntwicklungsschritt zu einem Schwach Activierbaren martensitischen Chromstahl, KfK Report 5060, Kernforschungszentrum Karlsruhe, June 1993.

21. H. Kayano et al., J. Nucl. Mater., 179-181, 671-674 (1991).

22. R. L. Klueh and P. J. Maziasz, Met. Trans. 20A, 373-381 (1989).

23. M. Tamura, H. Hayakawa, M. Tanimura, A. Hishinuma, and T. Kondo, J. Nucl. Mater., 155-157, 620-625 (1988). 
24. M. Yamanouchi, M. Tamura, H. Hayakawa, A. Hishinuma, and T. Kondo, J. Nucl. Mater., 191-194, 822-826 (1992).

25. F. Abe, T. Noda, H. Araki, and S. Nakazawa, J. Nucl. Mater., 179-181, 663-666 (1991).

26. A. Kohyama, Y. Kohno, K. Asakura, and H. Kayano, J. Nucl. Mater., 212-215, 684689 (1994).

27. K. Ehrlich, S. Kelzenberg, H. D. Röhrig, L. Schäfer, and M. Schirra, J. Nucl. Mater., 212-215, 678-683 (1994).

28. R. L. Klueh, Met. Trans. 20A, 463-469 (1989).

29. B. van der Schaaf, D. S. Gelles, S. Jitsukawa, A. Kimura, R. L. Klueh, A. Moslang, and G. R. Odette, J. Nucl. Mater., 283-287, 52-59 (2000).

30. V. S. Agueev, V. N. Bykov, A. M. Dvoryashin, V. N. Golovanov, E. A. Medvendeva, V. V. Romaneev, V. K. Sharmardin, and A. N. Vorobiev, Effects of Radiation on Materials, 14th International Symposium, ASTM STP 1046, eds. N. H. Packan, R. E. Stoller, and A. S. Kumar, American Society for Testing and Materials, Philadelphia, Vol. I, 98-113, 1989.

31. P. J. Maziasz, R. L. Klueh, and J. M. Vitek, J. Nucl. Mater., 141-143, 929-937 (1986).

32. R. L. Klueh, J. J. Kai, and D. J. Alexander, J. Nucl. Mater. 225, 175-186 (1995).

33. D. S. Gelles, J. Nucl. Mater., 212-215, 714-719 (1994).

34. E. A. Little and L. P. Stoter, Effects of Irradiation on Materials: Eleventh Conference, ASTM STP 782, eds. H. R. Brager and J. S. Perrin, American Society for Testing and Materials, Philadelphia, 207-233, 1982.

35. D. S. Gelles and L. E. Thomas, Ferritic Alloys for Use in Nuclear Energy Technologies, eds. J. W. Davis and D. J. Michel, Met. Soc., AIME, Warrendale, Pa., 559-568, 1984.

36. P. J. Maziasz and V. K. Sikka, Alloy Development for Irradiation Performance Semiannual Progress Report for Period Ending September 30, 1985, U.S. Department of Energy Report DOE/ER-0045/15, Office of Fusion Energy, Washington, D.C., 102-116, 1985.

37. J. D. Hunn, M. B. Lewis, E. H. Lee, Second International Topical Meeting on Nuclear Applications of Accelerator Technology, Gatlinburg, Tenn., American Nuclear Society, 375-381, September 1998.

38. P. Marmy and B. M. Oliver, J. Nucl. Mater. 318, 132-142 (2003).

39. Y. Dai, Y. Foucher, M. R. James, and B. M. Oliver, J. Nucl. Mater. 318, 167-175 (2003).

40. C. Wassilew, K. Herschbach, E. Materna-Morris, and K. Ehrlich, Topical Conference on Ferritic Steels for Use in Nuclear Energy Technologies, eds. J. W. Davis and D. J. Michel, The Metallurgical Society of AIME, Warrendale, Pa., 607-614, 1984.

41. R. L. Klueh and J. M. Vitek, J. Nucl. Mater. 182, 230-239 (1991).

42. R. L. Klueh and J. M. Vitek, J. Nucl. Mater. 161, 13-23 (1989).

43. R. L. Klueh and J. M. Vitek, J. Nucl. Mater. 132, 27-31 (1985).

44. D. S. Gelles, J. Nucl. Mater. 233-237, 293- (1996).

45. R. L. Klueh and D. J. Alexander, Effects of Radiation on Materials: 15th International Symposium, ASTM STP 1125, eds. R. E. Stoller, A. S. Kumar, and D. S. Gelles, American Society for Testing and Materials, Philadelphia, 1256-1266, 1992. 
46. W. L. Hu and D. S. Gelles, Influence of Radiation on Material Properties: $13^{\text {th }}$ International Symposium (Part II) ASTM STP 956, eds. F. A. Garner, C. H. Henager, Jr., and N. Igata, American Society for Testing and Materials, Philadelphia, 83, 1987.

47. V. K. Shamardin, A. M. Pecherin, O. M. Vishkarev, V. P. Borisov, and G. A. Tulyakov, Proc. Int. Conf. on Radiat. Mater. Sci., May 22-25, 1990, Alushta, USSR, 3-18.

48. R. L. Klueh and D. J. Alexander, J. Nucl. Mater., 179-181, 733 (1991).

49. C. Wassilew and K. Ehrlich, J. Nucl. Mater., 191-194, 850 (1992).

50. R. L. Klueh and D. J. Alexander, J. Nucl. Mater. 187, 60-69 (1992).

51. R. K. Nanstad, Encyclopedia of Materials Science and Engineering, ed. M. B. Bever, Pergamon Press, New York, 3928-3930, 1986.

52. B. Nath, E. Metcalf, and J. Hald, Microstructural Development and Stability in High Chromium Ferritic Power Plant Steels, eds. A. Strang and D. J. Gooch, The Institute of Materials, London, 123-144, 1997.

53. H. Cerjak, V. Foldyna, P. Hofer, and B. Schaffernak, Microstructural Development and Stability in High Chromium Ferritic Power Plant Steels, eds. A. Strang and D. J. Gooch, The Institute of Materials, London, 145-158, 1997.

54. J. Hald and Z. Kuboň, Microstructural Development and Stability in High Chromium Ferritic Power Plant Steels, eds. A. Strang and D. J. Gooch, The Institute of Materials, London, 159-178, 1997.

55. A. Strang and V. Vodarek, Microstructural Stability of Creep Resistant Alloys for High Temperature Plant Applications, eds. A. Strang, J. Cawley, and G. W. Greenwood, The Institute of Materials, London, 117-134, 1998.

56. P. J. Ennis, A. Zieliñska-Lipiec, and A. Czyrska-Filemonowicz, Microstructural Stability of Creep Resistant Alloys for High Temperature Plant Applications, eds. A. Strang, J. Cawley, and G. W. Greenwood, The Institute of Materials, London, 135144, 1998.

57. A. Orlová, J. Buršik, K. Kuchařová, and V. Sklenička, Microstructural Stability of Creep Resistant Alloys for High Temperature Plant Applications, eds. A. Strang, J. Cawley, and G. W. Greenwood, The Institute of Materials, London, 89-106, 1998.

58. M. Schwind, M. Hättestrand, and H.-O. Andrén, Microstructural Stability of Creep Resistant Alloys for High Temperature Plant Applications, eds. A. Strang, J. Cawley, and G. W. Greenwood, The Institute of Materials, London, 197-214, 1998.

59. M. Hättestrand, M. Schwind, and H.-O. Andrén, Advanced Heat Resistant Steel for Power Generation, eds. R. Viswanathan and J. Nutting, The Institute of Materials, London, 199-211, 1999.

60. S. Spigarelli, E. Cerri, E. Evangelista, and P. Bontempi, Advanced Heat Resistant Steel for Power Generation, eds. R. Viswanathan and J. Nutting, The Institute of Materials, London, 247-258, 1999.

61. Z. Kuboň, V. Foldyna, and V. Vodárk, Microstructural Stability of Creep Resistant Alloys for High Temperature Plant Applications, eds. A. Strang, J. Cawley, and G. W. Greenwood, The Institute of Materials, London, 257-270, 1998.

62. P. Bianchi, P. Bontempi, A. Benvenuti, and N. Ricci, Microstructural Stability of Creep Resistant Alloys for High Temperature Plant Applications, eds. A. Strang, J. Cawley, and G. W. Greenwood, The Institute of Materials, London, 107-116, 1998. 
63. M. Taneike, M. Kondo, and T. Morimoto, ISIJ International Supplement, 4, S111S120, 2001.

64. J. Hald, Proceedings of the $3^{\text {rd }}$ EPRI Conference on Advanced Materials Technology for Fossil Plants, eds. R. Viswanathan, W. T. Bakker, and J. D. Parker, Gomer Press, Llandysul, Ceredigion, UK, 115-124, 2001.

65. H. Naoi, M. Ohgami, Y. Hasegawa, H. Mimura, and T. Fujita, Advanced Heat Resistant Steel for Power Generation, eds. R. Viswanathan and J. Nutting, The Institute of Materials, London, 259-269, 1999.

66. R. Ishii, Y. Tsuda, M. Yamada, and M. Miyazaki, Advanced Heat Resistant Steel for Power Generation, eds. R. Viswanathan and J. Nutting, The Institute of Materials, London, 277-287, 1999.

67. W. C. Leslie, Met. Trans. 3, 5-17 (1972).

68. J. Nutting, Advanced Heat Resistant Steel for Power Generation, eds. R. Viswanathan and J. Nutting, The Institute of Materials, London, 12-30, 1999.

69. T. Fujita et al., Proc. $1^{\text {st }}$ Int. Conf. on Improved Coal Fired Power Plants, EPRI Report, CS-5581-SR, Electric Power Research Institute, 5-17, 1986.

70. K. Hayashi, T. Kojima, and Y. Minami, Advanced Heat Resistant Steel for Power Generation, eds. R. Viswanathan and J. Nutting, The Institute of Materials, London, 51-64, 1999.

71. V. Foldyna, Z. Kubon, V. Vodárek, and J. Purmenský, Proceedings of the $3^{\text {rd }}$ EPRI Conference on Advanced Materials Technology for Fossil Plants, eds. R. Viswanathan, W. T. Bakker, and J. D. Parker, Gomer Press, Llandysul, Ceredigion, UK, 89-98, 2001.

72. R. W. K. Honeycomb, Steels: Microstructure and Properties, Edward Arnold, London, 1981.

73. M. Miyazaki, M. Yamada, Y. Tsuda, and R. Ishii, Advanced Heat Resistant Steel for Power Generation, eds. R. Viswanathan and J. Nutting, The Institute of Materials, London, 574-585, 1999.

74. J. J. Kai and R. L. Klueh, J. Nucl. Mater. 230, 116-124 (1996).

75. R. Jayram and R. L. Klueh, Matall. and Mater. 29A, 1551-1558 (1998).

76. T. Gladman, Microstructural Stability of Creep Resistant Alloys for High Temperature Plant Applications, eds. A. Strang, J. Cawley, and G. W. Greenwood, The Institute of Materials, London, 49-68, 1998.

77. A. Golpayegani, M. Hättestrand, and H. O. Andrén, Parsons 2003: Engineering Issues in Turbine Machinery, Power Plant and Renewables, eds. A. Strang, R. D. Conroy, W. M. Banks, M. Blackler, J. Leggett, G. M. McColvin, S. Simpson, M. Smith, F. Starr, and R. W. Vanstone, The Institute of Materials, Minerals and Mining, London, 347-363, 2003.

78. A. Czyrska-Filemonowicz, K. Bryla, K. Spiradek-Hahn, H. Firganek, A. ZielinskaLipiec, and P. J. Ennis, Parsons 2003: Engineering Issues in Turbine Machinery, Power Plant and Renewables, eds. A. Strang, R. D. Conroy, W. M. Banks, M. Blackler, J. Leggett, G. M. McColvin, S. Simpson, M. Smith, F. Starr, and R. W. Vanstone, The Institute of Materials, Minerals and Mining, London, 365-377, 2003.

79. F. Abe, T. Horiuchi, and M. Taneike, Parsons 2003: Engineering Issues in Turbine Machinery, Power Plant and Renewables, eds. A. Strang, R. D. Conroy, W. M. Banks, M. Blackler, J. Leggett, G. M. McColvin, S. Simpson, M. Smith, F. Starr, and 
R. W. Vanstone, The Institute of Materials, Minerals and Mining, London, 379-395, 2003.

80. F. B. Pickering, Microstructural Development and Stability in High Chromium Ferritic Power Plant Steels, eds. A. Strang and D. J. Gooch, The Institute of Materials, London, 1-30, 1997.

81. A. M. Barnes, Microstructural Stability of Creep Resistant Alloys for High Temperature Plant Applications, eds. A. Strang, J. Cawley, and G. W. Greenwood, The Institute of Materials, London, 339-360, 1998.

82. J. Orr and L. Woollard, Microstructural Development and Stability in High Chromium Ferritic Power Plant Steels, eds. A. Strang and D. J. Gooch, The Institute of Materials, London, 53-72, 1997.

83. K. Spiradek-Hahn, P. Nowakowski, and G. Zeiler, Proceedings of the $3^{\text {rd }}$ EPRI Conference on Advanced Materials Technology for Fossil Plants, eds. R. Viswanathan, W. T. Bakker, and J. D. Parker, Gomer Press, Llandysul, Ceredigion, UK, 165-176, 2001.

84. A. Strang and V. Vodárek, Microstructural Development and Stability in High Chromium Ferritic Power Plant Steels, eds. A. Strang and D. J. Gooch, The Institute of Materials, London, 31-52, 1997.

85. K. Hidaka, Y. Fukui, S. Nakamura, R. Kaneko, Y. Tanaka, and T. Fujita, Advanced Heat Resistant Steel for Power Generation, eds. R. Viswanathan and J. Nutting, The Institute of Materials, London, 418-429, 1999.

86. S. H. Ryu, J. Yu, and B. S. Ku, Parsons 2000: Advanced Materials for 21st Century Turbines and Power Plant, eds. A. Strang, W. M. Banks, R. D. Conroy, G. M. McColvin, J. C. Neal, and S. Simpson, The Institute of Materials, London, 472-484, 2000.

87. P. D. Clarke, P. F. Morris, N. Cardinal, and M. J. Worrall, Parsons 2003: Engineering Issues in Turbine Machinery, Power Plant and Renewables, eds. A. Strang, R. D. Conroy, W. M. Banks, M. Blackler, J. Leggett, G. M. McColvin, S. Simpson, M. Smith, F. Starr, and R. W. Vanstone, The Institute of Materials, Minerals and Mining, London, 334-345, 2003.

88. F. Abe, M. Igarashi, N. Fujitsuna, K. Kimura, and S. Muneki: 'Advanced Heat Resistant Steel for Power Generation', (eds. R. Viswanathan and J. Nutting) 1999, Institute of Materials, London, 84-95.

89. A. Tohyama and Y. Minami, Advanced Heat Resistant Steel for Power Generation, eds. R. Viswanathan and J. Nutting, The Institute of Materials, London, 494-506, 1999.

90. K. Kimura, H. Kushima, F. Abe, and K. Yagi, Microstructural Stability of Creep Resistant Alloys for High Temperature Plant Applications, eds. A. Strang, J. Cawley, and G. W. Greenwood, The Institute of Materials, London, 185-196, 1998.

91. R. L. Klueh, Nuclear Technology 57, 114 (1982).

92. W. Bendick, F. Deshayes, K. Haarmann, and J.-C. Vaillant, Advanced Heat Resistant Steel for Power Generation, eds. R. Viswanathan and J. Nutting, The Institute of Materials, London, 133-143, 1999.

93. V. Foldyna, Z. Kuboň, A. Jakobová, and V. Vodárek, Microstructural Development and Stability in High Chromium Ferritic Power Plant Steels, eds. A. Strang and D. J. Gooch, The Institute of Materials, London, 73-92, 1997. 
94. R. Vanstone, Microstructural Stability of Creep Resistant Alloys for High Temperature Plant Applications, eds. A. Strang, J. Cawley, and G. W. Greenwood, The Institute of Materials, London, 457-470, 1998.

95. J. Hald, Microstructural Stability of Creep Resistant Alloys for High Temperature Plant Applications, eds. A. Strang, J. Cawley, and G. W. Greenwood, The Institute of Materials, London, 173-184, 1998.

96. J. M. Vitek and R. L. Klueh, Met. Trans. A 14A, 1047-1055 (1983).

97. Y. Murata, M. Morinaga, R. Hashizume, T. Azuma, Y. Tanaka, and T. Ishiguro, Advanced Heat Resistant Steel for Power Generation, eds. R. Viswanathan and J. Nutting, The Institute of Materials, London, 332-346, 1999.

98. D. V. Thornton and K. H. Mayer, Advanced Heat Resistant Steel for Power Generation, eds. R. Viswanathan and J. Nutting, The Institute of Materials, London, 349-364, 1999.

99. A. Czyrska-Filemonowicz, K. Bryla, K. Spiradek-Hahn, H. Firganek, A. ZielinskaLipiec, and P. J. Ennis, Parsons 2003: Engineering Issues in Turbine Machinery, Power Plant and Renewables, eds. A. Strang, R. D. Conroy, W. M. Banks, M. Blackler, J. Leggett, G. M. McColvin, S. Simpson, M. Smith, F. Starr, and R. W. Vanstone, The Institute of Materials, Minerals and Mining, London, 365-377, 2003.

100. Y. Hasegawa, T. Muraki, M. Ohgami, and H. Mimura, Proceedings of the $3^{\text {rd }}$ EPRI Conference on Advanced Materials Technology for Fossil Plants, eds. R.

Viswanathan, W. T. Bakker, and J. D. Parker, Gomer Press, Llandysul, Ceredigion, UK, 197-208, 2001.

101. P. Polcik, S. Straub, D. Henes, and W. Blum, Microstructural Stability of Creep Resistant Alloys for High Temperature Plant Applications, eds. A. Strang, J. Cawley, and G. W. Greenwood, The Institute of Materials, London, 405-430, 1998.

102. T. Muraki, Y. Hasegawa, H. Tamehiro, M. Ohgami, N. Maruyama, and M. Mikami, Proceedings of the $3^{\text {rd }}$ EPRI Conference on Advanced Materials Technology for Fossil Plants, eds. R. Viswanathan, W. T. Bakker, and J. D. Parker, Gomer Press, Llandysul, Ceredigion, UK, 437-455, 2001.

103. P. J. Ennis, A. Zielinska-Lipiec, O. Wachter, and A. Czyrska-Filemonowicz, Acta mater., 45, 4901-4907 (1997).

104. F. C. Monkman and N. J. Grant, Proceedings, American Society for Testing Metals, 56, 1956, 593-607.

105. L. Kloc, V. Sklenička, A. Dlouhý, and K. Kuchařová, Microstructural Stability of Creep Resistant Alloys for High Temperature plant Applications, (eds. A. Strang, J. Cawley, and G. W. Greenwood), 1998, The Institute of Materials, London, 445-455.

106. Z. I. Kowalewski, Arch. Mech., 47, 13-22 (1995).

107. R. W. Swindeman, V. K. Sikka, P. J. Maziasz, and D. A. Canonico, Fatigue, Environmental Factors, and New Materials, PVP-Vol. 374 (eds. H. S. Mehta, R. W. Swindeman, J. A. Todd, S. Yukawa, M. Zako, W. H. Bamford, M. Higuchi, E. Jones, H. Nickel, and S. Rahman), 1998, American Society of Mechanical Engineers, New York, 305-312.

108. R. W. Swindeman, Unpublished Research, Private Communication, 2004.

109. M. F. Ashby, Acta Metall., 20, 88-97 (1972).

110. T. Allen and R. L. Klueh, Advanced Accelerator Applications, Cladding and Duct Review, Argonne National Laboratory Report, ANL-AAA-025, August 31, 2002. 
111. R. L. Klueh and D. J. Alexander, J. Nucl. Mater., 258-253, 1269-1274 (1998).

112. R. L. Klueh and D. J. Alexander, Effects of Radiation on Materials: 18th International Symposium, ASTM STP 1325, eds. R. K. Nanstad, M. L. Hamilton, F. A. Garner, and A. S. Kumar, American Society for Testing and Materials, Philadelphia, 911-930, 1999.

113. R. L. Klueh, D. J. Alexander, and E. A. Kenik, J. Nucl. Mater. 227, 11-23 (1995).

114. R. L. Klueh, D. J. Alexander, and P. J. Maziasz, Met. Trans. A 28A, 335-343 (1997).

115. R. L. Klueh and A. M. Nasreldin, Met. Trans. A, 18A, 1279-1290 (1987).

116. R. L. Klueh, unpublished research, 2003.

117. P. J. Maziasz, N. D. Evans, and R. L. Klueh, unpublished research, 2003.

118. M. Igarashi and Y. Sawaragi, Proceedings International Conference of Power Engineering '97, Tokyo, July 13-17, 1997, Vol. 2, 107-112.

119. M. Igarashi, S. Muneki, H. Hasegawa, K. Yamada, and F. Abe, ISIJ International Supplement, 4, S101-109, 2001.

120. K. Kimura, K. Seki, Y. Toda, and F. Abe, ISIJ International Supplement, 4, S121S129, 2001.

121. M. Taneike, F. Abe, and K. Sawada, Nature 424, 294-296 (2003).

122. S. Muneki, H. Okubo, H. Okada, M. Igarashi, and F. Abe, Parsons 2003: Engineering Issues in Turbine Machinery, Power Plant and Renewables, eds. A. Strang, R. D. Conroy, W. M. Banks, M. Blackler, J. Leggett, G. M. McColvin, S. Simpson, M. Smith, F. Starr, and R. W. Vanstone, The Institute of Materials, Minerals and Mining, London, 569-579, 2003.

123. R. L. Klueh, D. S. Gelles, S. Jitsukawa, A. Kimura, G. R. Odette, B. van der Schaaf, and M. Victoria, J. Nucl. Mater., 307-311, 455-465 (2002).

124. S. Ukai and M. Fujiwara, J. Nucl. Mater., 307-311, 749-757 (2002).

125. J. Ritherdon, A. R. Jones, U. Miller, and I. G. Wright, Parsons 2003: Engineering Issues in Turbine Machinery, Power Plant and Renewables, eds. A. Strang, R. D. Conroy, W. M. Banks, M. Blackler, J. Leggett, G. M. McColvin, S. Simpson, M. Smith, F. Starr, and R. W. Vanstone, The Institute of Materials, Minerals and Mining, London, 927-937, 2003.

126. J.-J. Huet, Powder Metallurgy 10, 108-115 (1967).

127. S. Ukai, M. Harada, H. Okada, M. Inoue, S. Nomura, S. Shikakura, K. Asabe, T. Nishida, and M. Fujiwara, J. Nucl. Mater. 204, 65-73 (1993).

128. J.-J. Huet, L. Coheur, L. De Wilde, J. Gedopt, W. Hendrix, and W. Vandermeulen, Proceedings of Topical Conference for Ferritic Steels for Use in Nuclear Energy Technologies, eds. J. W. Davis and D. J. Michel, The Metallurgical Society of AIME, Warrendale, Pa., 329-334, 1984.

129. A. Alamo, H. Regle, and J. L. Bechade, Novel Powder Processing: Advances in Powder Metallurgy and Particulate Materials, Metal Powder Industries Federation, Princeton, N.J., 7, 169-182, 1992.

130. T. Okuda, S. Nomura, S. Sillkakura, K. Asabe, S. Tanouf, and M. Fujiwara, Proceedings of the International Conference on Solid State Powder Processing, eds. A. H. Clauer and J. J. de Barbadillo, The Minerals, Metals, and Materials Society, Warrendale, Pa., 195-202, 1990.

131. S. Ukai, T. Nishida, T. Okuda, and T. Yoshitake, J. Nucl. Mater., 258-263, 17451749 (1998). 
132. K. Shiba, K. Nakamura, and A. Hishinuma, J. Nucl. Mater., to be published.

133. R. Lindau, A. Möslang, M. Schirra, P. Schlossmacher, and M. Klimenkov, J. Nucl. Mater. 307-311, 769-772 (2002).

134. R. L. Klueh, P. J. Maziasz, I. S. Kim, L. Heatherly, D. T. Hoelzer, N. Hashimoto, E. A. Kenik, and K. Miyahara, J. Nucl. Mater. 307-311, 773-777 (2002).

135. M. J. Alinger, G. R. Odette, and G. E. Lucas, J. Nucl. Mater. 307-311, 484-489 (2002).

136. M. Tokiwai, M. Horie, K. Kako, and M. Fujiwara, J. Nucl. Mater. 204, 56-62 (1993).

137. R. F. Buck and W. M. Garrison, Adv. Mater. Proc. 150 (2), 27-30 (1996).

138. R. L. Klueh, N. Hashimoto, R. F. Buck, and R. A. Sokolov, J. Nucl. Mater., 283-287, 697-701 (2000).

139. A. Göcmen, P. J. Uggowitzer, C. Solenthaler, M. O. Speidel, and P. Ernst, Microstructural Stability of Creep Resistant Alloys for High Temperature Plant Applications, eds. A. Strang, J. Cawley, and G. W. Greenwood, The Institute of Materials, London, 311-321, 1998.

140. P. Bates, M. A. Walsh, and S. Price, Advanced Heat Resistant Steel for Power Generation, eds. R. Viswanathan and J. Nutting, The Institute of Materials, London, 309-321, 1999. 
ORNL/TM-2004/176

\section{INTERNAL DISTRIBUTION}

1. G. L. Bell

2. T. D. Burchell

3. J. M. Corum

4-15. W. R. Corwin

16. C. W. Forsberg

17. S. R. Greene

18. P. Hadley

19. N. Hashimoto

20. L. L. Horton

21. D. T. Ingersoll

22. Y. Katoh

23. J. W. Klett

24-29. R. L. Klueh

30. E. Lara-Curzio
31. T. E. McGreevy

32. L. K. Mansur

33. P. J. Maziasz

34. R. K. Nanstad

35. W. Ren

36. P. L. Rittenhouse

37. A. F. Rowcliffe

38. L. L. Snead

39. R. E. Stoller

40. R. W. Swindeman

41. P. F. Tortorelli

42. D. F. Wilson

43. S. J. Zinkle

\section{EXTERNAL DISTRIBUTION}

44. Todd Allen, College of Engineering, The University of Wisconsin, 533

EngineeringResearch Building, 1500 Engineering Drive, Madison, Wisconsin 53706

45. Ronald Ballinger, Department of Nuclear Engineering, Massachusetts Institute of Technology, 77 Massachusetts Avenue, NW22-117, Cambridge, Massachusetts 02139-4307

46. Michael Cappiello, Los Alamos National Laboratory, P.O. Box 1663, Los Alamos, New Mexico 87545

47. Trevor Cook, NE-20/Germantown Building, Office of Advanced Nuclear Research, U.S. Department of Energy, 1000 Independence Avenue, S.W., Washington, DC 20585-1290

48. Douglas Crawford, Argonne National Laboratory, P.O. Box 2528, Idaho Falls, Idaho 83403

49. William Halsey, Lawrence Livermore National Laboratory, 7000 East Avenue, P.O. Box 808, L-1, Livermore, California 94550

50. George Hayner, Idaho National Engineering and Environmental Laboratory, P.O. Box 1625, IF 654 221, MS 3750, Idaho Falls, Idaho 83415-3750

51. Anthony Hechenova, Harry Reid Center, MSM-102, HRC-415, University of Nevada, Las Vegas, 4505 Maryland Parkway, MS 4009, Las Vegas, Nevada 89154

52. Russell Jones, Pacific Northwest National Laboratory, P.O. Box 999/P8-15, Richland, Washington 99352 


\section{EXTERNAL DISTRIBUTION (continued)}

53. Susan Lesica, NE-20/Germantown Building, Office of Advanced Nuclear Research, U.S. Department of Energy, 1000 Independence Avenue, S.W., Washington, DC 20585-1290

54. Philip Macdonald, Idaho National Engineering and Environmental Laboratory, P.O. Box 1625, IF 654 321, MS 3870, Idaho Falls, Idaho 83415-3750

55. Stuart Maloy, Los Alamos National Laboratory, P.O. Box 1663, Los Alamos, New Mexico 87545

56. David Ostby, Idaho National Engineering and Environmental Laboratory, P.O. Box 1625, IF654 325, MS 3865, Idaho Falls, Idaho 83415-3750

57. Paul Pickard, Sandia National Laboratory, P.O. Box 5800, MS 1136, Albuquerque, New Mexico 87185

58. Ajit Roy, Mechanical Engineering/TBE-A211B, HRC-409, University of Nevada, Las Vegas, 4505 Maryland Parkway, MS 4009, Las Vegas, Nevada 89154

59. Robert Versluis, NE-20/Germantown Building, Office of Advanced Nuclear Research, U.S. Department of Energy, 1000 Independence Avenue, S.W., Washington, DC 20585-1290

60. Gary Was, Materials Science and Engineering, Nuclear Engineering, 1911 Cooley, 2104, University of Michigan, Ann Arbor, MI 48109 